\title{
Biosignature Preservation and Detection in Mars Analog Environments
}

\author{
Lindsay E. Hays, ${ }^{1}$ Heather V. Graham,2 David J. Des Marais, ${ }^{3}$ Elisabeth M. Hausrath, \\ Briony Horgan, Thomas M. McCollom, M. Niki Parenteau, Sally L. Potter-McIntyre, \\ Amy J. Williams, and Kennda L. Lynch ${ }^{9}$
}

\section{Table of Contents}

Abstract

1. Executive Summary $\quad 365$

2. Introduction 366

2.1. Habitable environments, biosignatures, preservation 366

3. Mars Analog Environments on Earth 367

3.1. Hydrothermal spring systems 367

3.1.1. Definition of hydrothermal spring systems

3.1.2. Habitability of hydrothermal spring systems

3.1.2.1. Habitability pros $\quad 369$

3.1.2.2. Habitability cons $\quad 369$

3.1.3. Biosignature preservation in hydrothermal spring systems 370

3.1.3.1. Biosignature preservation pros

$\begin{array}{ll}\text { 3.1.3.2. Biosignature preservation cons } & 371\end{array}$

3.2. Subaqueous environments 371

3.2.1. Definition of subaqueous environments 371

3.2.2. Habitability of subaqueous environments 372

3.2.2.1. Habitability pros $\quad 372$

3.2.2.2. Habitability cons $\quad 373$

3.2.3. Biosignature preservation in subaqueous environments 373

3.2.3.1. Biosignature preservation pros 373

$\begin{array}{ll}\text { 3.2.3.2. Biosignature preservation cons } & 374\end{array}$

3.3. Subaerial environments 374

3.3.1. Definition of subaerial environments

3.3.2. Habitability of subaerial environments

3.3.2.1. Habitability pros $\quad 374$

3.3.2.2. Habitability cons $\quad 376$

\footnotetext{
${ }^{1}$ Jet Propulsion Laboratory, California Institute of Technology, Pasadena, California.

${ }^{2}$ NASA Goddard Space Flight Center/USRA, Baltimore, Maryland.

${ }^{3}$ NASA Ames Research Center, Moffett Field, California.

${ }^{4}$ University of Nevada Las Vegas, Las Vegas, Nevada.

${ }^{5}$ Purdue University, West Lafayette, Indiana.

${ }^{6}$ University of Colorado, Boulder, Colorado.

${ }^{7}$ Southern Illinois University, Carbondale, Illinois.

${ }^{8}$ Towson University, Towson, Maryland.

${ }^{9}$ Georgia Institute of Technology, Atlanta, Georgia.

(c) 2016. All rights reserved.

Portions of this work were carried out at the Jet Propulsion Laboratory, California Institute of Technology, under a contract with the National Aeronautics and Space Administration.

(C) Lindsay E. Hays et al., 2017; Published by Mary Ann Liebert, Inc. This Open Access article is distributed under the terms of the Creative Commons Attribution Noncommercial License (http://creativecommons.org/licenses/by-nc/4.0/) which permits any noncommercial use, distribution, and reproduction in any medium, provided the original author(s) and the source are credited.
} 
3.3.3. Biosignature preservation in subaerial environments 376

$\begin{array}{ll}\text { 3.3.3.1. Biosignature preservation pros } & 376\end{array}$

$\begin{array}{lr}\text { 3.3.3.2. Biosignature preservation cons } & 377\end{array}$

3.4. Subsurface environments 377

3.4.1. Definition of subsurface environments 377

3.4.2. Habitability of subsurface environments 377 $\begin{array}{lr}\text { 3.4.2.1. Habitability pros } & 377\end{array}$

$\begin{array}{lr}\text { 3.4.2.2. Habitability cons } & 379\end{array}$

3.4.3. Biosignature preservation in subsurface environments 379

$\begin{array}{lr}\text { 3.4.3.1. Biosignature preservation pros } & 379\end{array}$

$\begin{array}{lr}\text { 3.4.3.2. Biosignature preservation cons } & 379\end{array}$

3.5. Iron-rich environments 379

3.5.1. Definition of iron-rich environments $\quad 379$

3.5.2. Habitability of iron-rich environments 381 $\begin{array}{ll}\text { 3.5.2.1. Habitability pros } & 381\end{array}$

\begin{tabular}{ll} 
3.5.2.2. Habitability cons & 381 \\
\hline
\end{tabular}

3.5.3. Biosignature preservation in iron-rich environments 381

$\begin{array}{ll}\text { 3.5.3.1. Biosignature preservation pros } & 381\end{array}$

3.5.3.2. Biosignature preservation cons $\quad 382$

4. Exploring Past Habitable Environments on Mars 382

4.1. Common challenges 382

4.1.1. Identification of sites 382

$\begin{array}{lr}\text { 4.1.1.1. Orbital observations for site selection } & 382\end{array}$

\begin{tabular}{lr} 
4.1.1.2. Surface observations & 383 \\
\hline .1.1.3. Sample collection & 383
\end{tabular}

4.1.1.3. Sample collection 383

4.1.1.4. Mars 2020 rover instrument suite $\quad 383$

4.1.2. Preservation 383

4.2. Orbital observations 384

4.2.1. Hydrothermal spring systems 384

4.2.2. Subaqueous environments

4.2.3. Subaerial environments 385

4.2.4. Subsurface environments 385

4.2.5. Iron-rich environments 385

4.3. Observations and sample selection on the ground 385

4.3.1. Hydrothermal spring systems 385

4.3.1.1. Observations $\quad 385$

$\begin{array}{ll}\text { 4.3.1.2. Sample selection } & 386\end{array}$

4.3.2. Subaqueous systems 386

$\begin{array}{lr}\text { 4.3.2.1. Observations } & 386\end{array}$

4.3.2.2. Sample selection 386

4.3.3. Subaerial environments 386

$\begin{array}{lr}\text { 4.3.3.1. Observations } & 386\end{array}$

$\begin{array}{ll}\text { 4.3.3.2. Sample selection } & 387\end{array}$

4.3.4. Subsurface environments 387

$\begin{array}{lr}\text { 4.3.4.1. Observations } & 387\end{array}$

$\begin{array}{ll}\text { 4.3.4.2. Sample selection } & 387\end{array}$

4.3.5. Iron-rich environments 387

$\begin{array}{lr}\text { 4.3.5.1. Observations } & 387\end{array}$

$\begin{array}{ll}\text { 4.3.5.2. Sample selection } & 388\end{array}$

4.4. Strategies and priorities 388

5. Urgent Needs and Future Research 389

Acknowledgments 390

Author Disclosure Statement 390

References 390

Abbreviations Used 400 


\section{Abstract}

This review of material relevant to the Conference on Biosignature Preservation and Detection in Mars Analog Environments summarizes the meeting materials and discussions and is further expanded upon by detailed references to the published literature. From this diverse source material, there is a detailed discussion on the habitability and biosignature preservation potential of five primary analog environments: hydrothermal spring systems, subaqueous environments, subaerial environments, subsurface environments, and iron-rich systems. Within the context of exploring past habitable environments on Mars, challenges common to all of these key environments are laid out, followed by a focused discussion for each environment regarding challenges to orbital and ground-based observations and sample selection. This leads into a short section on how these challenges could influence our strategies and priorities for the astrobiological exploration of Mars. Finally, a listing of urgent needs and future research highlights key elements such as development of instrumentation as well as continued exploration into how Mars may have evolved differently from Earth and what that might mean for biosignature preservation and detection. Key Words: Biosignature preservation-Biosignature detection-Mars analog environments-Conference report-Astrobiological exploration. Astrobiology 17, 363-400.

\section{Executive Summary}

$\mathbf{O}$ N May 16, 2016, ninety scientists gathered at the Conference on Biosignature Preservation and Detection in Mars Analog Environments, held at Incline Village, Nevada. The objective of the workshop was to assess the attributes and the preservation potential of the major types of biosignatures in diverse Mars analog habitable environments in order to develop strategies to detect a range of possible biosignatures on Mars in different geologic settings. The analog environments presented at the workshop were divided into hydrothermal spring systems, subaqueous environments, subaerial environments, subsurface environments, and iron-rich systems. Conferees assessed these environments in the context of four key questions:

- How do we use biosignatures to interpret the presence or absence of life in ancient Earth analog environments?

- How might we translate what we learn about preservation of biosignatures in Earth analogs to the different physical conditions/environments on Mars?

- How could/should this knowledge influence our strategies and priorities for the astrobiological exploration of Mars?

- What are the urgent needs for research as well as future research directions for both Mars research and terrestrial analogs?

Attendees reviewed prior investigations of each type of analog environment and identified the "pros" (strengths) and "cons" (weaknesses) regarding its habitability, its biosignature preservation potential, and the attributes of any associated diagnostic features that might be most readily detected by remote sensing or by ground-based observations.

Attendees identified common challenges shared by all types of environments that hinder identification of promising sites and evaluation of their biosignature preservation potential. Orbital observations for selecting the most promising sites are constrained by limitations in the spatial and spectral resolution of orbital instrumentation. Features that are diagnostic for deltas, spring deposits, and aqueously altered paleosols or bedrock fractures have particular value. A major challenge in our interpretations of orbital observations is determining how long a particular site had sustained habitable conditions. The duration of such conditions can have substantial effect on the potential for a site to sustain life and/or preserve biosignatures. Once such promising deposits are found, the next challenge in sample ac- quisition is to discriminate between potential biosignatures and features produced by nonbiological processes. Because the abundance of microorganisms can be highly dependent upon microenvironmental niches, sampling would likely confront substantial spatial heterogeneity among the promising deposits. Several factors present challenges to preservation of potential biosignatures. For example, the broad range in the availability and chemical activity of water affects processes that can destroy biosignatures (e.g., oxidation, weathering) as well as those (e.g., lithification) that can preserve them. The duration of exposure to destructive radiation (exposure age) is another key factor, particularly in the context of a thin martian atmosphere.

The discussions identified several strategies and priorities for astrobiological exploration. Examples include the following: (1) In many of the environments there is a tension between habitability and preservation-many of the conditions that make an environment more habitable can be destructive to one or more types of biosignatures. (2) Further investigations of analog environments in Archean terranes are warranted, as indicated by evidence that the early environments of Earth and Mars were much more similar than they are today. (3) Exploration must be coordinated across a broad range of spatial scales (from orbital reconnaissance to surface survey to observations at the outcrop and even "hand lens" scale) and temporal scales (e.g., persistence of habitable conditions, effects of climate variability). (4) A site where geologic records of a variety of adjacent habitable environments have been preserved is highly desirable. (5) Landed missions should be able to characterize multiple types of potential biosignatures. For example, potentially biological macrostructures would be easier to identify with cameras and could identify potential samples for chemical interrogation. (6) Deposits from past habitable environments having no evidence of life are still significant because they might document prebiotic conditions or provide evidence as to why life possibly never arose on Mars. (7) Meeting submissions and discussion indicate that the astrobiological potential of certain environments (e.g., subaqueous settings, hydrothermal spring systems) has been investigated much more extensively than others (e.g., deeper subsurface systems). Habitable subsurface environments might be quite vast and might have persisted for geologically long periods, but their potential for biosignature preservation is not well understood.

The conference identified key areas for future technological development. Improvements in the spectral and 
spatial resolution of orbiting spectrometers would improve our ability to detect and map aqueous mineral deposits and stratigraphic sequences that preserve evidence of habitable environments on geologically long timescales. Both orbiters and landers must detect and characterize mineral deposits with phyllosilicates, carbonates, silica, and evaporitic minerals with higher fidelity. Such instruments must identify aqueous deposits that have high biosignature preservation potential. More sensitive instruments are needed to detect and characterize trace organic compounds.

Future research should determine how martian environments may be chemically or physically different from Earth environments and may preserve or destroy biosignatures at different rates or in different proportions than occurs on Earth. A related topic would be to investigate what terrestrial analog environments might look like-and what biosignature signals might be-if photosynthetic organisms had not evolved. Biosignature preservation must be better understood in Mars analog environments (e.g., subsurface aquifers or hydrothermal systems) that might have been habitable for geologically long periods. Investigations should focus on the key processes that create habitable environments and that drive the transformations and fates of biosignatures in the geologic record.

\section{Introduction}

Fossil biosignatures preserve evidence about ancient life, but their formation is dependent on interactions between the physical and chemical properties of the material making the biosignature as well as rates of degradation and mineralization. Processes that occur after deposition can change the stability of the materials that are preserving the biosignatures and create challenges for interpretation of these biosignatures as life-based features. The interpretation of biosignatures, solo and in conjunction, as the product of life processes, and how the different physical conditions on Mars may affect these interpretations, should be considered when planning for the astrobiological exploration of Mars. Analog environments, both modern and ancient, on Earth provide crucial information for these interpretations.

As stated, the objective of the May workshop was to assess the attributes and preservation potential of various biosignatures in different Mars analog habitable environments on Earth, in order to develop strategies to detect a range of possible biosignatures on Mars in different categories of geologic settings. These environments that were identified based on the submitted abstracts include hydrothermal spring systems, subaqueous environments, subaerial environments, subsurface environments, and iron-rich systems. On Earth, these environments provide a favorable balance between rates of biological primary production, rates of destruction, and preservation of biosignatures. On Mars they might have lasted for a time sufficient for life to persist, and they might also have been adequately extensive to be identified in the rock record yet also amenable to exploration during a single landed mission.

One of the major purposes of the conference was to write a summary of the current knowledge in this area so that the conclusions drawn can be considered in making planning decisions - such as landing site prioritization for Mars 2020 landing site selection. This report summarizes the abstracts submitted; the oral and poster presentations; and notes taken during discussions after each paper, during the poster sessions, and during the high-level integrating discussions; as well as from a postconference survey. To make the report more complete and useful, the authors (the conference writing committee) cited the relevant literature in order to validate and, in some cases significantly, expand upon the content presented at the meeting. That said, these discussions often lacked information regarding the habitability and preservation potential for subsurface environments relative to other environments examined given that most of the attendees focused on the astrobiological significance of surface environments and given a low relative attendance by the subsurface research community.

\subsection{Habitable environments, biosignatures, preservation}

It is important to characterize the key resources that an environment must provide in order to become habitable. Habitable environments must furnish raw materials (the elements CHNOPS), a suitable solvent (liquid water), metabolically useful energy, and clement conditions (Fig. 1). Relatively clement conditions of temperature, $\mathrm{pH}$, salinity, radiation protection, and so on are more favorable for life because environmental extremes require more energy to mitigate. These resources and conditions must also be available simultaneously and for periods of time sufficiently long to enable life to adapt to any environmental changes. Accordingly, the attributes of habitable environments must be assessed on physical scales from microscopic to planetwide (Hays, 2015) and on temporal scales from the potentially short doubling time of a microorganism to periods that allow for long-term evolutionary change.

A "biosignature" is an object, substance, and/or pattern whose origin specifically requires a biological agent. The usefulness of a biosignature is determined not only by the probability of life creating it but also by the improbability of nonbiological processes producing it (Des Marais et al., 2008b; Des Marais, 2013)_and drawing the distinction between potential and definitive biosignatures (the difference between a biosignature that may have a biological origin and

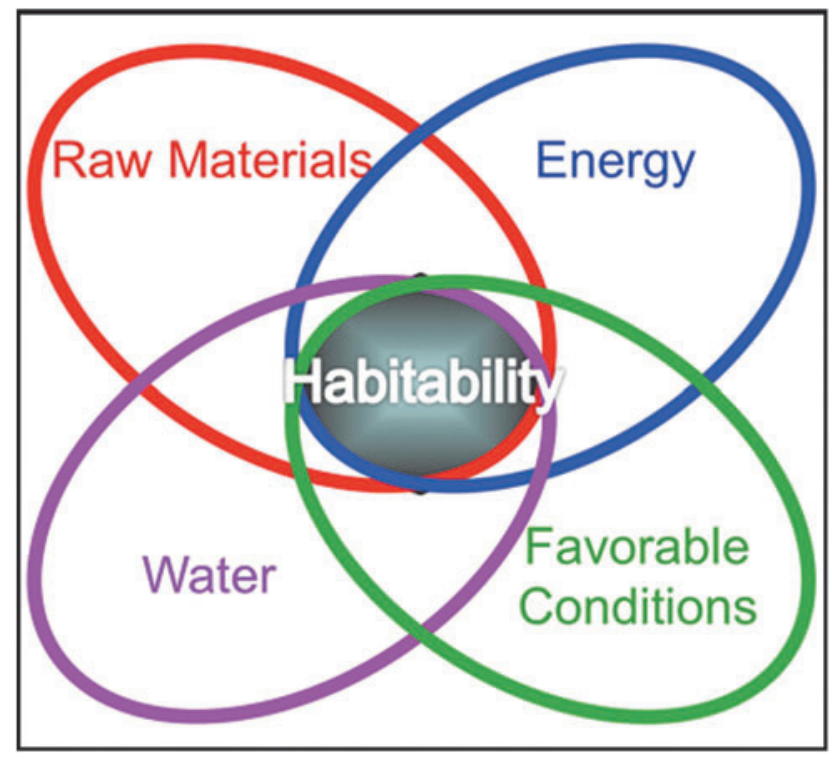

FIG. 1. Features that contribute to a habitable environment (Hoehler, 2007). 


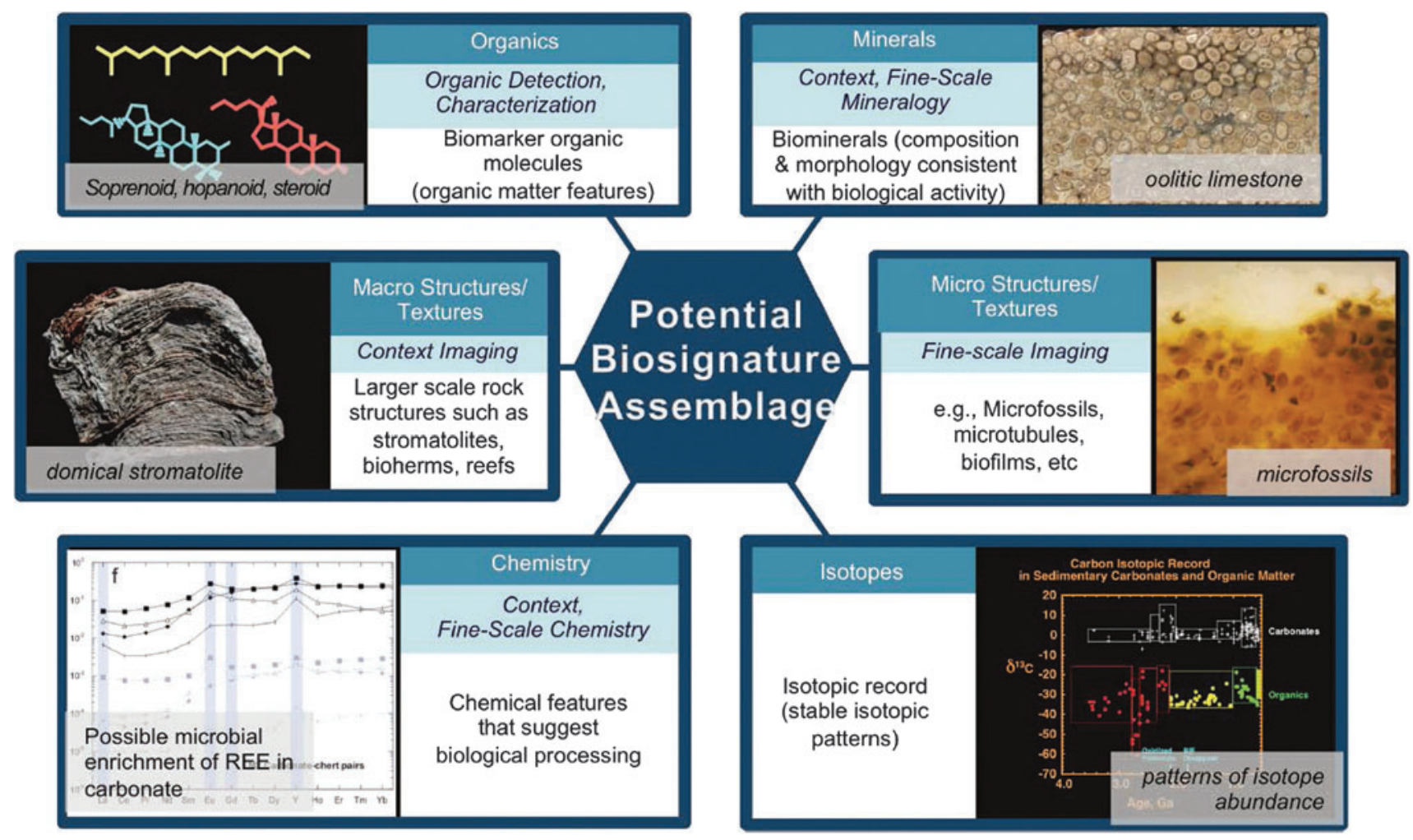

FIG. 2. The six types of potential biosignatures identified by the Mars 2020 Science Definition Team (From Mustard et al., 2013).

compels further investigation and one that specifically requires a biological agent to form). Many biosignatures from recent geologic epochs are easily contrasted from abiotic features (separating the "signal" from the "noise"), but modern biosignatures arose after billions of years of evolution. In early geologic records, the boundaries between biotic and abiotic features are far less distinct, and it is possible that no distinctions can be identified between prebiotic features and biosignatures during the transition from the prebiotic realm to the biosphere. The Mars 2020 Science Definition Team identified six classes of biosignatures (organic molecules, minerals, macro structures/textures, micro structures/textures, chemistry, and isotopes-see Fig. 2).

The presence of biosignatures in the geologic record depends upon several factors (Summons et al., 2011). The rates of production of distinctive biological features in habitable environments must exceed their rates of destruction by biological recycling and by abiotic processes (e.g., weathering, diagenesis, high temperatures and pressures, radiation, and impact cratering). Some types of biosignatures are more resistant to certain degradation processes than others, and some environments are more conducive to preserving certain types of biosignatures than others.

As a terrestrial planet, Mars has the raw materials for life, though perhaps in different proportions than on Earth. Prior efforts to identify habitable environments on Mars typically focused on finding evidence of liquid water in the planet's past, and these efforts have identified a substantial number of locations. Also, if biosignatures are to achieve abundances that enable their preservation and ultimate detection, the environment must provide either organic matter or quantities of energy (as chemical redox gradients or sunlight) sufficient to support the production of adequate quantities of biomass.

\section{Mars Analog Environments on Earth}

In this section, we have attempted to capture the topics raised during talks, posters, and discussion and include references to peer-reviewed literature for the five environments that were the focus of the workshop (Fig. 3).

\subsection{Hydrothermal spring systems}

3.1.1. Definition of hydrothermal spring systems. Hydrothermal activity is probably a widespread phenomenon among solid planetary bodies, wherein heat that is transported convectively from hotter interiors (e.g., via volcanism) encounters water as it passes through rocky crusts (Fig. 4). Hydrothermal systems can also occur when large impacts create localized sources of heat. The convective transfer of heat through a solid crust is much more rapid and efficient than conductive heat flow. Water is stable as a liquid over a remarkably broad temperature range, it has a relatively high heat capacity, and it is widespread and abundant in the cosmos. Thus, liquid water is probably both highly efficient and common as a medium for the convective transfer of heat from planetary terrestrial interiors to the surface. The physical and chemical attributes of hydrothermal convection systems are important drivers for sustaining local habitable environments, particularly under scenarios where surrounding landscapes are far less favorable for life. While studies of hydrothermal systems often focus on hot 


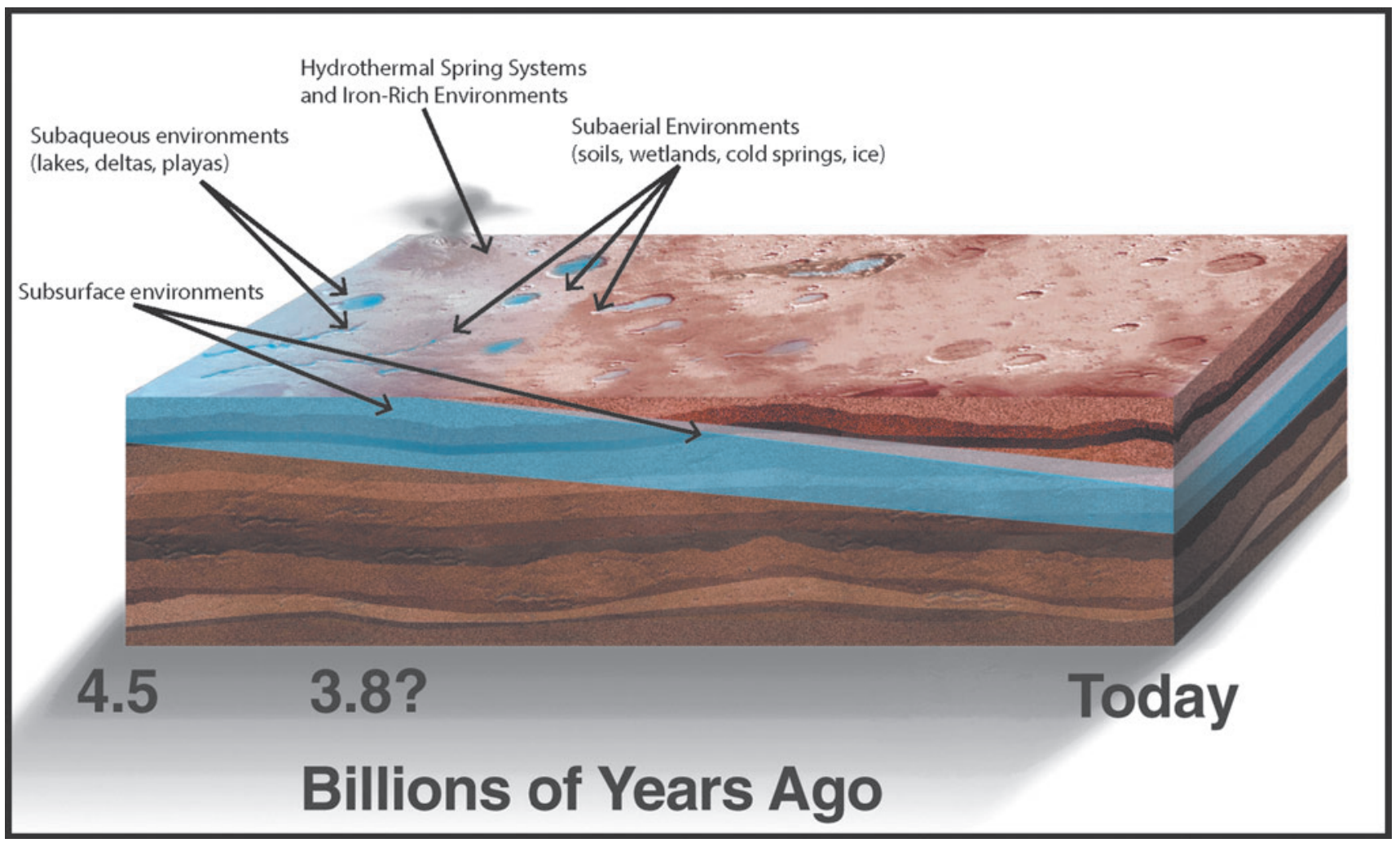

FIG. 3. The five types of ancient martian environments that were discussed at the workshop by way of terrestrial analogs (modified from Des Marais et al., 2008a).

\section{Geological setting of lower Warrawoona cherts}

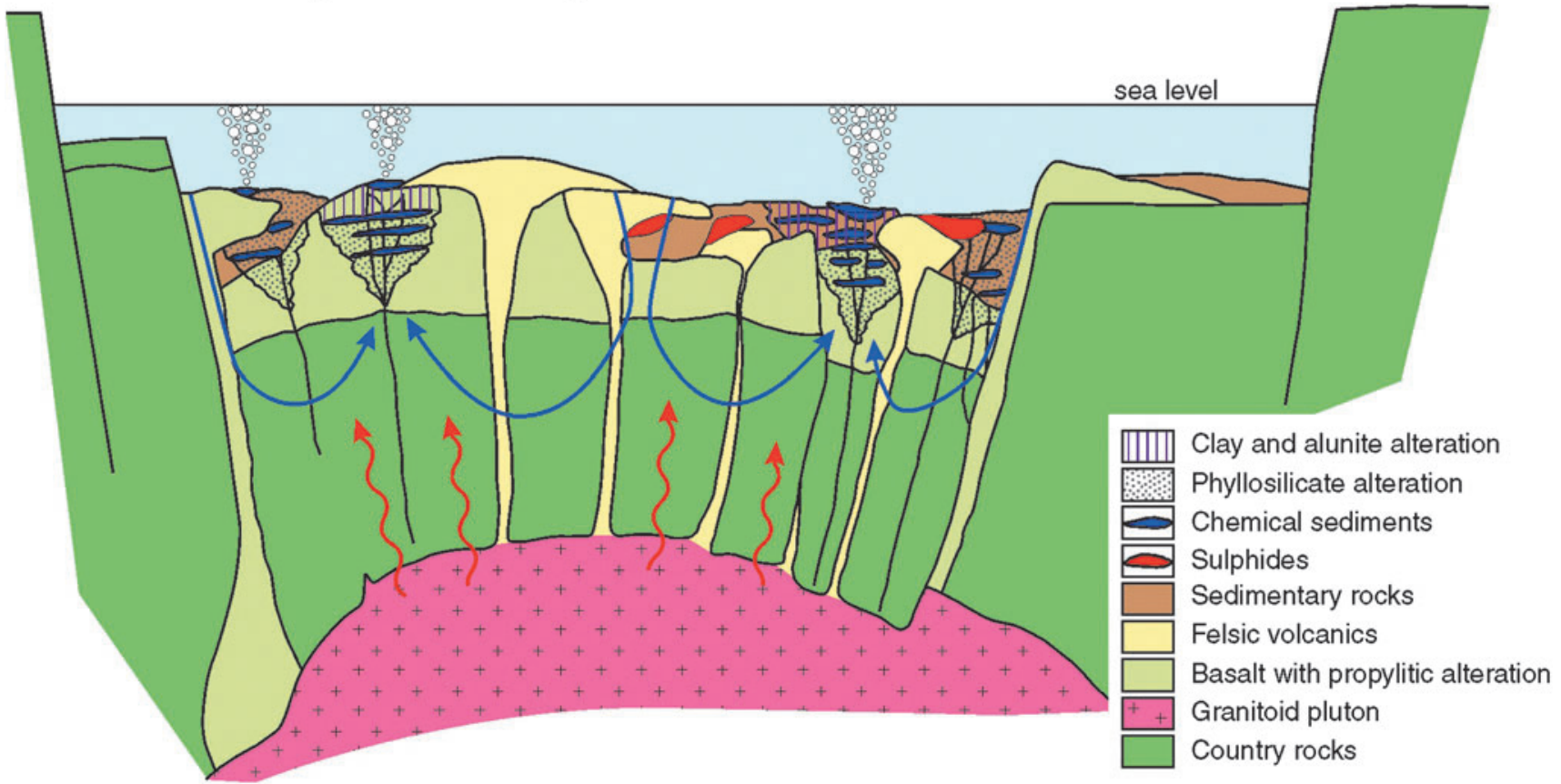

FIG. 4. The $c a$. $3.4 \mathrm{Ga}$ Dresser Formation is an example of an ancient hydrothermal spring system and its potential biosignatures in the Pilbara Craton, Western Australia. In this schematic cross section, geothermal heat flow and circulating water are indicated by the red and blue arrows, respectively. The chemical sediments, indicated as blue irregular shapes in the figure, include fabrics consistent with geyserite and the former presence of microbial communities (Djokic, 2015; Djokic et al., unpublished data). 
springs or submarine vents where fluids are discharged to the surface, fluid circulation and water-rock interactions may also sustain habitable environments within recharge zones in the subsurface. Thus, hydrothermal systems and processes on Earth are highly relevant for understanding analogous systems on Mars and other planets.

3.1.2. Habitability of hydrothermal spring systems. 3.1.2.1. Habitability pros. Hydrothermal convection systems span a range of depths where deep groundwater encounters and gains buoyancy from a heat source, ascends toward the surface, cools, and then either emerges at the surface or descends back down along the flanks of the ascending thermal plume.

Submarine hydrothermal systems are globally pervasive as key components of the mid-ocean ridge system, which is the world's most extensive mountain range with a total length of $80,000 \mathrm{~km}$. Early in Earth's history, greater abundances of radionuclides in the mantle created higher geothermal heat flow (Arevalo et al., 2009) that, in turn, probably sustained greater hydrothermal activity. Such activity probably hosted extensive microbial ecosystems (e.g., Van Kranendonk, 2006; Westall et al., 2015a). Widespread hydrothermal activity has also been proposed to sustain hydrologic cycles at regional scales on early Mars (e.g., Gulick, 1998, 2001).

In continental environments, hydrothermal systems can enhance the availability of liquid water in several ways. A thermal source can melt ground ice locally. The buoyant heated water can invade otherwise drier, shallower regions in the crust. Hydrothermal systems create springs or fumaroles that become oases in arid environments (e.g., the El Tatio region, Atacama Desert, Chile; Ruff and Farmer, 2016) that otherwise might be relatively unfavorable for extant life.

Hydrothermal systems can also develop in the aftermath of impact events that inject substantial amounts of thermal energy into the crust (e.g., Schwenzer et al., 2012a, 2012b). Impacts have been proposed to enhance the formation of phyllosilicates and to create local habitats on early Mars (Schwenzer and Kring, 2009).

Hydrothermal systems provide basic elements necessary for life such as carbon, hydrogen, oxygen, nitrogen, sulfur, phosphorus, magnesium, iron, potassium, molybdenum, zinc, and a host of other essential elements in trace quantities. Hydrothermal fluids extract elemental nutrients from host rocks via dissolution and chemical alteration to create solutes and mineral assemblages that are stable within the hydrothermal environments. The solutes ascend and become available at shallower, cooler depths and at the surface. Volcanic gases provide carbon, sulfur, and molecular hydrogen. Nitrogen is provided principally by meteoric water that has entered the hydrothermal system. Thus, hydrothermal systems are also "oases" for nutrients.

Hydrothermal systems enhance the opportunities for microorganisms to acquire energy either from sunlight or from energy-yielding oxidation-reduction (redox) chemical reactions. Submarine systems sustain extensive chemotrophic microbial communities (e.g., Baross, 1998), and investigations have revealed potential fossilized examples of such communities in Archean rocks (Westall et al., 2015a, 2015b; Van Kranendonk et al., 2016). Thermal springs and fumaroles can deliver liquid water to surface environments that are otherwise dry but where sunlight can provide energy for photosynthetic microorganisms. Hydrothermal systems also sustain redox reactions that provide energy for life. Deeper crustal environments tend to reflect the relatively reducing conditions of the upper mantle and lower crust, whereas surface environments are typically more oxidizing. As a consequence, convecting hydrothermal fluids create interfaces where more reduced species from depth are brought into direct contact with more oxidized species from the surface. Slow reaction kinetics result in redox disequilibria in such environments that can be exploited as metabolic energy sources by microbial communities (e.g., Spear et al., 2005; Shock et al., 2010). Examples include the mixing of $\mathrm{H}_{2}$ and $\mathrm{H}_{2} \mathrm{~S}$ from volcanic gases and $\mathrm{Fe}^{2+}$ from rocks with $\mathrm{O}_{2}$ from the surface. Hydrothermal systems actually sustain a multitude of redox reactions involving the constituents from rocks, volcanic gases, and the surface environment (McCollom and Shock, 1997; Shock et al., 2010; Amend et al., 2011). Microorganisms utilize virtually all of these reactions as sources of energy for metabolism.

Hydrothermal systems excel at meeting a key requirement for habitability, namely, that all the key resources must be available simultaneously (Walter and Des Marais, 1993). Both hydrothermal systems and life require liquid water in order to function and persist. By its very nature, geothermal convection provides chemical nutrients and sources of redox energy to aqueous solutions. Reactions with basaltic or ultramafic host rocks typically buffer hydrothermal fluids to near neutral to mildly alkaline $\mathrm{pH}$ values, but boiling or input of magmatic gases can cause very acidic conditions to develop (for example, from oxidation of $\mathrm{SO}_{2}$ or $\mathrm{H}_{2} \mathrm{~S}$ to sulfuric acid).

Hydrothermal systems sustain a broad range of temperatures, pressures, redox states, and fluid compositions. These diverse conditions sustain diverse microorganisms (Brock, 1978; Inskeep and McDermott, 2005). Such diversity enhances the capacity of microbial communities to adapt to changing environmental conditions and thus to survive over the long term. In addition to phototrophs, many microbial communities in hydrothermal environments utilize chemical energy sources. Thermophilic chemolithoautotrophic and heterotrophic bacteria and archaea are prevalent at temperatures above $70^{\circ} \mathrm{C}$ in terrestrial hydrothermal systems. For example, the Aquificales are a very conspicuous filamentous biomass in these systems from $\mathrm{pH} \sim 3$ to 9 , at temperatures from $60^{\circ} \mathrm{C}$ to $95^{\circ} \mathrm{C}$ (Reysenbach et al., 2005). These communities grow chemolithoautotrophically (often microaerophilically) using a wide variety of electron donors and acceptors, and are often associated with mineral precipitation. These biota also provide insights into the early evolution of the biosphere. The higher-temperature communities often harbor deeply branching archaeal groups such as the Aigarchaeota (e.g. Beam et al., 2015) and Korarchaeota (Reysenbach et al., 2000), whose inferred metabolisms range from chemolithotrophy to heterotrophy.

3.1.2.2. Habitability cons. In continental environments, the habitability of hydrothermal systems may be negatively impacted by their relatively short duration over geologic timescales (thousands to billions of years). The Yellowstone hydrothermal system, a product of hot spot volcanism, has been operating for $\sim 2.1$ million years (Christiansen, 2001). 
For impact-generated hydrothermal systems, such as the Sudbury impact structure in Canada $(62 \mathrm{~km} \times 32 \mathrm{~km} \times 15 \mathrm{~km}$ deep), it is thought that the crater size dictates the longevity of the system, which has been estimated to be $\sim 1$ million years (Ames et al., 1998; Osinski et al., 2012).

This shortcoming is not as severe for extensive submarine hydrothermal systems because the global mid-ocean ridge system has been continuously active for billions of years (e.g., Cawood et al., 2006). Westall et al. (2015a) proposed that subaqueous hydrothermal springs were more abundant on early Mars.

Another aspect of continental hydrothermal systems that may negatively impact their habitability is that they tend to be geographically restricted. While there may be over 12,000 hydrothermal features in Yellowstone, the pools, outflow channels, or fumarole areas tend to be on the scale of meters to hundreds of meters. Even the world's largest hot spring in the Waimangu hydrothermal system in New Zealand is $\sim 200 \mathrm{~m}$ in diameter (Keam, 1980).

The elevated temperature and low $\mathrm{pH}$ of some hydrothermal systems can function to limit microbial diversity and biomass production, while some chemical species can poison certain microbes altogether. The most thermophilic oxygenic phototroph known is a cyanobacterium, a species of Synechococcus, whose maximum growth temperature is $73^{\circ} \mathrm{C}$ (Peary and Castenholz, 1964). This temperature can be considered the upper limit for photosynthesis. Beyond this temperature, chemosynthetic microbes (chemotrophs) flourish. The most thermophilic anoxygenic phototroph is the green nonsulfur bacterium Chloroflexus, whose upper temperature limit is $69^{\circ} \mathrm{C}$ (Castenholz and Pierson, 1995).

Acidity can function to limit microbial diversity, especially among phototrophs. Cyanobacteria cannot withstand pH levels of less than 5.5-6.0 (Castenholz, 1988) and thus are not widespread community members of acidic hydrothermal systems. However, red unicellular eukaryotic algae belonging to the order Cyanidiales are able to tolerate $\mathrm{pH}$ levels from 0.2 to 4.0 and temperatures up to $56^{\circ} \mathrm{C}$ (Castenholz and McDermott, 2010). The most acid-tolerant anoxygenic phototrophs are the purple nonsulfur bacteria, which can withstand environmental $\mathrm{pH}$ levels of $\sim 3$ but whose growth optima are $\sim 5$ and above (Pfennig, 1974; Madigan et al., 2005).

Because oxygenic photosynthesis is generally not limited by the availability of water as its electron donor or $\mathrm{CO}_{2}$ for carbon fixation, it is the most productive type of photosynthesis. In contrast, anoxygenic photosynthesis is usually limited by the flux of reductants from the environment (such as $\mathrm{H}_{2}$ and $\mathrm{H}_{2} \mathrm{~S}$ from hydrothermal systems), and rough calculations suggest that these types of communities might be 2-3 orders of magnitude less productive than oxygenic ones (Des Marais, 2000). Chemotrophs tend not to synthesize as much biomass as phototrophic communities (Campbell et al., 2016).

Other selective pressures from the geosphere include aqueous species that can inhibit photosynthesis. Sulfide at tens of micromolar and greater concentrations has been shown to poison photosystem II in cyanobacteria, effectively shutting off oxygenic photosynthesis (Oren et al., 1977).

3.1.3. Biosignature preservation in hydrothermal spring systems. 3.1.3.1. Biosignature preservation pros. Hydrothermal systems can entomb and preserve evidence of microorganisms that lived there (Walter and Des Marais, 1993; Cady and Farmer, 1996; Walter et al., 1996; Westall et al., 2015a, McCollom et al., 2016; Munoz-Saez et al., 2016; Fig. 5). Solute-laden fluids that approach or emerge at the surface can form mineral precipitates. Because the solubility of silica is strongly temperature-dependent, hot fluids emerging from great depths typically deposit siliceous sinters. Bicarbonate-rich waters outgas $\mathrm{CO}_{2}$ at the surface and deposit calcareous sinters (Fouke et al., 2000). Ferrous iron can oxidize to create various iron oxides and other species (Parenteau and Cady, 2010; Sklute et al., 2016) (see the "Iron-rich environments" section below for detailed discussion). Dissolved barium emerging in near-surface environments can form precipitates with oxyanions. Accordingly, the same set of processes and physical conditions that sustain habitable environments also provides mineral deposits that can entomb and preserve biosignatures.
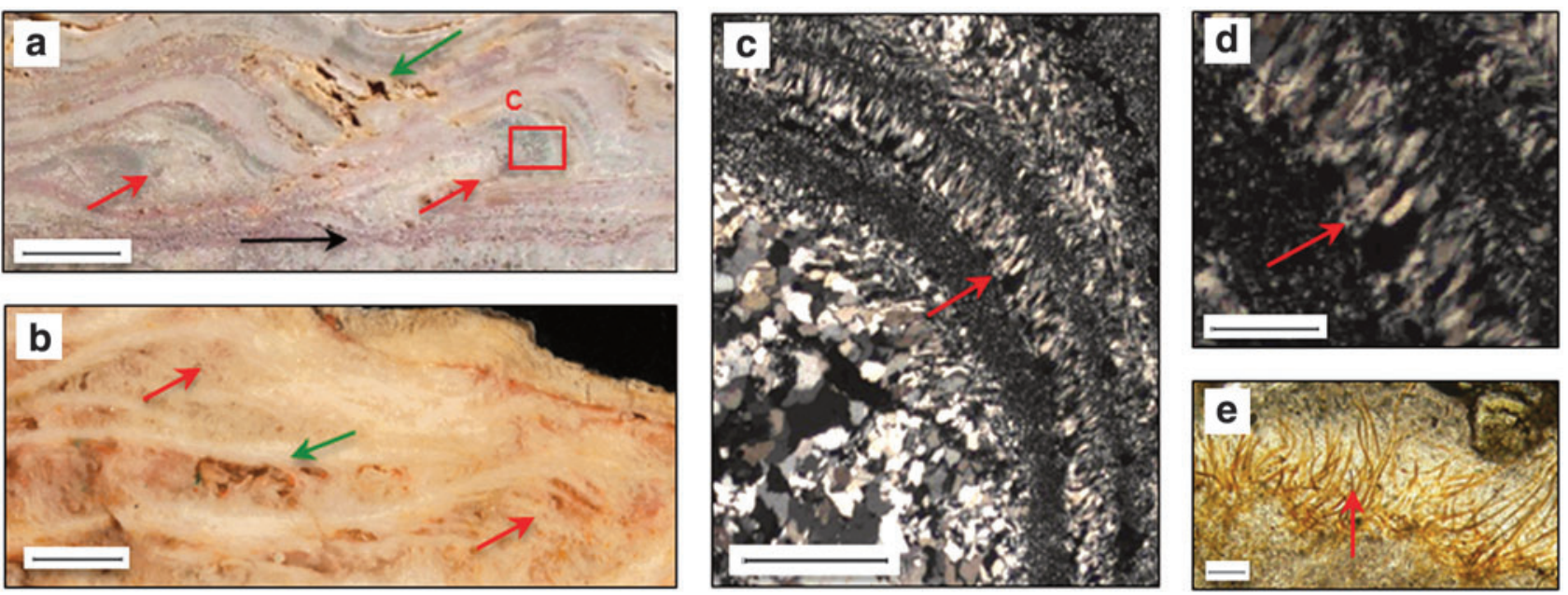

FIG. 5. Examples of potential biosignatures in hydrothermal spring deposits: palisade textures in terracettes sinter fabrics (Djokic et al., 2017). 
The primary precipitates encrust and permineralize microbes to preserve a suite of textures, biofabrics, microfossils, and organic compounds such as lipid biomarkers. Recent work (Campbell et al., 2016; Hinman et al., 2016; Stevens et al., 2016; Szynkiewicz and Mikuchi, 2016) reviewed the variety of mineral deposits and biosignatures that occur along environmental gradients in thermal spring waters having a range of compositions. They described in detail the variety of preserved textural-mineral macroscopic and microscopic textures. These deposits and their features have parallels in some early Archean hydrothermal deposits on Earth (e.g., Westall et al., 2015a; Van Kranendonk et al., 2016).

There is a rich history of studies on the mechanisms of silica permineralization in microfossil preservation in hydrothermal systems (e.g., Cady and Farmer, 1996; Farmer and Des Marais 1999; Phoenix et al., 2000; Konhauser et al., 2001; Mountain et al., 2003; Benning et al., 2004; Ferris and Magalhaes, 2008). All examples of hot spring deposits that have been identified, both modern and ancient, contain demonstrable microfossils as well as features that appear to be microfossils but whose biological origin is difficult to prove (e.g., Walter et al., 1996; Hickman-Lewis et al., 2016; Van Kranendonk et al., 2016). Confirmed microfossils are morphological fossils that retain carbonaceous remains of microbial cells (Schopf and Walter, 1983; Buick, 1990; Schopf, 1999; Cady et al., 2003). Van Kranendonk et al. (2016) documented fossiliferous thermal spring deposits in Archean rocks in Western Australia. The sites illustrated the geometry of the hydrothermal systems and the associated mineral deposits, biosignatures, and related features that help characterize these ancient environments. This study documented how multiple indicators of ancient processes, environmental conditions, and biosignatures can confirm the presence of fossiliferous thermal spring deposits.

There have also been studies that examined the production and preservation of microbial lipids in modern and subrecent siliceous sinters that have not undergone significant diagenesis (Jahnke et al., 2001, 2004; Pancost et al., 2005, 2006; Talbot et al., 2005; Gibson et al., 2008; Kaur et al., 2008, 2011). Jahnke et al. (2016) demonstrated that siliceous deposits associated with a mildly alkaline thermal spring can be rich repositories of lipid biomarkers, including hopanoids and branched alkanes, from cyanobacteria and other organisms. The abundances of these biomarkers are related to the nature of the depositional environments and the diversity of their biota. The extent of preservation of lipid biomarkers in ancient sinters might be quite variable but should be possible in at least some cases.

McCollom et al. (2016) addressed the habitability of a variety of surface, shallow, and subsurface environments. Regarding hydrothermal systems, he noted that, volumetrically, Earth's ocean crust is the largest potential habitat on Earth, yet we know remarkably little about the organisms that live there. Also we have relatively little knowledge about the potential for biosignature preservation in these environments. The mid-ocean ridge hydrothermal system, that is, the region that hosts thermally driven convection beneath the seafloor, occupies about one-quarter of the areal extent of Earth's crust (Heezen et al., 1959; Edwards et al., 2005). This system might have hosted the most continuously habitable environments on Earth.
3.1.3.2. Biosignature preservation cons. Thermal spring deposits in subaerial environments (e.g., inactive spring mounds) are subjected to oxidizing conditions that severely impact the potential to preserve organic matter. This situation is much less severe for spring mineral deposits emplaced in subaqueous environments (e.g., diatom marshes). Key factors include the length of time that the deposits are exposed to oxidants, the abundances of oxidants, and the time required to lithify sediments and thereby greatly reduce rates of diagenesis as microbial remains are protected from later-stage oxidizing fluids.

Because the greatest variety of biosignatures are associated with phototrophic communities in hydrothermal systems, sinter facies above the upper temperature limit for photosynthesis exhibit a severe decrease in the types of textures preserved (Campbell et al., 2016). Additionally, these biosignatures tend to be heterogeneously distributed, introducing difficulties when searching for samples to collect in the field.

\subsection{Subaqueous environments}

3.2.1. Definition of subaqueous environments. Subaqueous environments discussed here include deltaic and perennial lake systems as well as transient lake and playa systems, although many of the concepts apply to shallow oceanic environments as well, which may have existed on Mars (Villanueva et al., 2015). Aqueous environments related to emergence of groundwater tables, including springs and wetlands, are discussed under subaerial environments. Water bodies and their subsequent sedimentary deposits are excellent areas to host the water and metabolites needed for life and for the collection, concentration, and preservation of organic material that could serve as potential biosignatures. Geologic formations that arise in subaqueous depositional environments are visible throughout the martian surface, easily recognized remotely, and could offer an array of potential preserved biosignatures (Fig. 6).

Mars analog lakes are often divided into two major types of lake systems: open and closed. Open systems are perennial lakes with both inflow and outflow. The chemistry of these lakes tends to be controlled by the fluvial input/output, and these systems usually maintain stable lake levels throughout their life span. These systems are usually freshwater systems although they can be slightly brackish. On Earth, open systems are often oligotrophic (nutrient poor) with welloxygenated bottom waters, hence they tend not to preserve high abundances of organic matter $\left(\sim 0.2-8 \mathrm{~g} \mathrm{~cm}^{-1}\right.$ year $\left.^{-1}\right)$ (Einsele, 2000; Wetzel, 2001; Sobek et al., 2009).

Closed lake systems (also known as closed basins or endorheic basins) are transient lake basins that have inflow from surface streams, precipitation, and/or groundwater, but no outflow other than evaporation (Wetzel, 2001). On Earth, the chemistry of these systems is controlled by the lake level as the concentration of dissolved species builds over time. Hence, many of these lakes are saline. These lakes are typically permanently stratified and are mesotrophic (medium nutrient content) or eutrophic (nutrient rich); hence they tend to preserve higher amounts of organic matter than open lake systems $\left(\sim 14-1000 \mathrm{~g} \mathrm{~cm}^{-1}\right.$ year $^{-1}$ ) (Cole, 1994; Einsele, 2000; Wetzel, 2001; Sobek et al., 2009). 

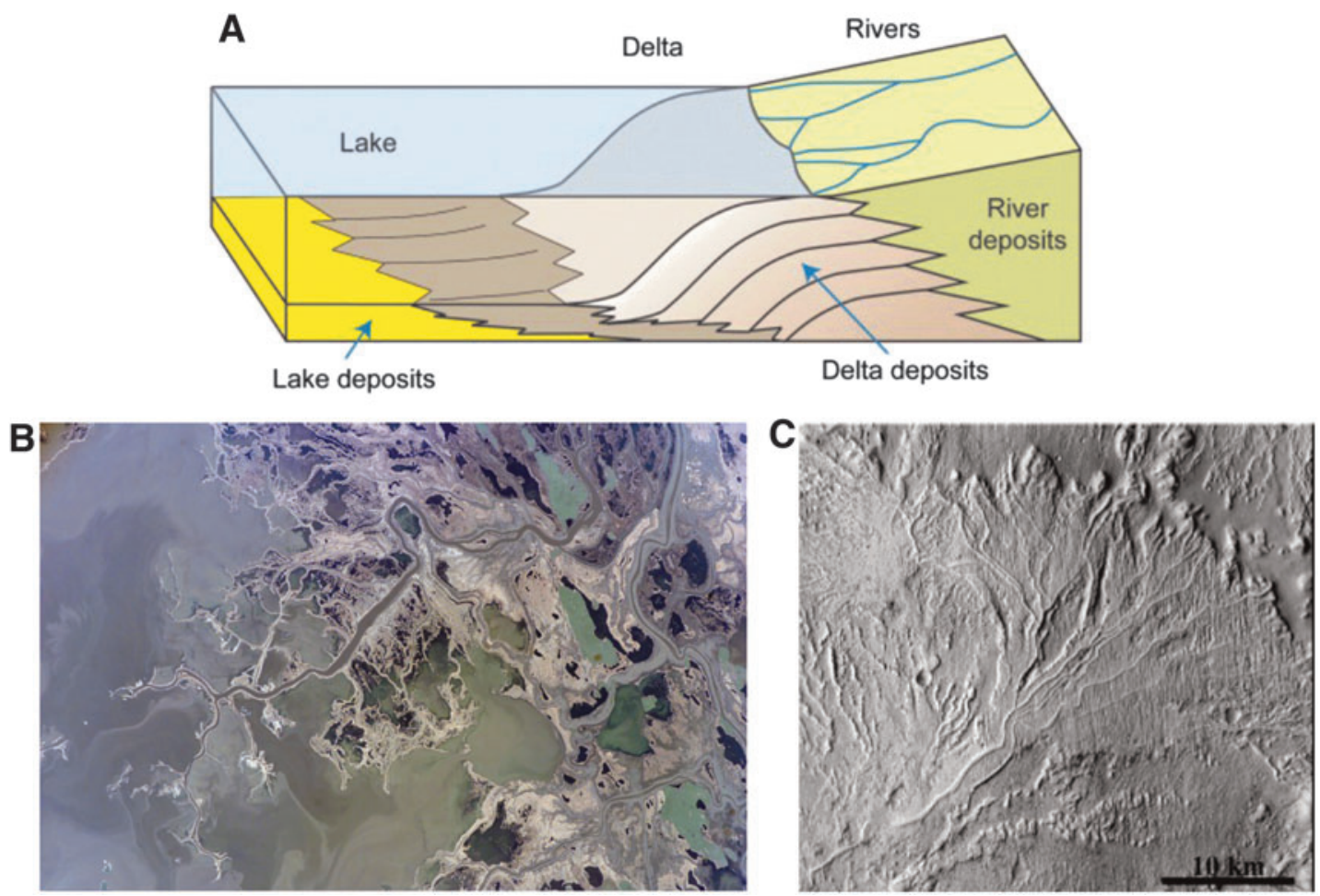

FIG. 6. (a) Schematic cross section of a delta system grading into a lacustrine setting. Blue arrow indicates prograding fining upward sequence of prodelta deposits. (b) An aerial view of the Saskatchewan River delta flowing into a large catchment with onshore embayments as well as visible supra- and subaerial alluvial fans [(a) and (b) credit: NASA/JPL/ Imperial College]. (c) A similar system exposed in the Aeolis/Zephyria Plana region of Mars (from Burr et al., 2009).

Closed lake systems can be perennial or ephemeral. Perennial systems are those that have reasonable inflow to support a consistent water fill and a sufficient depth to maintain lacustrine sedimentation processes (usually greater than 2-4 m) (Currey, 1990; Einsele, 2000; Takano and Waseda, 2003). Ephemeral lakes are often referred to as playa lakes or sabhkas and are typically ephemeral on a seasonal or irregular basis. They may have active groundwater systems that maintain active salt precipitation at the surface through evaporitic pumping. On geologic timescales some perennial lake systems alternate with classic ephemeral lakes. These systems also tend to be hypersaline, although salinity also varies throughout geologic time (Einsele, 2000; Hynek et al., 2015; Lynch et al., 2015).

Deltas are important sedimentary environments for biosignature preservation because, on Earth, they contain diverse sub-environments that both support and preserve abundant microorganisms. Deltas form where rivers deposit more sediment into the edge of a basin faster than erosion can carry it away (Colella and Prior, 1990; Olariu and Bhattacharya, 2006). Deltas display a number of architectural features such as channels, levees, splays, and mounds that can be used to reconstruct basin history (Posamentier and Kolla, 2003). Well-preserved versions of these features are obvious on the surface of Mars as well. Similarly, marginal marine environments (shallow restricted marine environments such as lagoons) likely existed on the selvages of the northern plains and perhaps even in larger impact craters (Westall et al., 2015a, 2015b).
3.2.2. Habitability of subaqueous environments. 3.2.2.1. Habitability pros. Delta plains on Earth are fecund, highly diverse habitats dominated by phototrophy (Naeem et al., 2000; Mitsch and Gosselink, 2000; Gopal and Chauhan, 2001). Microbial communities in these habitats can be highly productive given that waters are shallow and often in the photic zone. Marine deltas, in particular, are able to accommodate significant biological diversity since this is a mixing zone for fresh and salt water (Mitsch and Gosselink, 2000). Habitability of ancient deltas on Mars may have been supported by (1) the in situ protection from radiation afforded by the water column and its turbidity and (2) chemical gradients within the water column and at the sediment-water interface (Santschi et al., 1990). Element and nutrient exchange can occur between water and sediments in pores and at the surface interface (Lerman, 1978; Callender and Hammond, 1982). Delta plains can also support diverse subaerial environments including soils and wetlands (see the "subaerial environments" section below for a detailed discussion).

While microbial biodiversity can be limited in some lacustrine systems on Earth by low nutrient availability, high salinity, and extreme $\mathrm{pH}$, microorganisms are otherwise often abundant in both the water column and the sediments (Wetzel, 2001; Lynch et al., 2016). Deep-water open lake systems can host unique features such as hydrothermal vents or brine seeps that can help provide energy to sustain diverse microbial ecosystems. Two key examples of this are the hydrothermal vents at the bottom of Lake Tanganyika of the East African Rift and the brine seeps at the bottom of 
Lake Huron in North America (Tiercelin et al., 1993; De Wever et al., 2005; Voorhies et al., 2012). Both open and closed-basin systems can host the formation of microbialitescharacteristic sedimentary structures formed by the trapping of mineral detritus in the extracellular polymeric substances formed by microbial mats (Noffke et al., 2001). Active microbialite communities can be found in the closed-basin Great Salt Lake and the open-basin Pavilion Lake and modern stromatolite formations found in Shark Bay, Western Australia (Papineau et al., 2005; Russell et al., 2014, Lindsay et al., 2017). Microbially induced sedimentary structures are preserved and exceptionally well-studied in the modern Pilot Valley Basin, Utah, and on geologic timescales in the ancient Strelley Pool Chert stromatolites and Dresser Formation microbialites of the Archean-aged Pilbara Craton (Van Kranendonk et al. 2003; Allwood, et al., 2006; Noffke et al., 2013; Russell et al., 2014; Lynch et al., 2015; Westall et al., 2015b; Lindsay et al., 2017). Likewise, microbially induced sedimentary structures can be found in most aquatic environments, both marine and lacustrine, including tidal flats, lagoons, riverbeds, dunes, and sabkhas (see Noffke et al., 2001; Bose and Chafetz, 2012; Noffke et al., 2013, and references therein).

Because groundwater supplies much of the water to playa lakes, these environments can provide a conduit between the subsurface and the surface habitats (Rosen, 1994). These environments can be stratified due to salinity, density, or temperature with episodic mixing, which can compartmentalize habitability in the water column. While desiccation of ephemeral lakes can make long-term habitability and evolution difficult for some microorganisms in the water column, both microbial and multicellular life have evolved metabolic strategies to survive these events (Jahnke et al., 2014). Additionally, for some specialized microorganisms, the salts and sediments provide needed protection from radiation and are often ecosystems independent of the intermittent water column altogether, such as the endolithic communities found in the halite rocks of the Atacama Desert and the microbial ecosystem present in the sediments of the Pilot Valley basin in Utah (Davila et al., 2015; Lynch et al., 2016). Microbes adapted to the physical and chemical conditions of these subaqueous environments could have once lived in the vast playa regions of Mars identified by morphology and evaporite minerals.

3.2.2.2. Habitability cons. The key nutrient and sediment source for many lacustrine and deltaic systems is fluvial input; however, fluvial input can be subject to seasonal or longer-term climatic variations, including ice cover. Likewise, the sizeable temperature and chemistry fluctuations that can affect lakes and other closed basins can also negatively impact habitability and decrease productivity.

The high biomass production associated with deltaic habitats on Earth is related to energy availability dependent on fluvial inputs of carbon and nutrients from productive surface environments (Milliman, 1991; Gopal and Chauhan, 2001). A sterile continental landscape would have limited nutrient runoff; thus, deltas might not be advantageous niche space for heterotrophs on a world with limited surface habitability and surface biomass (Westall et al., 2015a, $2015 b$ ). However, very little organic carbon in deep marine sediments is of terrestrial origin (Berner, 1989; Hedges and
Keil, 1995). Instead, most marine organic matter is derived from marine microorganisms, indicating that at least large and deep habitable subaqueous environments can be selfsustaining. Certainly, there was ample life in the oceans of Earth before the surfaces were colonized by life; however, it is unclear whether or not smaller lake systems in a largely sterile surface environment would provide sufficient nutrients to support an isolated ecological community.

3.2.3. Biosignature preservation in subaqueous environments. 3.2.3.1. Biosignature preservation pros. Subaqueous deposits preserve a diverse suite of possible biosignatures derived from both upstream subaerial life and in situ aquatic life. Potential biosignatures would include preserved organic molecules, organic structures (e.g., cells), mineral indications of life, and isotopic markers. Deltaic and lacustrine formations have been well studied on Earth where phototrophs dominate the productivity of the ecosystems. Both deltas and ephemeral lake systems can preserve biosignatures on geologic timescales (Potter-McIntyre et al., 2014).

Some deltaic deposits can represent very long timescales of deposition (tens of thousands to tens of millions of years), and the terrestrial record demonstrates that barring any subsequent erosion, deltaic sediments can be well preserved on geologic timescales (Lowe, 1980). However, identifying long-lived versus short-lived deltaic systems from orbit is challenging, and given the relatively short-lived time of surface water on Mars, there may be no long-term (by Earth standards) deltaic systems present (Eigenbrode et al., 2016). Independent of organic matter, delta sediments can preserve the record of climate and hydrodynamic changes within the grain size and sedimentation patterns as well (Goodbred and Kuehl, 2000; Postma, 2001; Castelltort and Van Den Driessche, 2003).

Organic matter that is swept into a delta will be entombed by the near constant and often rapid sedimentation typical of deltas (Müller and Suess, 1979). On Earth, most (>70\%) of this organic matter is derived from terrestrial biota, ranging from dissolved and particulate organic carbon to refractory molecules and larger detritus (Berner, 1989; Milliman, 1991; Hedges et al., 1997; Seki et al., 2010). Preservation of terrestrial organic matter in these aquatic settings can obscure biosignatures derived from less productive communities within the water column (Graham et al., 2016; Johnson et al., 2015). Organic matter is concentrated hydrodynamically in dense anoxic bottomsets where reducing conditions prevail, promoting preservation of organic compounds by slowing oxidative diagenesis (Müller and Suess, 1979; Berner, 1989). The precipitation of diagenetic cements is often influenced by microbes, and it is not well known how diagenesis might proceed in a delta where biology is absent or limited. Cements can pristinely entomb cells; however, some cement precipitates can occlude fabrics that would indicate growth (Konhauser et al., 1994, 1998; Wacey et al., 2011).

The distribution of sediments based on grain size is key to organic preservation in lakes and deltaic systems. The finer particles settle out last and generally have greater surface area to support reactions with organics, thus facilitating their deposition, burial, and long-term preservation (Mayer, 1994). The relationship between grain size and enhanced 
organic preservation is evident in the greater abundance of organic carbon in deep facies when compared with nearshore deposits (Eigenbrode and Freeman, 2006). Sulfurization by sulfide mineral encapsulation or direct sulfurization of organic molecules is key to the preservation of biosignatures in many terrestrial records (e.g., hydrothermal, marine, lakes), and such conditions are favored in water bodies that have anoxic water columns or sediments (Raven et al., 2015). This may also have been an important process on Mars given the widespread occurrence of sulfate minerals.

Closed-basin lakes have excellent preservation potential due to the commonly reducing to anoxic environments present in the sediment-water interface and the littoral and pelagic sedimentation processes that occur in lakes over $4 \mathrm{~m}$ in depth (Currey, 1990). Additionally, in playas, the precipitation of salts can entomb biosignatures and fluid inclusions and protect these features from radiation and oxidants (Benison et al., 2008; Azúa-Bustos et al., 2012; Conner and Benison, 2013). Given groundwater input, playa environments can also record biosignatures of subsurface communities, as well as surface habitats (Vreeland et al., 2000).

3.2.3.2. Biosignature preservation cons. Organic biosignature preservation is often poor in high-energy depositional settings within deltas. Typically, deposits in high-energy settings are coarser sediments. Long-term organic preservation in high-energy settings is compromised by oxidizing fluids and gases passing through the more permeable and porous sediments. For this reason, biosignature preservation is generally confined to more quiescent settings such as lakes or within the deeper delta facies, where low permeability and porosity mudstones are deposited and reducing conditions are maintained (Mayer, 1994).

Estimating the timescale of deposition in subaqueous settings can be problematic. Relative timing of deposition can be determined stratigraphically, but the duration may be either the accumulation of many years of deposition or a single rapid depositional event. Duration may be determined by close examination of sediment features, but this would not be possible from orbit.

\subsection{Subaerial environments}

3.3.1. Definition of subaerial environments. The category of subaerial environments includes all environments at the surface or in the near-surface not covered by a body of water but where water is derived directly from precipitation, snow melt, or ambient-temperature groundwater. Thus, this diverse suite of environments includes soils, wetlands, and cold springs, as well as glaciers and snow packs (Fig. 7). While these environments can support very different ecosystems with a wide range of biomass and have different biosignature preservation potentials, we group them together in this section because they are often colocated both on modern Earth and in the terrestrial rock record. In particular, these environments are commonly identified in Archean and Proterozoic rocks by the presence of paleosol profiles, which can be topped by wetlands, ephemeral ponds, and springs, and are also the best indicator of a paleosurface where a preserved microbial mat may be located. Thus, on Mars, these diverse environments are likely to be found in the rock record at the same landing site.

Soils form when rain or snowmelt percolates down through surface rocks or sediments to cause top-down chemical weathering. Soil mineralogy varies with climate and environment but is typically dominated by smectites, kaolins, and other phyllosilicates. Well-drained soils can be highly oxidizing and often contain iron oxides, but soils formed under poorly drained conditions, including in saturated environments like wetlands, become reducing and precipitate sulfides and other ferrous alteration phases. Exposure of these reduced phases to atmospheric oxygen or oxygenated fluids can cause oxidation and precipitation of iron oxides or acid sulfates along wetland margins, at subsurface horizons, or at springs. Soils are preserved in the geologic record as paleosols, and the composition and morphology of paleosols preserve evidence of past climate, aqueous conditions, and both macro- and microbiota (e.g., Sheldon and Tabor, 2009).

Cold springs are subaerial environments where ambienttemperature water emerges from the subsurface onto the surface. Typically, the flow path for the water is along faults or fractures, and changing chemical conditions as the water emerges onto the surface lead to the precipitation of mineral deposits. The mineralogy of spring deposits is variable and depends on the composition of the water as well as the microorganisms present. Commonly, tufas (calcium carbonates), clays, and iron (oxyhydr)oxides precipitate in these environments; and these deposits-along with textural, mineralogical, and chemical biosignatures-can be preserved over geologic time.

Glaciers form when snow accumulates to form a persistent body of dense ice that moves under its own weight. Warm-based glaciers are lubricated by melt at their base, which causes significant chemical and physical weathering (e.g., Anderson, 2007), whereas cold-based glaciers are frozen at their base and flow via internal deformation. Snowpacks form where snow persists but has not yet undergone compaction to form a glacier, including on the top surface of a glacier.

3.3.2. Habitability of subaerial environments. 3.3.2.1. Habitability pros. Subaerial environments support a variety of microbial metabolic pathways both at the surface and in the near-surface environment. These environments can support both chemotrophic and phototrophic microbial communities, which may be present in the form of microbial mats, endoliths, or other microbial communities of varying complexity and density. Exposure to solar radiation at the surface can support phototrophic microbial communities, and workshop participants suggested that higher-energy radiation characteristic of the modern martian surface may support radiotrophic communities in these environments. In addition, the surface-atmosphere interface creates many different types of redox gradients that support diverse communities of chemotrophs at the surface and in the near-surface. These redox gradients are formed due to downward flow of precipitation in soils, groundwater fluctuations, subglacial fluid flow, and spring emergence.

Habitable subaerial environments exist over a range of climatic conditions. Soils form even under extremely cold 

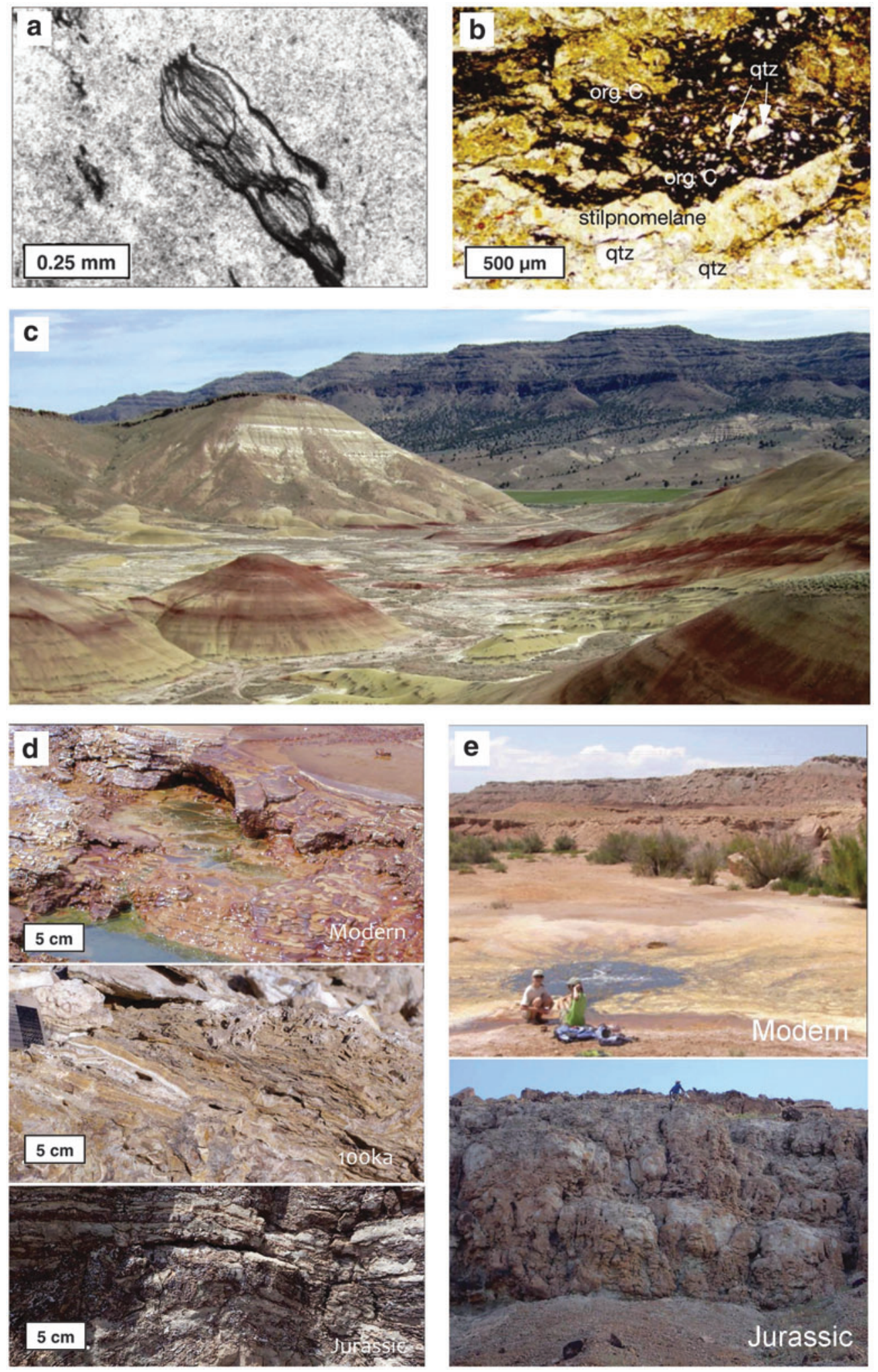

FIG. 7. (a) Opaque filamentous structures associated with $0.05-0.1 \mathrm{wt} \%$ organic carbon in a 2.76 Ga basaltic paleosol in the Pilbara Craton (modified from Rye and Holland, 2000). (b) Organic carbon in the carbonate-rich 2.6-2.7 Ga Kaapvaal Craton paleosol, part of a unit interpreted as a surface layer containing 0.1-0.36 wt \% organic carbon (modified from Watanabe et al., 2000). Both (a) and (b) are interpreted to be organic matter from surface microbial mats. (c) Example of a paleosol sequence, John Day Fossil Beds National Monument, Oregon (credit: B. Horgan). (d) Modern microbialites compared to layered textures consistent with microbialites in $100 \mathrm{ka}$ and Jurassic spring deposits. (e) Modern circumneutral cold spring supporting surface microbial communities near Green River, Utah, compared to outcrop of Jurassic cold spring deposits in the Brushy Basin Member of the Morrison Formation, Colorado ((d) and (e) modified from Potter-McIntyre et al., 2016). 
climates on Earth (e.g., Mahaney et al., 2014), and springs fed by groundwater can exist in virtually any climate regime. Surface microbial communities like microbial mats and snow algae can persist below the freezing point of pure water (Hoham, 2000), and subglacial environments could provide some protection from even extreme climate change. Furthermore, subaerial environments can be extensivesoils, in particular, represent the most widespread nonmarine habitable environment on Earth. The different types of subaerial environments are also often found occurring in close proximity, as the precipitation that creates snowpacks, glaciers, and soils also feeds groundwater tables that can create wetlands and springs as they interact with topography and lithologic units. Thus, subaerial environments can contain a suite of habitats that foster diverse microbial communities.

3.3.2.2. Habitability cons. The main challenge for subaerial environments is that their habitability is often highly dependent on climate and can be adversely affected by changes in climate over time. On Mars, the habitability of near-surface environments would have been strongly affected by obliquity-driven climate change and, on longer timescales, the overall decrease in water activity at the surface (e.g., Ehlmann et al., 2011; Ehlmann, 2016). Thus, here we consider how habitability in subaerial environments would have changed on Mars over time.

Under the wetter climates of Noachian Mars, continuously or seasonally wet subaerial surface environments were probably widespread (e.g., Carter et al., 2015). These longlived environments can be identified by the presence of clayrich paleosols, and extensive or thick spring deposits (using methods discussed below), both of which strongly suggest long-term interactions with liquid water (Horgan, 2016).

The thinning of the martian atmosphere from the Hesperian into the Amazonian would have substantially decreased the diversity and productivity of subaerial environments over time (Westall et al., 2015a; Davila and Schulze-Makuch, 2016). As the climate cooled and the surface dried up, snowpacks and glaciers may have become more common, and subglacial environments in particular may have become refugia that offered some protection from increasing radiation and climate variability (Cousins, 2011). During the Hesperian, liquid water was largely driven underground or frozen at the surface but may have emerged as local springs or perhaps even regional playas during fluctuations in the groundwater table (e.g., Andrews-Hanna et al., 2007). Both wet subglacial environments and cold springs could have potentially existed on Mars late into the Hesperian (e.g., Fastook et al., 2012), so these environments may have represented niches for habitability after Mars lost much of its surface water.

Under modern martian climatic conditions, neither liquid water nor ice is stable at the surface over much of the planet, and even glaciers and ground ice do not show evidence for sufficient melting to produce liquid water (Fassett et al., 2010). Modern soils formed under recent climatic conditions on Mars (which are typically referred to as regoliths, as soil is strictly defined as including organic material) show weak evidence for chemical alteration (Yen et al., 2005; Amundson et al., 2008; Retallack, 2014) and are exposed to extreme radiation fluxes, low atmospheric pressures, and diurnal temperature cycles that would severely limit their habitability (e.g., Hassler et al., 2014). These soils could be habitable by some measures, as multiple observations have shown evidence for soil interactions with atmospheric water vapor (e.g., Martín-Torres et al., 2015), and energy would be available in the form of incipient chemical alteration, solar radiation, and higher-energy radiation. However, this environment would, under the best circumstances, support an ecosystem of very limited biomass and diversity that would be unlikely to be preserved as clear and concentrated biosignatures.

Spring activity is also limited on modern Mars. Recurring slope lineae identified at some equatorial sites have been proposed to indicate seasonal near-surface flows of brine, potentially sourced from near-surface aquifers or from deliquescence of salts by atmospheric water vapor (Ojha et al., 2015; Stillman et al., 2016; Wilson et al., 2016). However, the water activity for brines in these scenarios may be too low to support life (Rummel et al., 2014). Additionally, our knowledge of ancient spring deposits on Earth is somewhat limited, as spring deposits have only recently been recognized in the ancient rock record (Potter-McIntyre et al., 2016; Van Kranendonk et al., 2016).

3.3.3. Biosignature preservation in subaerial environments. 3.3.3.1. Biosignature preservation pros. Subaerial environments can preserve a variety of organic, textural, chemical, mineralogical, and isotopic biosignatures, as reviewed by Horgan (2016). Archean and Proterozoic paleosols in terrestrial cratons preserve organic carbon in concentrations ranging from 0.01 to $0.36 \mathrm{wt} \%$ (Gay and Grandstaff, 1980; Watanabe et al., 2000, 2004; Rye and Holland, 2000). The organics are found both at the top of the paleosol profiles as well as in their subsurface horizons, and are attributed, respectively, to fragments of surface microbial mats and downward transport of surface organics during soil formation (Watanabe et al., 2004; Rye and Holland, 2000). Some of these occurrences are associated with anoxic surface ponds (Watanabe et al., 2004), and reducing conditions during paleosol formation appear to enhance organic preservation, as oxidized paleosols contemporaneous with these examples do not contain organics (Gay and Grandstaff, 1980).

In general, highly leached and oxidized paleosol profiles, including laterites, have poor organic preservation potential. However, these paleosols can preserve chemical biosignatures, including "bleached" Fe-poor upper horizons attributed to organic acids from surface microbial communities (Gutzmer and Beukes, 1998; Neaman et al., 2005), and phosphorus depletion in the upper portion of profiles that could indicate uptake by microorganisms (Horodyskyj et al., 2012).

A common characteristic of these paleosol biosignatures is that they are concentrated at or near the top of the soil profile; thus, a major requirement for biosignature preservation in paleosols is preservation of the paleosurface through rapid burial. Paleosol sequences, which form when weathering occurs along with recurring sedimentation, can preserve paleosurfaces, diverse geochemistries and redox states, and local surface aqueous environments, enabling multiple preservation mechanisms. While no paleosol sequences have been identified in the Archean and Proterozoic rock record (only individual paleosols as discussed above), 
studies of more recent paleosol sequences have shown concentrations of organics occur in subsurface sulfate nodules (Noe Dobrea et al., 2016) and as lignites in wetlands sediments (Retallack et al., 2000).

Biosignature preservation in cold springs is enhanced by the diversity of mineral deposits (e.g., carbonates, clays, sulfates/salts, amorphous minerals) that they produce, which enable multiple preservation mechanisms. Ostwald ripening (where large crystals form at the expense of smaller crystals, resulting in massive, anhedral crystal habits in Jurassic tufas) has been shown to preserve microbial body fossils and trace fossils in carbonates on geologic timescales (PotterMcIntyre et al., 2016). Additionally, energy availability produces abundant biomass in cold springs; therefore, biosignatures are highly concentrated in cold springs.

3.3.3.2. Biosignature preservation cons. A key challenge for biosignature preservation in paleosols in particular is that the local concentration of biomass can be quite variable, with relatively high concentrations only at the surface associated with microbial mats or perhaps in sediments produced in a highly productive persistent wetland environment. As such, even though many paleosols may have high chemical energy availability (e.g., subsurface redox gradients), this may not be consistently associated with significant biomass. Furthermore, it is unclear how widely distributed surface microbial communities would have been on either ancient Earth or Mars, especially prior to the evolution of photosynthesis. This dependence on surface communities also makes rapid burial key for preservation. While preservation in most other surface and aqueous environments is dependent on relatively rapid burial, the surface communities that subaerial environments depend on for habitation are especially sensitive to erosion, and rapid burial of these communities is a necessity for preservation. Lastly, the mineralogy and chemistry of many paleosols may not be sufficient for organic preservation. While high clay mineral (phyllosilicate) abundances in mature soils would help prevent later fluid flow and diagenesis, many clay-rich but oxidizing soils do not retain organics in the first place, as discussed above. Spring deposits would also require limited erosion and rapid burial in order to protect against erosion and destructive radiation. However, spring deposits preserve abundant textural and mineralogical biosignatures, so organics may not be necessary for biosignature detection.

\subsection{Subsurface environments}

There were only a few attendees who represented investigations of subsurface environments; however, substantial discussion of subsurface environments occurred during the workshop, and submitted abstracts reflect the growing interest in this region (Boston and Alexander, 2016; Onstott et al., 2016; Sapers et al., 2016).

3.4.1. Definition of subsurface environments. For the purposes of this document, the subsurface is considered to include all environments beneath the active regolith, except for those directly impacted by hydrothermal circulation, which are considered in the "Hydrothermal spring systems" section. Among the environments encompassed by this definition are shallow aquifers with pore spaces filled with liquid water or ice, deeper igneous crust, deep sedimentary deposits, and caves.

Current surface conditions on Mars are inhospitable to life as we know it, owing to cold temperatures and low atmospheric pressure that preclude standing water as well as harsh ionizing radiation that will destroy complex organic molecules. These harsh surface conditions potentially extended back to the Noachian/Hesperian boundary, so surface environments including lakes/deltas may not have been habitable for much of Mars' history. Conversely, subsurface refugia may have extended the window of habitability, and subsurface pockets of habitable conditions could potentially still harbor extant life and their biosignatures.

Habitable environments within the subsurface will include any locations where there is a potential for liquid water to exist, availability of elemental nutrients and energy sources, physical pore space to inhabit, and temperatures low enough for life to exist (Boston et al., 1992; Michalski et al., 2013; Parnell and McMahon, 2016). Owing to decreasing pore space and increasing temperatures with depth, there is likely to be a depth limit to inhabitable environments in the deep subsurface. The exact depth limit of habitable conditions is currently unknown, but it is likely to be in the $5-10 \mathrm{~km}$ range (Michalski et al., 2013). Potentially habitable lava tubes are known to exist on the Moon and Mars, and caves could potentially form on other planets from additional processes such as the sublimation of ice (Fig. 8).

Volumetrically, the subsurface represents the most extensive potentially habitable environment on Mars. Evidence for the existence of liquid water in the deep subsurface includes widespread phyllosilicates and other aqueous alteration products in exhumed terrains interpreted to represent ancient deep crust (e.g., Ehlmann et al., 2011) and catastrophic discharges of fluids from the subsurface dating from the Hesperian to as recently as a few million years ago (Burr et al., 2002; Neukum et al., 2010; Lasue et al. 2013). In the current era, subsurface water may be present at depth owing to thermal gradients and lithostatic pressure or to the presence of salts that depress the freezing point (Clifford et al., 2010). Heating by volcanic processes or impacts may also create localized regions of liquid water within an otherwise frozen crust.

3.4.2. Habitability of subsurface environments. 3.4.2.1. Habitability pros. On Earth, the subsurface supports a significant amount of biomass, and the same may be true of Mars. In a paper that stimulated considerable interest and discussion, Whitman et al. (1998) even suggested that the standing biomass in the terrestrial subsurface rivaled that of surface environments. Although some more recent studies have yielded significantly smaller estimates for the subsurface biomass (Kallmeyer et al., 2012), estimates of the mass of the subsurface biosphere in continental crust remain in the $10^{16}$ to $10^{17} \mathrm{~g} \mathrm{C}$ range (McMahon and Parnell, 2013), suggesting that subsurface conditions on Mars could similarly support a substantial biomass. It must be noted, however, that the bulk of the terrestrial biomass reflected in these estimates may rely, directly or indirectly, on chemical energy inputs from surficial photosynthetic communities. The amount of subsurface biomass on Earth that is supported by locally generated chemical energy sources alone remains poorly known but is likely to be considerably smaller than that of 


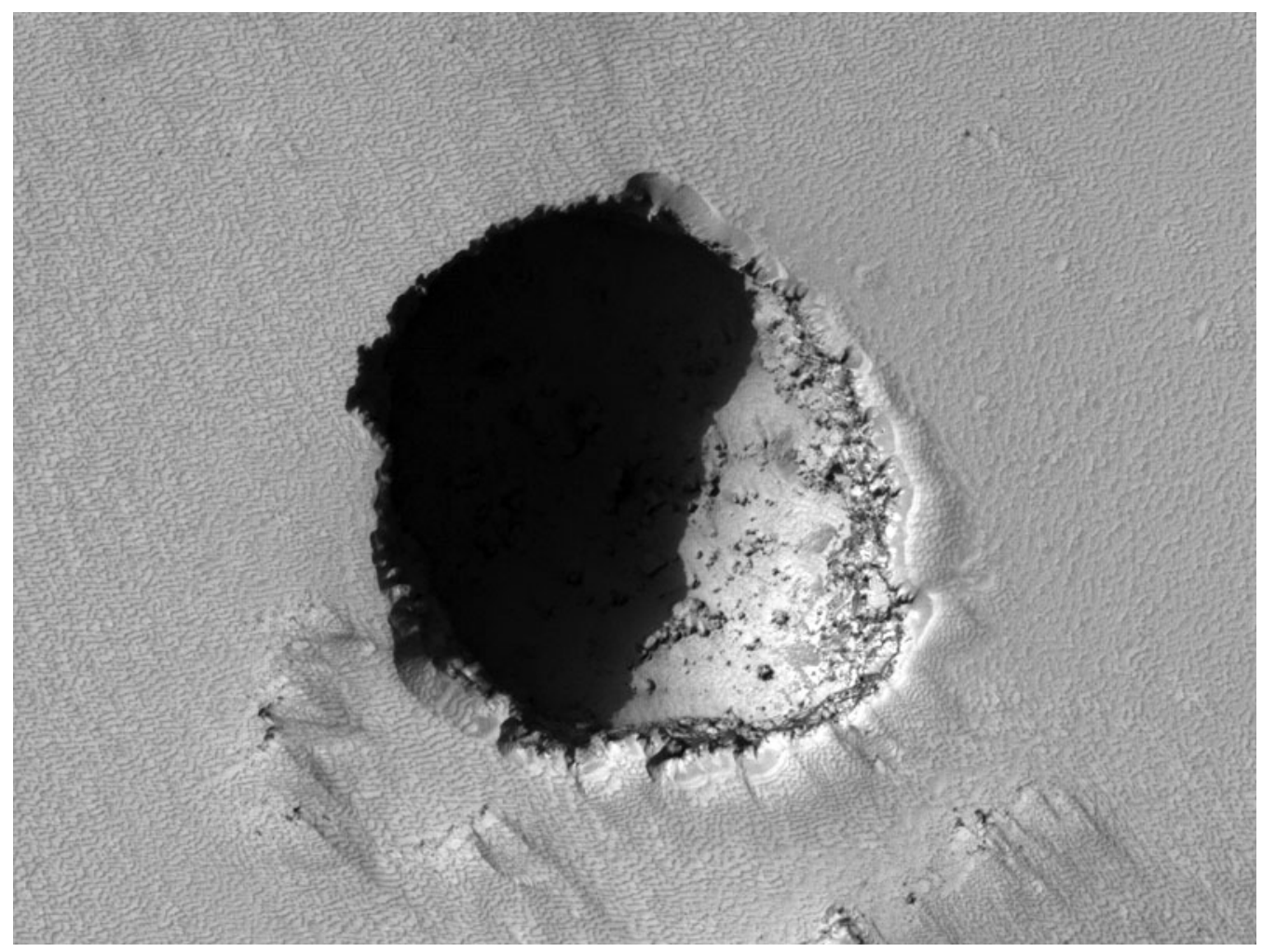

FIG. 8. Cave skylight on the flank of Pavonis Mons in the Tharsis Region taken by the HiRISE camera on the Mars Reconnaissance Orbiter. Cave entrance is estimated to be $180 \mathrm{~m}$ wide. Credit: NASA/JPL/University of Arizona.

the surface-connected microbial community (Bach and Edwards, 2003; Edwards et al., 2012). Caves can also host extensive microbial biomass, which forms important microand macro-biosignatures, both structural and molecular (Frape and Fritz, 1987).

The martian subsurface likely provides physical environments capable of supporting life and protection from inhospitable surface conditions. Subsurface environments can provide liquid water at depth even when the surface is below freezing (Clifford et al., 2010; Michalski et al., 2013) and provide protection from the radiation and oxidants present at the surface. Liquid water may also be present in small amounts in otherwise frozen shallow deposits owing to the presence of salts that depress the freezing point; terrestrial microorganisms can metabolize in briny solutions to temperatures below $-30^{\circ} \mathrm{C}$ (e.g., Bakermans and Skidmore, 2011). Caves act as insulating environments and may provide conditions (e.g., temperature and humidity) vastly different from external conditions (AzúaBustos et al., 2009). Caves may also host ice that could persist through changes in obliquity or be seasonally present due to periodic recharge from the near-surface/subsurface (Williams et al, 2010; Boston and Alexander, 2016). The ice-rock interface may have a persistent liquid water film that is sufficient to sustain habitable conditions (Popa et al., 2012) - cell concentrations as high as $10^{2}$ to $10^{9}$ have been observed on fracture surfaces in ice (Onstott et al., 2016).

The subsurface provides long-term stable conditions that could allow life to adapt to the environment. Conditions in subsurface environments can remain stable for very long periods (millions of years or more), allowing microorganisms to adapt to the environment and for energy sources to accumulate. For example, recent studies of the terrestrial subsurface have identified deep fluids with residence times exceeding a billion years that have accumulated high $\mathrm{H}_{2}$ concentrations (Holland et al., 2013). These fluids can support biological activity where they intersect with more shallow fluids (Lin et al., 2006; Sherwood Lollar et al., 2007). Caves are also long-lasting terrestrial environments (millions of years) and are likely to persist for even longer periods of time in tectonically quiescent environments such as on Mars.

Subsurface environments provide a variety of energy sources that can support biological activity. Water-rock interactions and radiolysis can provide abundant, localized energy sources to support subsurface communities. Much of the crust of Mars is composed of basalt and ultramafic rocks. On Earth, groundwater circulating through basalts in both subaerial and submarine settings is thought to support indigenous chemolithotrophic microbial communities relying on energy sources generated by reaction of water with basalt, such as iron oxidation, sulfide oxidation, sulfate reduction, hydrogen oxidation, and methanogenesis (e.g., Stevens and McKinley, 2000; Bach and Edwards, 2003; Lin et al., 2006; Lever et al., 2013; Osburn et al., 2014; Simkus et al., 2016). Reaction of ultramafic rocks with water, a process known as serpentinization, produces molecular hydrogen $\left(\mathrm{H}_{2}\right)$ and methane $\left(\mathrm{CH}_{4}\right)$ that support microbial activity (McCollom and Seewald, 2013; Schrenk et al., 2013). Utilization of many energy sources in these environments may require input of electron acceptors $\left(\mathrm{O}_{2}, \mathrm{NO}^{3-}, \mathrm{SO}_{4}{ }^{2-}\right)$ from the surface, but plausible scenarios exist to transport such compounds into subsurface environments on Mars if they are present at the surface (Boston et al., 1992; Fisk and Giovannoni, 1999; Michalski et al., 2013). An additional source of metabolic energy in subsurface environments is 
radiolysis of water, whereby radiation from radioactive elements like $\mathrm{K}$ and $\mathrm{U}$ form molecules such as $\mathrm{H}_{2}$ and hydrogen peroxide (Lin et al., 2005). Caves may also include gases from deep within the crust, allowing an additional energy source (Boston and Alexander, 2016).

Hydrology and enhanced fluid flow along fractures can focus energy and nutrient sources with the capacity for localized sites of heightened biological activity, facilitating targeted searches for habitable environments. Cell concentrations can reach as high as $10^{9}$ cells/g in the subsurface, and cells on fracture surfaces can reach $10^{5}$ cells $/ \mathrm{cm}^{2}$ (Wanger et al., 2006). Although concentrations on Earth tend to be highest for sedimentary rocks, cell concentrations as high as $10^{5}$ to $10^{8}$ have been observed for ash tuffs and metamorphic rocks on Earth (Onstott et al., 2016). Caves can provide preferential groundwater conduits and reservoirs for nutrients and energy captured from surface or subsurface weathering (Léveillé and Datta, 2010).

Caves, in addition to providing many of the benefits listed above such as long-term environmental stability, protection from inclement surface conditions, and a variety of localized chemical gradients, also provide the benefit of an intermediate environment between the surface and subsurface (Boston and Alexander, 2016). Caves are likely to provide higher levels of humidity, as well as access to atmospheric gases within the subsurface, which could provide redox gradients that could be utilized for metabolic energy (Boston and Alexander, 2016).

3.4.2.2. Habitability cons. On Earth, cell density gradually decreases with depth, suggesting that biomass in deep subsurface environments on Mars may also be decreased relative to what we observe close to the surface on Earth. The habitability of many subsurface environments may also require communication with the surface to supply critical nutrients (e.g., electron acceptors, elemental nutrients, organic matter) and remove waste products. In the absence of such communication, habitable environments may be much more limited. At present, little information is available concerning the magnitude of surface inputs to subsurface environments on Mars. Environments such as caves that are more closely connected to the surface may also be more vulnerable to threats to habitability such as cold temperatures.

Habitable environments in the subsurface will also be spatially limited owing to restrictions on distribution of pore spaces (fractures), temperatures above the upper limit for life (currently $122^{\circ} \mathrm{C}$ for life on Earth; Takai et al., 2008), and presence of liquid water.

3.4.3. Biosignature preservation in subsurface environments. 3.4.3.1. Biosignature preservation pros. There are many different types of biosignatures that may potentially be produced by microorganisms in subsurface environments, including biominerals, textures, microbial body fossils, macroscopic biopatterns, organic and inorganic chemical compounds, and isotopes. Potential biosignatures include minerals precipitated as a direct result of biological activity (e.g., Fe oxides, sulfides), preservation of microbial structures such as biofilms by precipitating minerals such as carbonates filling fractures (Pedersen et al., 1997), organic compounds produced by biological activity (e.g., lipids, amino acids), textures indicative of microbial activity (e.g., microtubules; Fisk et al., 1998; Furnes et al., 2004), changes in trace element distri- butions (Leslie et al., 2013, 2014), and isotopic composition of organic matter, the breakdown products of organic matter, or minerals (e.g., Alt and Shanks, 1998). In caves and lava tubes, various mineral textures, microstromatolitic textures, and isotopic signatures in minerals and organic matter have been identified as biosignatures (Boston et al., 2001; Léveillé et al., 2007).

The interaction of fluid and rock in the subsurface leads to mineral alteration and widespread precipitation of secondary minerals, and precipitation of these secondary minerals creates a favorable environment for preservation of biosignatures. For example, microbes may induce precipitation of minerals that possess structural characteristics indicative of a biological role in their formation (e.g., Cady and Farmer, 1996; Farmer and Des Marais 1999; Konhauser et al., 2002). Mineral precipitation may also entrap organic compounds or retain isotopic signals of biological activity (Boston et al., 2001). Preservation of biosignatures also actively occurs in terrestrial caves by mineral precipitation (Léveillé et al., 2007; Richardson et al., 2012; Boston and Alexander, 2016); these authigenic minerals will also possess a record of environmental conditions and water-rock interactions that would provide additional context to biosignature formation and preservation.

Owing to interactions of fluid and rock, conditions in the subsurface will tend to be reducing, with low levels of oxidants. In the absence of these compounds, oxidative decomposition of organic compounds may be restricted. Access to the subsurface through caves, impact excavations, and potentially recurring slope lineae means that potential biosignatures preserved beneath the surface may also be exposed at the surface for detection. Lava tubes also often form relatively near the surface, thereby facilitating possible exposure (Boston and Alexander, 2016).

3.4.3.2. Biosignature preservation cons. Subsurface environments on Earth have only recently begun to be the focus of intensive scientific attention; consequently, the types of biosignatures that subsurface communities might create remain largely unknown. Most work to date has focused on characterizing the genetic and metabolic diversity of subsurface communities (Northup et al., 2011; Popa et al., 2012; Lever et al., 2013; Osburn et al., 2014) and on characterizing the distribution of bioorganic compounds such as lipids and amino acids (Lipp et al., 2008; Lomstein et al., 2012). However, how biosignatures of subsurface communities might be preserved over time remains unknown. Although it has been suggested that microtubules observed in some subsurface basalts might be a biosignature (Fisk et al., 1998; Staudigel et al., 2008), the biological origin of these structures remains unproven, and alternative explanations have been proposed (French and Blake, 2016). Potential biosignatures that could persist for millions to billions of years in the subsurface have not yet been identified.

\subsection{Iron-rich environments}

3.5.1. Definition of iron-rich environments. Iron-rich aqueous environments provide a variety of habitable settings on Earth and potentially Mars (Fig. 9). Both groundwater and hydrothermal systems can mobilize iron-bearing minerals to provide subsurface and subaqueous habitats high in dissolved iron, such as groundwater circulating through 

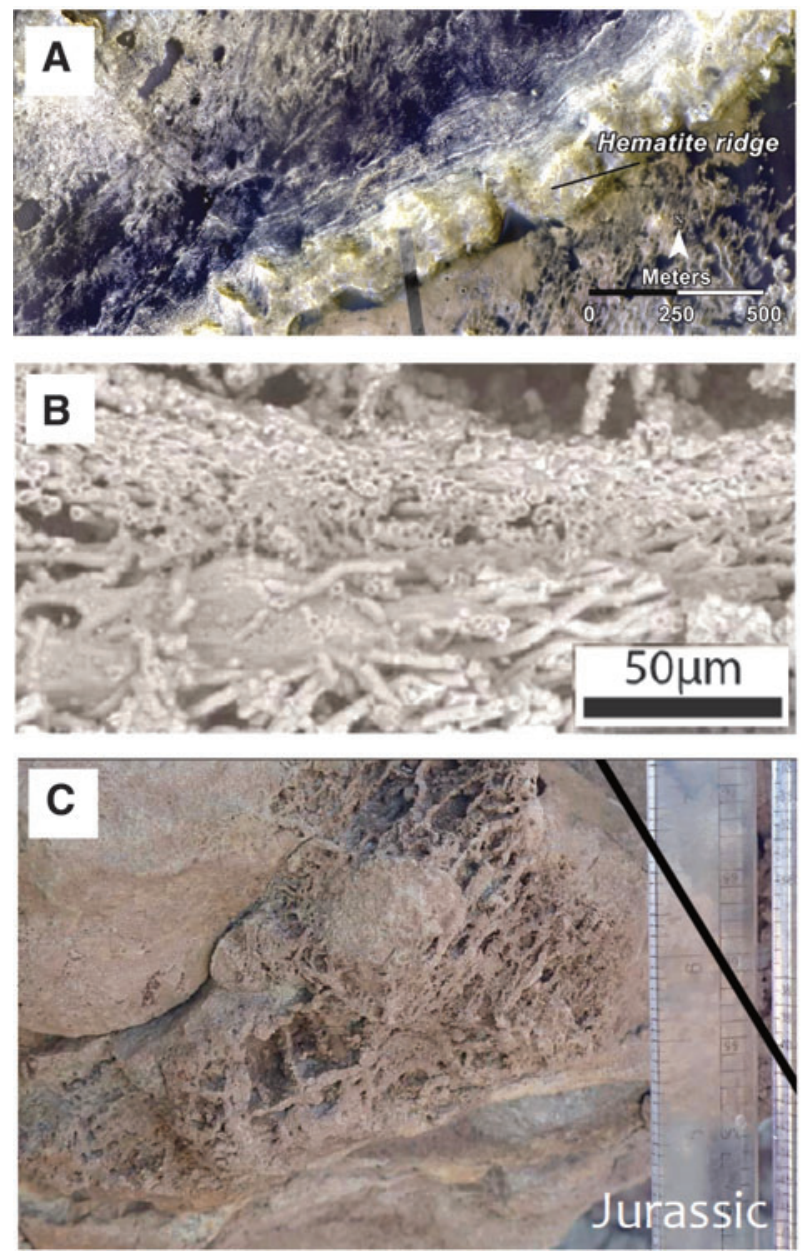
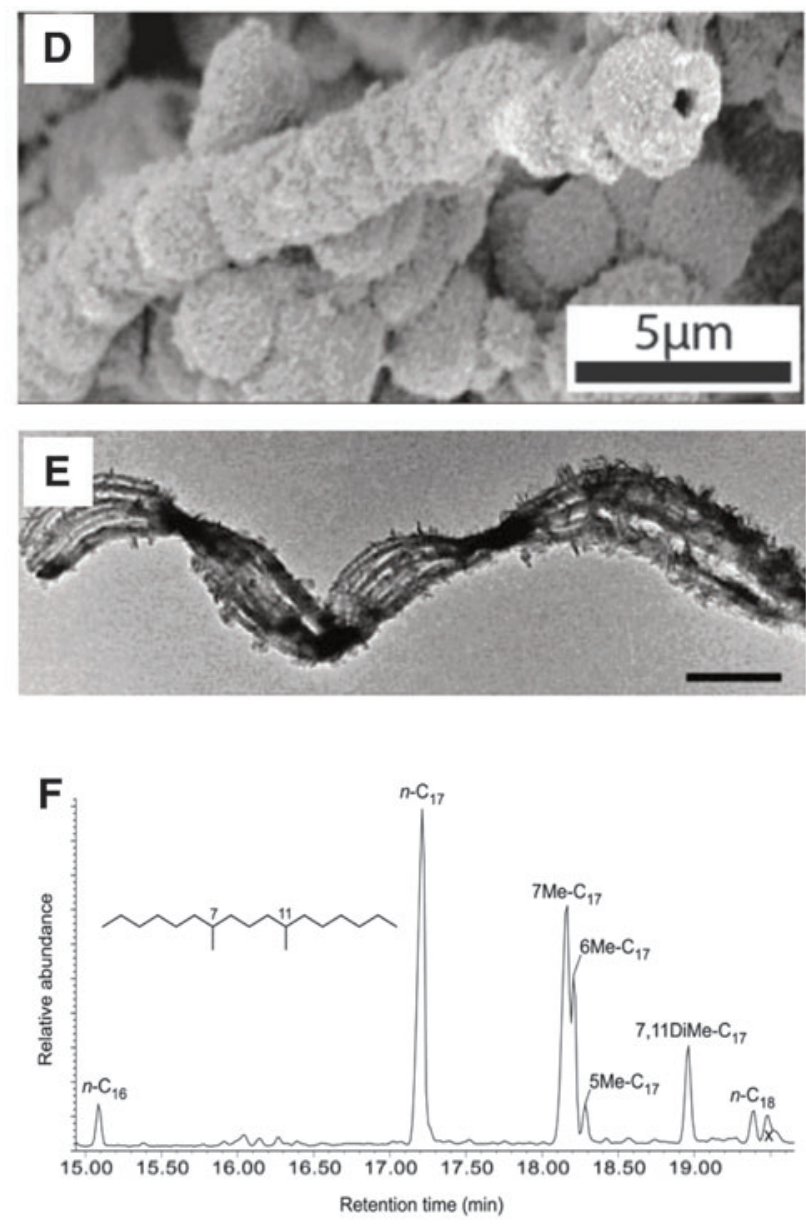

FIG. 9. (a) Example of iron-rich environment on Mars: Hematite Ridge in Gale Crater. Image Credit: NASA/JPLCaltech/Univ. of Arizona. (b) Biofabric composed of masses of filamentous microbes encrusted by iron oxides from acid mine drainage at Iron Mountain, California (Williams et al., 2016). (c) Jurassic iron and carbonate biofabric from a spring deposit in the Brushy Basin Member of the Morrison Formation. These delicate macroscopic terracette features have undergone 150 million years of diagenetic alteration yet are still recognizable in outcrop (Potter-McIntyre et al., 2016). (d) Iron-encrusted filamentous microbe from Iron Mountain (Williams et al., 2016). (e) Transmission electron microscope image of iron-mineralized spiral stalk from Mariprofundus ferrooxydans (scale bar $=1 \mu \mathrm{m}$; Chan et al., 2011). (f) Lipid biomarkers (midchain mono- and dimethylalkanes) isolated from modern and subrecent iron-mineralized microbial mats (Parenteau et al., 2014, 2016).

permeable rock, ferruginous marine and lacustrine settings, and deep-sea hydrothermal vents. These iron-rich groundwaters can also be expressed at the surface to form subaerial habitats, such as seeps and springs. Solid iron mineral phases and ore bodies, when in contact with water, can also provide habitable environments, such as igneous rocks (basalts) and massive sulfide deposits.

Subsurface iron-rich environments occur when anoxic groundwater high in $\mathrm{Fe}(\mathrm{II})$ circulates in permeable rock. Sedimentary features such as concretions form when this water encounters oxygen-rich groundwater, inducing the oxidation and precipitation of the iron (Chan et al., 2004). These concretions are hard, compact masses of minerals that differ in composition from their host rock and are typically composed of an $\mathrm{Fe}(\mathrm{III})$-rich outer rind and an Fe-poor core. The hematite-cemented concretions found in the Jurassic Navajo Sandstone of southern Utah are considered analogs of the martian "blueberries" detected in Meridiani Planum by the Mars Exploration Rover Opportunity (Chan et al., 2004). While the $\mathrm{pH}$ of the terrestrial and martian settings may differ, the physical formation processes may be similar.

The main geologic record of subaqueous iron-rich environments on Earth are iron formations (IFs). IFs are thickly to finely laminated subaqueous deposits (although some lack banding and exhibit a granular texture) that contain greater than $15 \%$ iron, often as layers of iron oxides alternating with chert. IFs may contain hematite, magnetite, carbonates, silicates, and interbedded shales (Sumner 2004). These sedimentary deposits are nearly always Precambrian in age and accumulated in deep ocean basins or shallow platformal areas with inputs of reduced iron and silica from deep ocean hydrothermal activity (e.g., Fryer, 1983; Klein and Beukes, 1989; Beukes and Klein, 1992; Morris, 1993).

Deep-sea hydrothermal vents provide another example of a subaqueous iron-rich habitat. Modern examples of these vents exist at the Loihi Seamount in the Hawaiian 
Archipelago. The vents, located $\sim 1000 \mathrm{~m}$ below the surface, are situated on the summit of the shield volcano and emit fluids high in $\mathrm{CO}_{2}$ and $\mathrm{Fe}(\mathrm{II})$ (Emerson and Moyer, 2002).

In subaerial environments, iron seeps and springs are the surface expression of $\mathrm{Fe}$ (II)-rich groundwater, which can be sourced from the dissolution of iron-rich country rock in low- and high-temperature (hydrothermal) systems. Iron seeps are characterized by flocculent, ochreous masses of iron oxyhydroxides (e.g., ferrihydrite) (Emerson and Revsbech, 1994). Iron hot springs are also characterized by primary iron precipitates such as ferrihydrite, but in areas where the sinter has aged, diagenetic transformation of the ferrihydrite to more thermodynamically stable phases such as hematite and goethite occurs (Wade et al., 1999).

A gossan is the result of near-surface iron-rich fluid circulation and is defined as an oxidizing massive sulfide deposit, that is, large deposits of pyrite and other metal sulfides in a host rock. Massive sulfides are emplaced during a variety of endogenous or exogenous ore-forming processes, including magmatic, hydrothermal, and metamorphic processes (endogenous), and sedimentary or surficial processes (exogenous) (Dill, 2010). The gossan, or supergene environment, forms in the near surface where meteoric water interacts with the exposed sulfide, oxidizing these nearsurface minerals and driving forward chemical weathering. Percolation of these meteoric waters deeper into the massive sulfide will lead to continued oxidation of the hypogene, or primary sulfide minerals (commonly pyrite) into iron (oxyhydr)oxides (e.g., hematite or goethite). The oxidation of the hypogene produces acidity; therefore, these types of environments produce acid rock drainage.

3.5.2. Habitability of iron-rich environments. 3.5.2.1. Habitability pros. Iron is one of the most abundant redoxactive metals in Earth's crust, and the oxidation of dissolved and solid-phase Fe(II) can power microbial metabolisms in both acidic and circumneutral settings and under aerobic and anaerobic conditions (e.g., Winogradsky, 1888; Ingledew, 1982; Widdel et al., 1993; Straub et al., 1996). Chemotrophic iron oxidizers can exploit the redox gradient of $\mathrm{Fe}(\mathrm{II})$ and $\mathrm{O}_{2}$ at oxic/anoxic interfaces to fuel their growth (e.g., Emerson and Revsbech, 1994; Baker and Banfield, 2003). Some of these chemotrophs can grow anaerobically using nitrate as an oxidant instead of $\mathrm{O}_{2}$ (Straub et al., 1996). If other reductants such as $\mathrm{H}_{2}$ or organic carbon are present, chemotrophs can also use $\mathrm{Fe}(\mathrm{III})$ as an oxidant, a process termed dissimilatory iron reduction (Lovely, 1993). Growth on $\mathrm{Fe}(\mathrm{II})$ is not restricted solely to chemotrophs, as anoxygenic phototrophs can use $\mathrm{Fe}(\mathrm{II})$ as an electron donor for photosynthesis (Widdel et al., 1993; Heising and Schink, 1998; Heising et al., 1999).

Many iron-rich settings may represent long-lived habitable environments. The large volume of certain iron deposits can reflect a relatively steady supply of energy and reduced iron inputs over geologic timescales. For example, most Precambrian IFs were deposited from 3.8 to $1.8 \mathrm{Ga}$ (Klein, 2005), potentially representing a continuously habitable environment on the scale of $c a .2$ billion years. Other large iron-bearing deposits such as massive sulfide deposits may be long-lived, on the order of thousands to hundreds of millions of years, based on the time required for such a large volume to be weathered or altered such that all the iron is oxidized and no longer able to support microbial growth (Albers and Bain, 1985; Fernández-Remolar et al., 2003). The longevity of subsurface iron-rich habitats is unknown, but modeling of the dissolution of iron minerals and transport of $\mathrm{Fe}(\mathrm{II})$-rich groundwater indicates that formation of the concretions may have been episodic over geologic time (Chan et al., 2007).

Other characteristics of iron can enhance the habitability of surface environments. The anoxic Archean Earth experienced a much higher UV flux due to the absence of an ozone layer (Sagan, 1973; Margulis et al., 1976). Both iron and elemental sulfur have been shown to provide some shielding against UV radiation, which may delay or prevent the breakdown of organic matter due to radiolysis (Cockell, 1998; Gomez et al., 2003). Iron can also protect microbial cells from UV-induced DNA mutations and lethal cell damage (Olson and Pierson, 1986; Pierson et al. 1993). The absorption coefficient for ferric (Fe(III)) iron in particular is an order of magnitude greater than that of ferrous (Fe(II)) iron (Cockell and Knowland, 1999). Whether the oxidized ferric iron was produced biotically or abiotically, it would confer greater microbial survival in surface environments on early Earth and potentially Mars.

3.5.2.2. Habitability cons. The primary total organic carbon (TOC) input into iron systems is much lower than in other environments (e.g., marine systems) due to the energy requirements of microorganisms living in iron-bearing habitats, which are strongly to mildly acidic (Parenteau and Cady, 2010; Graham et al., 2016; Johnson et al., 2016). Microorganisms must invest a significant amount of energy to pump protons out of their cells to maintain a neutral intracellular $\mathrm{pH}$, and consequently do not produce as much biomass as microorganisms growing in more benign environments. Additionally, acidity can bottleneck microbial diversity in an environment, as microorganisms must evolve to cope with the elevated acidity. In isolated environments with limited TOC sources to fuel heterotrophic growth, microbial populations consequently synthesize limited biomass (Tyson et al., 2004). However, additional allochthonous TOC input from eukaryotes (e.g., plants) in a highly acidic environment may generate greater microbial diversity, such as in the Río Tinto system (Amaral Zettler et al., 2002).

3.5.3. Biosignature preservation in iron-rich environments. 3.5.3.1. Biosignature preservation pros. Preservation of microorganisms occurs when cells are rapidly buried in fine-grained iron sediments, or rapidly encrusted or permineralized in fine-grained primary iron precipitates (Farmer and Des Marais, 1999). In these environments, anoxic conditions may be maintained that restrict the oxidative destruction of organic compounds and permit early diagenetic mineralization (Cady et al., 2003).

When microbial cells are rapidly encrusted in iron-rich minerals, they may form textural or morphologic biosignatures, which may be long-lived in select environments even after diagenetic alteration of the iron oxyhydroxides. This has been documented in gossans thousands to several millions of years old (Fernández-Remolar and Knoll, 2008; Williams et al., 2015, 2016) and in iron oxyhydroxides in lacustrine units from the Jurassic (155-148 Ma) (PotterMcIntyre et al., 2014, 2016). On Earth, iron-oxidizing 
chemotrophs often deposit distinctive mineral structures (stalks, etc.) that can be intimately associated with organic compounds (e.g., Edwards et al., 2004; Chan et al., 2011). These structures can be preserved in the geologic record (e.g., Alt, 1988).

In addition to textural or morphological biosignatures, the cellular remains of microorganisms can be preserved as lipid biomarkers in iron-rich deposits. The carbon skeletons of branched or cyclic lipids are more resistant to degradation after cell death and can survive in the rock record for billions of years (Waldbauer et al., 2009). Such "geolipids" provide important fossil information and can help reconstruct the record of past microbial ecosystems on early Earth and potentially Mars. Iron has been shown to enhance the early preservation of lipids by rapidly encrusting the cell and protecting the lipids by making them unavailable to enzymatic degradation by the cell's own lytic enzymes, or those of heterotrophs (Parenteau et al., 2014, 2016).

Even though microfossils have not been found in the ironrich layers of IFs, putative cells rimmed and fully replaced with hematite have been reported in the chert layers of the Gunflint Iron Formation (Barghoorn and Tyler, 1965). Allen et al. (2001) also reported iron permineralized structures resembling cells in chert layers from the Mink Mountain locality of the Gunflint. In addition to the microfossils, iron mineralized polymeric substances were detected, which prompted the authors to suggest that microbial mats may have played a role in iron oxide precipitation and IF formation (Allen et al., 2001; Schelble et al., 2004). Such reports lend support to the hypothesis that iron may play a role in the long-term preservation of cells.

Although organic carbon is thermodynamically unstable in the presence of $\mathrm{Fe}$ (III), organic matter may coprecipitate or chelate in iron complexes or be deposited in interbedded evaporites or clays to be preserved over longer timescales (Lalonde et al., 2012). While organic matter is often found in very limited concentrations within the iron oxide-facies of IFs (Kaufman et al., 1990), this may reflect a lower initial TOC input rather than poor preservation by iron (Parenteau and Cady, 2010; Parenteau et al., 2016).

3.5.3.2. Biosignature preservation cons. The preservation potential of microbial biosignatures in iron-rich environments is diminished by (1) the degradation of organic matter in the presence of $\mathrm{Fe}$ (III) over geologic timescales or at elevated temperatures, (2) biosignature formation over short timescales, which then must be resistant over long timescales to be preserved, (3) ionizing and potentially UV radiation, which may lead to organic matter degradation, and (4) the heterogeneous distribution of iron biosignatures.

As noted above, the preservation of organic carbon by iron oxides is not thermodynamically favored in the presence of $\mathrm{Fe}(\mathrm{III})$, and organic carbon can decay quickly in oxidizing environments if not captured in an environment that exhibits preferential preservation (Cady and Farmer, 1996; Walter et al., 1996, 1998; Farmer, 1999; Sumner, 2004; Hofmann et al., 2008). For example, in the same nearsurface (upper $5 \mathrm{~m}$ ) environment, a phyllosilicate-rich layer may contain 10 times more TOC than the surrounding ironrich layers, and iron-rich hyperacidic environments demonstrate poor preservation of dissolved organic matter (Bonaccorsi and Stoker 2008; Davila et al., 2008).
Ferric iron (Fe(III)) has been shown to confer protection to microorganisms and enhance survival in high UV environments on early Earth (see Section 2.1). However, UV radiation may conversely lead to poor biosignature preservation. This is due to the ability of radiation to drive the oxidation of $\mathrm{Fe}$ (II) to $\mathrm{Fe}$ (III) in laboratory experiments (Cairns-Smith, 1978; Braterman et al., 1983). This change in oxidation state can destroy biosignatures that formed in a previously reduced or mixed valence system. Textural and morphological biosignatures can also be destroyed when the metastable primary iron oxyhydroxides recrystallize to more thermodynamic stable forms (Parenteau and Cady, 2010). An iron-mineral environment may be less able to protect organics from ionizing radiation.

Biosignatures can also be heterogeneously distributed in subsurface, subaqueous, and subaerial iron habitats. Microbial communities can be patchy in their distribution, and their concentration can be highly dependent on microenvironmental niches (e.g., Pierson et al., 1999) or small point sources of Fe(II) (Emerson and Moyer, 2002).

\section{Exploring Past Habitable Environments on Mars}

\subsection{Common challenges}

During the discussions at the conference about biosignature preservation in a variety of environments, a number of common challenges were identified among these environments. Rather than include these challenges in each of the following environmental sections, we have chosen to highlight them in a single section, and they have been split below into two groups: challenges to sample selection that will affect the potential to identify biosignatures and challenges that affect biosignature preservation.

4.1.1. Identification of sites. Once there is a commitment to send a mission such as Mars 2020 to a surface environment to search for biosignatures that might be present and preserved, there are additional challenges to both identifying the correct site and identifying the correct samples to collect.

4.1.1.1. Orbital observations for site selection. The first challenge in identifying an appropriate site-regardless of the environment that is being targeted-is the limit in resolution of our orbital assets. For example, the High Resolution Imaging Science Experiment (HiRISE) on the Mars Reconnaissance Orbiter is capable of sub-meter-perpixel resolution, and the Compact Reconnaissance Imaging Spectrometer for Mars (CRISM) is capable of $\sim 18 \mathrm{~m}$ per pixel resolution. Although this is certainly sufficient resolution to identify some of the larger-scale environmental features (e.g., deltas, meter-scale outcrop features), these data sets can provide only broad context for identification of most types of environments that are under consideration here. This potentially introduces a bias toward prioritizing environments that are more easily identified remotely, including environments whose geologic record is better exposed through erosion and dust removal, and environments that have larger areal footprints, regardless of their potential for biosignature preservation.

Additionally, the orbital reconnaissance of potential sites for exploration cannot provide a reliable indication of how 
long any given environment may have been habitable. Whether a particular environment was persistently habitable and its record covers an extended period of time (hundreds to thousands of years or more) or whether a particular deposit accumulated relatively quickly (years to hundreds of years) would have a significant effect on the potential for biosignatures to have been created and preserved.

Although some aspects of accessibility can be remotely assessed for a particular site before selection (e.g., average slopes or rough terrain), the specific challenges that are unique to any given site may not be obvious until the surface mission is in place. As the Mars Exploration and Mars Science Laboratory rovers have traversed the surface, there have been significant improvements in correlating ground and remote observations, but how the accessibility of a particular site may affect the ability of a mission to identify and collect the appropriate samples for detection of potential biosignatures cannot be fully known in advance. This challenge would have a greater effect on environments where full characterization would likely require sampling across significant vertical or horizontal extent and thus where accessibility of the entire appropriate facies would be important.

4.1.1.2. Surface observations. Even after a particular site has been selected for the next mission, surface operations face the following challenges to proper sample selection; these apply to all the environments being considered in this report.

The first challenge would come from recognizing the particular features of a habitable environment in the absence of abundant life (or potentially life at all). Many of the features that we use to identify different facies are dependent on both biotic and abiotic processes. Additionally, the abundance of photosynthetic microorganisms on this planet certainly has an effect on the particular features that are used to identify a preserved inhabited environment, and it must be considered which features on the outcrop scale should be targeted for sampling given the possibility that photosynthesis may have never evolved on Mars. For example, phototrophs in hydrothermal spring systems synthesize more biomass than chemotrophs and produce a wider variety and abundance of preserved organic molecules and meso- and microscale textures. These textures may be detectable on the outcrop scale, aiding in the identification of past habitable environments for further sampling. In contrast, there are fewer types and less abundant preserved textures associated with chemotrophic communities, possibly making their detection at the outcrop scale above the background geologic "noise" more difficult. Studies of biosignature production and preservation in analog environments are key for characterizing signatures associated with chemotrophic communities should photosynthesis have never evolved on Mars. This challenge has a particularly strong effect on the identification of mineralogical, chemical, and isotopic biosignatures, where relatively few studies have explored the nonbiological processes that could closely mimic biotic features if given longer timescales to do so.

In all the environments under consideration here, a major challenge for selecting the best sampling location is the spatial heterogeneity of the most promising deposits, which includes local, chemical, or sedimentological variability. The initial concentration of microorganisms can be highly dependent on microenvironmental niches (e.g., Pierson et al.,
1999), or small point sources of nutrients may dramatically affect the density of biosignatures in a given environment (Emerson and Moyer, 2002). Within lacustrine environments, a particular section of mudstone may have significantly more organic material than another just a few meters away, or within a hydrothermal spring environment there may be a particular section where the microfossils are more abundant than in adjacent sections (e.g., Campbell et al., 2015, 2016; Van Kranendonk et al., 2016). While this challenge may not be as much of a problem for macroscopic biosignatures, it is the reason why multiple field seasons interspersed with lab work are typically required in order to achieve a complete environmental characterization and sampling campaign in terrestrial environments. This challenge can be mitigated somewhat due to the advanced instrumentation on the Mars 2020 rover that is typically not available during terrestrial field campaigns. However, as noted here, these instruments might not be equally effective in all environments.

4.1.1.3. Sample collection. One of the final common challenges - and one that in terrestrial environments can be a mitigation strategy for spatial heterogeneity-is the number and size of samples collected. While overcollecting is a way to obtain the maximum number of samples with detectable biosignatures on Earth, there is a limit to the number and volume of samples that will be collected (e.g., as determined by the capabilities of the Mars 2020 rover sampling system) and could be returned (determined by the size of the potential sample return missions). Currently, the Mars 2020 rover sampling system is designed to collect between 35 and $40 \sim 15 \mathrm{~g}$ samples of rock and regolith (Farley, personal communication). This extremely limited amount of sample mass-some of which would be committed to other science objectives and planetary protection assays - will be a challenge for detecting all types of biosignatures and in all potential environments.

4.1.1.4. Mars 2020 rover instrument suite. Given that the instrumentation for the Mars 2020 rover has already been selected, a challenge in identifying the correct samples to collect will certainly come from the limits of the Mars 2020 instrument suite. Though the in situ science capabilities of the Mars 2020 rover have a high potential to identify features consistent with habitable environments and life, certain instruments may be more or less appropriate for identifying sampling locations in different environments (e.g., the fluorescence of hematite in Raman imaging can overwhelm the organic carbon signal at certain wavelengths) (Emry et al., 2015). This challenge is dependent on both the environment and the biosignatures that are being identified. Therefore, analog studies in a variety of relevant analog environments will be important in the coming years.

4.1.2. Preservation. The first challenge to preservation comes from the variable water activity and water availability within the environments. There is significant variation in both of these factors across any environment, and both water activity and water availability can affect the habitability of an environment as well as the chemical/redox environment that would allow for biosignatures to be preserved. This challenge would affect all the environments under consideration, as well as all the biosignatures, but may 
be mitigated somewhat once the region is explored in situ by careful identification of the different mineralogical and morphological facies within an environment that indicate different levels of water activity.

A second challenge to preservation would be destruction of biosignatures by chemical oxidants that are prevalent throughout the martian surface environment. For example, the presence of perchlorate measured by both the Phoenix lander (Hecht et al., 2009) and the Curiosity rover (Leshin et al., 2013) indicates that this salt is prevalent throughout the martian regolith, and reactions with organic biomarkers that may be present in the surface environment can, in the presence of additional energy, degrade this signal over time. Oxidants such as these would, under certain conditions, alter or degrade organic biomarkers and would likely have an effect in any of the environments discussed here.

A key factor related to biosignature degradation is the highly ionizing radiation environment on the surface of Mars. Generally, ionizing radiation is known to destroy biomolecules, such as proteins or DNA. Most bacteria cannot survive doses $>200 \mathrm{~Gy}$, although extremely radiation-resistant microorganisms on Earth, such as Deinococcus radiodurans, can survive $\sim 17,000$ Gy by developing a high intracellular $\mathrm{Mn}: \mathrm{Fe}$ ratio that limits Fenton chemistry and thus reactive oxygen species, which would damage DNA and proteins (Daly, 2009). For comparison, the ionizing radiation dose at the martian surface is estimated at 0.54-0.85 Gy/year (Dartnell et al., 2007). Studies have indicated that within 300 million years, preservation of $>500 \mathrm{amu}$ functionalized organic molecules within the top $\sim 5 \mathrm{~cm}$ of rock drops 1000 fold due to ionizing radiation (Pavlov et al., 2012). Additionally, radiation threatens the preservation of organic biosignatures and would also have an effect on isotopic ratios of these organic molecules.

Exposure age will affect biosignature degradation depending on how long rocks are subject to radiation processes. While there are certainly some surfaces with relatively young exposure ages $(78 \pm 30$ million years calculated for a scarp in Gale Crater; Farley et al., 2014), and weathering rates on Mars are generally significantly slower than in terrestrial environments, the exposure of organic biomarkers to surface ionizing radiation via physical and chemical weathering processes will eventually degrade all biomarker signals in all environments. A corollary to this is that in all the environments and all the biosignatures under consideration, rapid burial is a key factor to biosignature preservation. It is not only the exposure age between the present and when the rocks were exposed most recently that needs to be taken into account but also the exposure age between when the biosignatures were first produced and when they were no longer in contact with the surface environment. A mitigating factor for this challenge, as well as the previous two, would be to specifically look for outcrops to sample that had been recently exhumed - the less time that any biosignature was exposed to the surface environment, the more likely that the signal would remain preserved.

\subsection{Orbital observations}

This section addresses how orbital observations of each environment type are affected by particular attributes of that environment.
4.2.1. Hydrothermal spring systems. Hydrothermal spring systems present some challenges to efforts to search for evidence of habitable environments and biosignatures on Mars. Sinter deposits on Earth have been identified from orbit and correlated with ground-based field studies (e.g., Plescia and Johnson, 2016; Skok et al., 2016). However, presently the number, extent, and diversity of documented martian hydrothermal deposits is very small, and identification of such deposits from orbital observations remains a significant challenge. Although mineral deposits that are likely hydrothermal in origin have been identified within Gusev Crater based on Spirit observations (Ruff et al., 2011), these deposits are generally too limited in areal extent to be detectable by orbital observation. This circumstance contrasts sharply with, for example, orbital observations that have documented widespread and diverse fluvio-lacustrine deposits. Accordingly, potential landing sites in many fluviolacustrine terrains offer opportunities to address multiple science and exploration objectives.

The presence of several former martian hydrothermal systems has been inferred from orbit based on the presence of fluvial features that originate in volcanic terranes. A leading example is the enormous Dao Vallis spring alcove and channel located on the flanks of the Hadriaca Patera volcano (Squyres et al., 1987). Another example is the array of stream channels that emanate from a breach in rim of the summit caldera of Apollinaris Patera (El Maarry et al., 2011). Perhaps even more compelling is the presence of hot spring mineral deposits within calderas or in features that resemble spring mounds. For example, Skok et al. (2010) have identified silica deposits in Nili Patera, within the Syrtis Major volcanic complex. In addition, hydrothermal fluids can circulate through systems of fractures that can become filled with mineral deposits that are relatively resistant to erosion. Van Kranendonk et al. (2016) described large mineralized fractures in the Pilbara craton of Western Australia. These features are readily observable from orbit but would be difficult to uniquely differentiate from fracture fills due to low-temperature fluid flow (e.g., Léveillé et al., 2014).

4.2.2. Subaqueous environments. Potential deltas have been identified on Mars in orbital imagery based on the presence of kilometer-scale fan-shaped deposits located where a fluvial drainage network terminates at the edge of a basin (open or closed; Di Achille and Hynek, 2010). However, as this general definition also applies to alluvial and other depositional fans emptying into dry basins, as opposed to lakes, additional morphological evidence is required to uniquely identify a delta. Most well-developed deltas differ from alluvial fans in that they can exhibit multiple depositional lobes, basinward migration of channel-lobe transitions, and complex systems of inverted channels indicating fluvial avulsion over the putative delta plain (e.g., Wood, 2006; Rice et al., 2013). These characteristic delta features can be identified from orbit as long as the delta itself is well-preserved-a highly eroded delta would be difficult to differentiate from an alluvial fan or other sedimentary deposits. In general, only a handful of exceptionally preserved fan deposits on Mars are considered conclusively identified deltas. Additional lines of evidence that a delta formed in a long-lived lake environment include orbital visible/near-infrared (VNIR) spectra indicating 
hydrated minerals (e.g., silica, clays, ) associated with bottomset beds in the delta or associated lake sediments (e.g., Milliken and Bish, 2010); however, dust can obscure such signatures, as is the case in the extensive deltaic deposits in Gale Crater (Grotzinger et al., 2015).

In the absence of clearly recognizable deltas, lake deposits can be difficult to identify uniquely from orbit (e.g., Grotzinger et al., 2015). Lake sediments are typically flatlying layers found inside a basin, but multiple other sedimentary processes could also produce deposits of similar morphology, including various airfall and pyroclastic processes, as well as alluvial fans. Identifying paleolake sediments based on mineral data derived from orbital spectroscopy can also prove difficult, as the minerals produced by lacustrine processes are also non-unique (phyllosilicates, silica, carbonates, sulfates, chlorides, etc.). The sedimentological character and mineralogy of the layered deposit along with the regional context can help make a case for a lacustrine origin. A case for a perennial lake has been made in Holden Crater based on the presence of light-toned flat-lying layers containing hydrated minerals and Holden's context within the larger Uzboi-Ladon-Morava outflow system (Grant et al., 2010). Similarly, globally distributed chloride deposits are interpreted to be the remnants of ancient playas, based on their occurrence in local topographic lows, close associations with phyllosilicates, and correlation with preserved fluvial networks (Glotch et al., 2010; Osterloo et al., 2010).

4.2.3. Subaerial environments. Paleosols contain high abundances of phyllosilicates that could be identified by orbital spectroscopy. However, the well-developed (i.e., highly altered and biologically productive) portions of most individual soil profiles are meter-scale in depth, which is too small to identify from orbit with current spectrometers. Thus, paleosols that could be identified from orbit would either be exceptionally thick profiles, including laterites where kaolins overlie smectite clays, or paleosol sequences, which are one type of phyllosilicate-bearing sedimentary sequence. While other processes can produce thick sedimentary clay deposits, a paleosol sequence could be identified based on the presence of regionally extensive clay-rich deposits not confined to a basin. On Mars, Noachian lateritelike weathering profiles are globally distributed and occur at several of the proposed Mars 2020 landing sites (Ehlmann et al., 2009; Ruff et al., 2014; Carter et al., 2015), and while these are probably poor sites for organic preservation, these localities could preserve chemical or isotopic biosignatures. In addition, the thick regional package of Noachian clay-rich layered sediments at Mawrth Vallis is consistent with a paleosol sequence (Noe Dobrea et al., 2010, 2011). The Mawrth Vallis sequence also contains both ferrous and ferric alteration minerals along with sulfates and silica (Bishop et al., 2008, 2013; Farrand et al., 2009, 2014), potentially indicating iron and sulfur redox gradients and mineral precipitation in subsurface aquifers, surface wetlands, and surface springs (Horgan et al., 2015).

Cold spring environments could be identified via orbital VNIR spectroscopy by looking for carbonates, clays, and iron oxides in close proximity; however, these environments tend to be localized and therefore difficult to identify with the resolutions currently available.
4.2.4. Subsurface environments. Evidence for exposure of subsurface materials at the surface includes morphological evidence for deep erosional processes or uplift, and mineralogical indicators of subsurface alteration (Ehlmann et al., 2013). However, it remains difficult to uniquely differentiate units altered in the subsurface from surface units buried after surface alteration with orbital data alone.

Ancient subsurface environments may be exposed by erosion or uplift, and identification of geologic features that are indicative of these processes would target these environments. Impacts may also expose subsurface materials in crater walls or deposit subsurface materials into the ejecta blanket where they could be examined by landers. Lastly, orbital images reveal evidence of several thousand caves on Mars, indicating both the presence of these environments and an ease of identification (Boston and Alexander, 2016).

Hydrated minerals and sulfates in exposed subsurface materials would be indicative of the presence of aqueous fluids, but as discussed above, conclusively identifying minerals emplaced in the subsurface is challenging. Some minerals might also indicate temperatures or other conditions of fluid-rock interactions. In addition, since subsurface communities will likely rely on chemical forms of energy that depend on oxidation/reduction (redox) reactions, identification of redox gradients in exposed subsurface environments will provide additional evidence of habitability. These gradients are potentially observable in the mineralogy of deposits, for example by variations in oxidation state of Fe-bearing minerals (ferric/ferrous minerals) or S-bearing minerals (sulfides/sulfates), although sulfides are not detectable with orbital spectroscopy.

4.2.5. Iron-rich environments. Iron-rich environments can be identified on Mars with CRISM VNIR spectral data (e.g., hematite and goethite; Christensen et al., 2000, 2001; Fallacaro and Calvin 2006; Milliken et al., 2010; Fraeman et al., 2013). It is difficult or impossible to spectrally identify sulfides (as in massive sulfide deposits or within hydrothermal vents), although the presence of an iron and/or sulfur oxidation state gradient may indicate these environments and such a gradient has been proposed to exist at both Gale Crater and Mawrth Vallis on Mars (Horgan et al., 2015). Massive exposures of coarsely crystalline gray hematite, such as those identified with the Thermal Emission Spectrometer on board the Mars Global Surveyor (Christensen et al., 2000, 2001), may indicate large IFs (Fallacaro and Calvin 2006). Other alteration minerals common to iron-rich environments like Fe sulfates (Alpers et al., 1989) could also be identified with CRISM where they are abundant or are laterally extensive (e.g., Milliken et al., 2008; Farrand et al., 2009, 2014; Wray et al., 2011).

\subsection{Observations and sample selection on the ground}

This section addresses how ground observations and sample selection at each environment type are affected by particular attributes of that environment. Much of the following content was addressed during meeting discussions.

4.3.1. Hydrothermal spring systems. 4.3.1.1. Observations. The former presence of hydrothermal activity can be indicated by the alteration zones along former fractures, 
minerals that frequently accompany hydrothermal activity, and geomorphic features related to spring mounds and other related sedimentary deposits (e.g., Ruff et al., 2011). Some examples of hydrothermal minerals (among many) include opaline silica, carbonates, phyllosilicates, and sulfides.

4.3.1.2. Sample selection. Ideally an important suite of samples from a hydrothermal system would be collected along the former thermal gradient from the high-temperature source to the distal deposit emplaced under surface ambient conditions. Geochemical and mineralogical analyses of such a sample suite could reconstruct the conditions during the system's active phase. Any biosignatures in this sample suite could potentially indicate the diversity of life-forms that had adapted to the range of conditions along this environmental gradient. In a subsurface hydrothermal system, samples of fracture fills of varying mineralogy, as well as samples of unaltered and altered parent rock, would also be important.

4.3.2. Subaqueous systems. 4.3.2.1. Observations. On the ground, deltaic deposits are best identified by lithology, texture, and bed geometry. The distinct patterns of distributary channels and discharge lobes can be distinguished from alluvial fans, as was found at Gale Crater (Mangold and Ansan, 2004; Wood, 2006). In the field the coarseningupward sequences of the prodelta can be observedpossibly even from orbit (Pondrelli et al., 2008; Schon et al., 2012). Well-preserved deltas will include the continuous vertical transition from a full subaqueous facies to subaerial features such as soil development or dune deposition, although erosion of any of these features can occur after deposition. These features, as well as outflow channels and prodelta deposits, can be seen from orbit. However, the underlying lacustrine deposit is most promising for preserving biosignatures, yet it is difficult to identify from orbit.

One challenge of deltaic deposits, even on the ground, is accurately constraining their age and duration. In some cases, the age of the deltaic deposits can be determined from orbit by relating the stratigraphy to the cratering record, but the small exposure area of deltas makes this comparison challenging (Warner et al., 2015). Timescales for sediment emplacement could potentially be estimated by applying sediment transport models. Channel width and meander wavelength can be used to calculate flow magnitudes that, when compared with expectations of precipitation, can indicate time of deposition, although the range is often quite large. For example, some estimates indicate that deltaic deposits at Holden Crater would have taken between thousands and millions of years to accumulate (Moore et al., 2003). Physical models such as these are imperfect for application to Mars given that the effects of reduced gravity on sedimentary processes are not well understood. Exposure ages are also important for estimating the radiation damage that deltaic sediment may have experienced. Such ages can be estimated from orbit based on crater densities and evidence for recent erosion; however, a better estimate would use the exposure age of rocks based on cosmogenic nuclides, a measurement that must be made in situ (Farley et al., 2013) or with returned samples.

A rover could identify horizontal planar stratification with interbedding of fine-grained siliciclastics and salts, includ- ing carbonates and/or sulfates. Thick sulfate deposits that grade laterally into shoreline sands (identified by ripple marks and basinward dipping strata), fluvial channels (from episodic flooding into a desiccated lake) are also identifying characteristics. Other sedimentary structures that could be present are mudcracks and paleosols. The best samples for detection of biosignatures in this environment would be wavy, laminated morphologies indicative of biofilm fabrics, evaporites that could host fluid inclusions or even endoliths, and other microbial morphologies such as desiccated flexible microbial mats that have become curled.

The SHERLOC and SuperCam instruments on Mars 2020 might detect organic biosignatures preserved in deltaic systems. The Mars Science Laboratory mission has characterized the sedimentology of fluvial-lacustrine systems in detail at the rover scale. The lack of a quantitative mineralogy instrument on Mars 2020 will prevent any detailed analysis like that of Mars Science Laboratory, but the SuperCam VNIR spectrometer should be able to remotely identify clay minerals like smectites that are critically important for organic preservation in these environments. The fluorescence spectrometers on SHERLOC can detect condensed carbon and aromatic organics by deep UV-induced fluorescence, and SHERLOC's Raman spectrometer will allow classification of aromatic and aliphatic organics. Raman spectrometry can also be used to detect minerals relevant to aqueous chemistry. While these measurements would allow us to identify reduced carbon compounds, there may not be sufficient structural information to distinguish between a biological signal and extraterrestrial organic input.

4.3.2.2. Sample selection. While the Mars 2020 instrument suite may be limited in its ability to confirm the biological origin of subaqueous organic matter, there are other targets of astrobiological interest from these environments. Morphological targets that are common to these environments and are well preserved regardless of exposure age can include biofilm fabrics, evaporites, and microbial morphologies.

4.3.3. Subaerial environments. 4.3.3.1. Observations. At outcrop scales, paleosols can be identified by the presence of mineral, textural, or color horizons, pedogenic morphologies (centimeter-scale granular, platy, or prismatic structures), chemical profiles indicating top-down leaching, and the association of these features with paleosurfaces or unconformities (Retallack et al., 1999; Sheldon and Tabor, 2009). Further characterization of paleosols can be accomplished through measurements of isotopes and elemental chemistry to determine paleoclimate during formation, as well as chemical and mineralogical analyses to determine the redox state and chemistry of leaching fluids. Reducing soils and wetlands that are good targets for enhanced biosignature preservation would be indicated by concentrations of ferrous iron in clays, sulfides, or amorphous phases. The instrument suite on Mars 2020 would be well suited to identify and investigate paleosols on Mars: the imaging systems could be used to identify paleosurfaces and surface aqueous features, and pedogenic textures; Mastcam-Z multispectral imaging could be used to identify the distribution of ferric and ferrous minerals and thus redox gradients; SuperCam could measure elemental profiles; SHERLOC 
and SuperCam Raman and SWIR spectrometers could be used to identify clay and sulfate minerals; and SHERLOC could be used to search for organics at or near paleosurfaces.

Glacial environments are most easily identified when glacial morphologies are exposed at the surface; however, this requires long-term exposure that would adversely affect preservation. How glacial deposits like subglacial alteration rinds, glacial flour, and so on would manifest or be identified in the geologic record is unclear; thus, the biosignature preservation potential of glacial sediments or environments is not well understood. However, glacial sediments could also be preserved in downstream lakes or alluvial fans.

Cold spring deposits could be characterized from a rover with relative ease due to the abundant macroscopic textural and mineralogical diagnostic characteristics, including terraces and terracettes (centimeter-scale terraces), wavy laminae, and alternating, layered mineralogies [e.g., calcium carbonate and iron (oxyhydr)oxides] and a variety of facies such as vent, pond, channel, and proximal and distal facies (described in Fouke et al., 2000).

4.3.3.2. Sample selection. The main samples of interest from many of these subaerial environments would be mineral deposits precipitated in surface or subsurface redox gradients produced by groundwater fluctuation at the surface, water flow along subsurface barriers, or at springs-in particular, sulfates, and iron oxides. Ideally, redox gradients should be sampled. Depending on the mineralogy, these samples could contain organics, mineralogical, chemical, and isotopic biosignatures. In addition, other mineral deposits produced at springs, such as carbonates and silica, would be key astrobiological samples, as they could contain organics, microfossils, textural biosignatures, mineralogical, chemical, and isotopic biosignatures. Samples of sediments accumulated at paleosurfaces, as indicated by unconformities and tops of chemical profiles, would also be desirable, as these are the most likely place to find biosignatures produced by microbial mats and could contain organics, chemical, mineralogical, or isotopic biosignatures. Within this category, reduced clay-rich soils -ideally wetlands-type saturated soils — would be of the highest priority. Finally, samples representative of chemical profiles with depth in soils would also be useful to better understand the climate, environment, and chemistry of the subaerial habitat, as well as to search for chemical/isotopic biosignatures. In particular, sampling parent material at depth in the soil profile would be key for establishing a baseline for mineralogical/chemical/isotopic biosignatures.

4.3.4. Subsurface environments. 4.3.4.1. Observations. Far-range cameras such as Mastcam-Z will be able to identify areas that are promising to investigate, such as where subsurface material has been exposed in crater walls or the ejecta blanket and can be further examined. Such cameras would also identify the mouths of caves, although those would be challenging to access and explore for a Curiosity-style rover.

Remote compositional instruments such as Mastcam-Z, ChemCam, and SuperCam would also be able to help identify signatures of deep habitable environments such as minerals potentially indicative of redox disequilibrium (e.g., Fe-containing minerals) or subsurface alteration. These instruments would also be able to identify evidence of the type of focused fluid flow that might provide a more heavily inhabited environment, such as a fracture or vein. They might also be able to detect evidence of discharge of groundwater that might provide biosignatures from the subsurface. Laser-based instruments (LIDAR, LIBS, LIF, Raman spectroscopy), in particular, would be effective in subsurface cave environments without the need for constant illumination. Contact chemical and mineralogy measurements would be able to indicate potentially habitable conditions such as mineralogy indicative of subsurface fluid-rock alteration, potential biosignatures such as evidence of redox disequilibrium, and elemental chemistry that indicate chemical changes such as leaching consistent with interaction with biota and biotic organic compounds (e.g., Hausrath et al., 2008, 2009, 2011; Liermann et al., 2007; Baumeister et al., 2015). Measurements of organic compounds such as by the SAM instrument or Raman measurements would be able to provide direct evidence of potential organic biosignatures such as lipids, amino acids, DNA, and so on.

4.3.4.2. Sample selection. The top samples to collect from subsurface environments would include samples likely to capture potentially habitable environments, such as aqueously altered samples from caves, impacts, megabreccias, exhumed materials, deep aquifers, and chemical and redox gradients.

4.3.5. Iron-rich environments. 4.3.5.1. Observations. Subsurface iron-rich habitats can be recognized by identifying massive red-orange iron oxides or extensive iron-oxide cementation within permeable rock (e.g., sandstone). These environments may contain macroscale iron concretions within the outcrop or weathered out and resting on the surface of the ground. Zoning may be visible on the outcrop face, indicative of diffusion and alteration within the outcrop. Subaqueous IF-like deposits would appear as thickly to thinly laminated bands of iron and silica, or a granular texture with no apparent banding, with interbedded carbonates and shales. These deposits can be thick and laterally extensive. Subaqueous hydrothermal vent deposits may be visible as "thin skins" of iron (oxyhdr)oxides on top of reduced iron-bearing country rock. However, this cap of Fe(III) may readily weather away. Subaerial iron seeps and springs would be recognizable as mounds of flocculent, ochreous iron oxyhydroxides (e.g., ferrihydrite), or denser iron oxides (e.g., hematite or goethite) on top of compositionally different host rock (likely igneous rocks underlying hydrothermal springs). Lastly, gossans or massive sulfide deposits would be visible as extensive red outcrops of iron oxides and may exhibit a spotty presence of residual pyrite/ sulfide minerals or efflorescent iron sulfate salts.

Instrument packages for a rover would be well-suited to analyze iron-rich environments. In terms of imaging, a reconnaissance (long distance) camera would see the characteristic red color of iron oxides in all of these iron-rich environments, even on the generally red surface of Mars. The iron oxides may appear more massive, laminated, or concentrated at the formation than in surrounding substrate. Topographically, these deposits may form capping or resistant units that retain higher elevations than the surrounding landscape. A high-resolution ("hand lens") camera may see carbonates, sulfides, phyllosilicate layers, efflorescent sulfate salts, and 
thinly laminated iron oxides and silica and/or a variety of iron oxide textures and biofabrics (as described above).

In terms of composition, a long-distance mineralogy instrument may detect iron oxides, oxyhydroxides, and oxyhydroxysulfates (hematite, goethite, jarosite), iron sulfides (pyrite), sulfates (gypsum and a variety of ferric and ferrous sulfate salts), carbonates, and possibly quartz. In addition to the major phases described above, a high-resolution mineralogy instrument may detect minor phases: iron oxides, oxyhydroxides, and oxyhydroxysulfates (magnetite, ferrihydrite, schwertmannite), iron sulfides (pyrrhotite, chalcopyrite, sphalerite, etc.), carbonates (siderite, ankerite, etc), sericite, illite, other phyllosilicates, barite, and amorphous silica, among other minor phases. It would be critical to map these phases in relation to textures and fabrics possibly detectable with the "hand lens" camera. An instrument capable of measuring elemental abundances would see $\mathrm{Fe}, \mathrm{S}$, and $\mathrm{Si}$. Lower-abundance elements would include metals such as $\mathrm{Cu}, \mathrm{Zn}, \mathrm{Ag}$, and $\mathrm{Au}$, cations associated with phyllosilicates (e.g., $\mathrm{Al}, \mathrm{K}, \mathrm{Mg}$ ), and elements from carbonates such as $\mathrm{Ca}$ and $\mathrm{Mg}$. Lastly, an organic molecule detection instrument may detect aromatic and short- and long-chain aliphatic molecules if they are (1) relatively young or (2) preferentially preserved in subenvironments within the iron oxides.

These general rover strategies translate well to the Mars 2020 rover payload. Both Mastcam-Z and SuperCam can determine mineralogical composition, while SuperCam can also determine elemental composition, and PIXL can map fine-scale elemental compositions. SHERLOC can characterize aliphatics and aromatics in association with millimeter- to centimeter-scale structures/biofabrics, and the associated instrument WATSON can image macroscale biogenic textures. Potential limitations include the ability of SHERLOC to resolve organics on mixed mineralogy iron or silica matrices (Emry et al., 2015), and the potential transformation of metastable iron phases by higher power lasers (Hanesch, 2009).

4.3.5.2. Sample selection. To best capture the diversity within an iron-rich environment that may contain preserved biosignatures, we propose sampling the following zones for potential sample return: (1) perform a survey and sample along any redox gradient (e.g., within an aquifer, along a gradient of oxidative products), (2) after identifying a putative cycle of deposition, sample both the base and top of the cycle, and (3) sample diversity of mineralogical types and macroscale textures along the lateral extent of the outcrop exposure.

\subsection{Strategies and priorities}

How could/should this knowledge influence our strategies and priorities for the astrobiological exploration of Mars?

(1) In many of the environments discussed, there is a dichotomy between habitability and preservationmany of the conditions that make an environment more habitable are destructive to one or more of the biosignatures of interest. For example, fluid flow in the subsurface of hydrothermal environments helps create the redox gradients that support communities that inhabit the outflow channel. Fluids are also es- sential for lithification and the associated decrease in permeability essential for long-term preservation. Preservation is enhanced by rapid burial and mineral precipitation that encases and lithifies biological materials in less permeable matrices-in these cases, silica from hydrothermal environments, or silicaenriched aqueous environments, is an important material for preservation. However, these same fluids can degrade biosignatures such as mineralogy, chemistry, and micro- and macrostructures. One strategy for astrobiological exploration has to be to seek out a "sweet spot" where these two balance each other so that long-term preservation is possible. This sweet spot may occur as conditions change through time.

(2) Studies of temporally appropriate terrestrial analogs of early Mars merit additional study. Specifically, the Archean eon on Earth is probably the best environmental analog for early Mars. In particular, Fe(II)rich environments are good analogs for an anoxic, ferruginous early Mars (e.g., Westall et al., 2015b). Therefore, the limited rock record from this time period merits further investigation. Examples of such include investigations of biosignatures from chemotrophic (i.e., pre-photosynthetic) life in diverse surface environments, identification of previously unknown deposits (e.g., acquisition of new drill core samples), and investigation of recent analogs to understand how microbial communities may have inhabited and interacted with their local environments. One major caveat is that preservation from early Earth environments might have differed in important ways from preservation in similar early Mars environments, even during times such as the preNoachian/Noachian periods when there was more water around and a hotter planet, more similar to early Earth.

(3) The astrobiological exploration of Mars must be coordinated across a broad range of spatial and temporal scales. Different regions typically embody diverse features that may vary widely in the type, abundance, and quality of evidence that might have been preserved. Rovers can ascertain the paleoenvironmental contexts of deposits at spatial scales ranging from that of a geologic field site down to the microscopic. In situ studies also can determine the major processes that degrade or preserve complex organic compounds and other types of potential biosignatures.

(4) A site that includes a variety of geologic records indicative of habitable environments would be most desirable. For example, if a hydrothermal system was adjacent to or within a fluvial-lacustrine environment, then a single mission might exploit the favorable attributes of both types of habitable environments. Consequently, one site would offer a greater diversity of preserved biosignatures and potentially habitable conditions.

(5) Although organic biosignatures received considerable attention at the workshop, a consensus emerged that landed missions should also seek a diverse suite of potential biosignatures. Macrostructures would be easier 
to identify with the cameras on the rover and could be a good sign to focus sampling efforts on a particular area. Patterns of isotopic abundance can indicate interactions between various local processes, and bulk isotopic signatures can exhibit better preservation potential than organic molecules over long timescales.

(6) Missions should also seek environments on Mars where life conceivably might have originated or where chemical reactions that could have spanned the prebioticbiotic transition could have been present. Conceivably life never arose on Mars, perhaps because the environment deteriorated over time. Accordingly, ancient martian habitable environments might provide insights into the nature of conditions and processes that occurred prior to the origins of life on other rocky planets.

(7) Discussions about the current state of the science for each of the environments under consideration, and how well we can apply our current understanding of terrestrial analogs to Mars, showed that investigations of certain environments (e.g., subaqueous settings, hydrothermal spring systems) are further advanced than others (e.g., subsurface) and illustrated how this has a significant effect in shaping our current strategies. A secondary factor is the state of the science of remote identification of these environments. The scale and surface expression are very different between these different types of environments and lead to preferential selection of those that can be more easily identified. However, more research into advancing our understanding of all of the environments, as well as the best ways to identify them remotely, would allow the environments with the best potential past habitability and biosignature preservation to be prioritized.

\section{Urgent Needs and Future Research}

While there are many avenues of research that would aid our orbital and ground identification of environments that can preserve past biosignatures, the assembled community tended to agree that the most urgent need is a better understanding of the capabilities of specific instrumentation on the Mars 2020 rover to identify biomarkers in different environments. Specifically, we need a better understanding of how well these instruments can separate the biotic signal from the abiotic background noise. Since the instrumentation on the Mars 2020 rover has already been selected, it is crucial to understand if those instruments are capable of making detections that would facilitate sample selection in one environment over another. These findings could be significant in framing astrobiological goals during the site selection process.

Two aspects of future mission development that would help astrobiological exploration were consistently highlighted in discussions:

(1) Improved spatial and spectral resolution of spectrometers and imagers on orbiters to enable remote identification of stratigraphic, geomorphic, and mineralogical relationships in order to support remote assessment of environments of interest, and,

(2) Improved instrumentation on rovers that might detect and identify a diversity of potential in situ biosignatures, including ancient organic molecular biosignatures, designed with the ability to differentiate biotic and abiotic signals in micro- or macrostructures. Instrumentation could also be better attuned to the unique complications of biosignature preservation on Mars (e.g., deeper drilling to access potentially better preserved organics).

Although neither of these are trivial, the current limitations in instrumentation add an additional layer of complexity onto the process of identifying which environments would be best for potential biosignature preservation and detection. Ultimately, our ability to successfully identify biosignatures on Mars strongly depends on our ability to leverage our knowledge from terrestrial analogs to identify a landing and sampling site with high biosignature preservation potential. Without these advances in instrumentation, we may not have the data necessary to better identify these critical sites.

The conference discussions also clearly indicated that the distinctions between "subsurface" and "near-surface" environments should be better defined. Research is required to characterize more effectively any exhumed geologic deposits from past subsurface environments regarding their habitability and their potential to preserve biosignatures. The conference abstracts and discussions indicated that subsurface environments currently are not as well characterized as near-surface environments, though this community was not as well represented as others in the assembled participants. But conceivably, martian subsurface environments could have sustained habitable environments and life continuously for billions of years. Further research could indeed strengthen the case for the astrobiological exploration of these environments relative to the others under consideration.

Significant research is needed to improve our ability to apply our current understanding of terrestrial life to the astrobiological exploration of martian environments. A major knowledge gap that will directly impact our ability to choose an appropriate landing site is what terrestrial analog environments might look like-what the biosignature signals might be-if photosynthetic microorganisms had not evolved and instead the environments were only inhabited by chemosynthetic microorganisms (as in Westall et al., 2016, and 2013). On Earth, significant amounts of biomass in many of these environments are attributable to photosynthetic microorganisms, and some micro- and macroscale structures (e.g., stromatolites) may be the result of phototaxis, or the presence of nutrient or oxygen gradients created during oxygenic photosynthesis (Bosak et al., 2010; Mata et al., 2012). Ancient martian environments may not have remained habitable long enough for photosynthesis to evolve, and a worthy avenue of research would explore how biosignature signals would be expressed and preserved in this different energy regime. In fact, subsurface environments may serve as model ecosystems where phototrophic activity is not directly active and may help to better assess chemotrophic-centric biosignatures.

Additional investigations would include how martian environments may be chemically or physically different from Earth environments and may preserve or destroy biosignatures at different rates or in different proportions than expected from terrestrial analogs.

Finally, strategies to search for past life on Mars are also relevant to the search for extant life. Even though any 
currently habitable martian environments might be extremely difficult to access directly by spacecraft, the search for evidence of extant martian life still merits attention. For example, a campaign to identify potential biosignatures at sites that were habitable in geologically recent times could demonstrate that life persists in multiple locales on Mars.

\section{Acknowledgments}

The authors would like to acknowledge the meeting Conveners, Dave Beaty, Mary Voytek, and Michael Meyer, as well as additional members of the Scientific Organizing Committee, Abigail Allwood, Nathalie Cabrol, Wendy Calvin, Jack Farmer, Richard Leveille, and Anna-Louise Reysenbach for putting together the conference and for review of the manuscript. Additionally, all attendees at the workshop (complete abstract author list available at http://www.hou.usra.edu/meetings/ biosignature2016/authorindex.cfm) provided significant material and discussion that have formed the basis of this work.

\section{Author Disclosure Statement}

No competing financial interests exist.

\section{References}

Albers, J.P. and Bain, J.H.C. (1985) Regional setting and new information on some critical geologic features of the West Shasta district, California, USA. Econ Geol 80:2072-2091.

Allen, C.C., Westall, F., and Schelble, R.T. (2001) Importance of a martian hematite site for astrobiology. Astrobiology $1: 111-123$.

Allwood, A.C., Walter, M.R., Kamber, B.S., Marshall, C.P., and Burch I.W. (2006) Stromatolite reef from the Early Archaean era of Australia. Nature 441:714-718.

Alpers, C.N., Nordstrom, D.K., and Ball, J.W. (1989) Solubility of jarosite solid solutions precipitated from acid mine waters, Iron Mountain, California, USA. Bulletin de la Société Géologique de France 42:281-298.

Alt, J.C. (1988) Hydrothermal oxide and nontronite deposits on seamounts in the eastern Pacific. Mar Geol 81:227-239.

Alt, J.C. and Shanks, W.C. (1998) Sulfur in serpentinized oceanic peridotites: serpentinization processes and microbial sulfate reduction. J Geophys Res 1103:9917-9929.

Amaral Zettler, L.A., Gómez, F., Zettler, E., Keenan, B.G., Amils, R., and Sogin M.L. (2002) Microbiology: eukaryotic diversity in Spain's River of Fire. Nature 417:137.

Amend, J.P., McCollom, T.M., Hentscher, M., and Bach, W. (2011) Catabolic and anabolic energy for chemolithoautotrophs in deep-sea hydrothermal systems hosted in different rock types. Geochim Cosmochim Acta 75:5736-5748.

Ames, D.E., Watkinson, D.H., and Parrish, R.R. (1998) Dating of a regional hydrothermal system induced by the $1850 \mathrm{Ma}$ Sudbury impact event. Geology 26:447-450.

Amundson, R., Ewing S., Dietrich W., Sutter B., Owen J., Chadwick O., Nishiizumi, K., Walvoord, M., and McKay, C. (2008) On the in situ aqueous alteration of soils on Mars. Geochim Cosmochim Acta 72:3845-3864.

Anderson, S.P. (2007) Biogeochemistry of glacial landscape systems. Annu Rev Earth Planet Sci 35:375-399.

Andrews-Hanna, J.C., Phillips, R.J., and Zuber, M.T. (2007) Meridiani Planum and the global hydrology of Mars. Nature 446:163-166.

Arevalo, R., Jr., McDonough, W.F., and Luong, M. (2009) The $\mathrm{K} / \mathrm{U}$ ratio of the silicate Earth: insights into mantle compo- sition, structure and thermal evolution. Earth Planet Sci Lett 278:361-369.

Azúa-Bustos, A., González-Silva, C., Mancilla, R.A., Salas, L., Palma, R.E., Wynne, J.J., McKay, C.P., and Vicuña, R. (2009) Ancient photosynthetic eukaryote biofilms in an Atacama Desert coastal cave. Microb Ecol 58:485-496.

Azúa-Bustos, A., Urrejola, C., and Vicuña, R. (2012) Life at the dry edge: microorganisms of the Atacama Desert. FEBS Lett 586:2939-2945.

Bach, W. and Edwards, K.J. (2003) Iron and sulfide oxidation within the basaltic ocean crust: implications for chemolithoautotrophic microbial biomass production. Geochim Cosmochim Acta 67:3871-3887.

Baker, B.J. and Banfield, J.F. (2003) Microbial communities in acid mine drainage. FEMS Microbiol Ecol 44:139-152.

Bakermans, C. and Skidmore, M.L. (2011) Microbial metabolism in ice and brine at $-5^{\circ} \mathrm{C}$. Environ Microbiol 13:2269-2278.

Barghoorn, E.S. and Tyler, S.A. (1965) Microorganisms from the Gunflint Chert. Science 147:563-575.

Baross, J.A. (1998) Hydrothermal vents-thermophiles and hyperthermophiles. McGraw-Hill Yearbook of Science and Technology, McGraw-Hill, New York, pp 180-183.

Baumeister, J.L., Hausrath, E.M., Olsen, A.A., Tschauner, O., Adcock, C.T., and Metcalf, R.V. (2015) Biogeochemical weathering of serpentinites: an examination of incipient dissolution affecting serpentine soil formation. Appl Geochem 54:74-84.

Beam, J.P., Jay, Z.J., Schmid, M.C., Rusch, D.B., Romine, M.F., Jennings, Rde.M., Kozubal, M.A., Tringe, S.G., Wagner, J., and Inskeep, W.P. (2015) Ecophysiology of an uncultivated lineage of Aigarchaeota from an oxic hot spring filamentour 'streamer' community. ISME J 10:210-224.

Benison, K.C., Jagniecki, E.A., Edwards, T.B., Mormile, M.R., and Storrie-Lombardi, M.C. (2008) "Hairy blobs": microbial suspects preserved in modern and ancient extremely acid lake evaporites. Astrobiology 8:807-821.

Benning, L.G., Phoenix, V.R., Yee, N., and Tobin, M.J. (2004) Molecular characterization of cyanobacterial silicification using synchrotron infrared micro-spectroscopy. Geochim Cosmochim Acta 68:729-741.

Berner, R.A. (1989) Biogeochemical cycles of carbon and sulfur and their effect on atmospheric oxygen over Phanerozoic time. Palaeogeogr Palaeoclimatol Palaeoecol 75:97-122.

Beukes, N.J., and Klein, C. (1992) Models for iron-formation deposition. In The Proterozoic Biosphere: A Multidisciplinary Study, edited by J.W. Schopf and C. Klein, Cambridge University Press, Cambridge, UK, pp 147-156.

Bishop, J.L., Dobrea, E.Z.N., Mckeown, N.K., Parente, M., Ehlmann, B.L., Michalski, J.R., Milliken, R.E., Poulet, F., Swayze, G.A., Mustard, J.F., Murchie, S.L., and Bibring, J.-P. (2008) Phyllosilicate diversity and past aqueous activity revealed at Mawrth Vallis, Mars. Science 321:830-833.

Bishop, J.L., Loizeau, D., Mckeown, N.K., Saper, L., Dyar, M.D., Des Marais, D.J., Parente, M., and Murchie, S.L. (2013) What the ancient phyllosilicates at Mawrth Vallis can tell us about possible habitability on early Mars. Planet Space Sci 86:130-149.

Bonaccorsi, R. and Stoker, C.R. (2008) Science results from a Mars drilling simulation (Río Tinto, Spain) and ground truth for remote science observations. Astrobiology 8:967-985.

Bosak, T., Bush, J.W., Flynn, M.R., Liang, B., Ono, S., Petroff, A.P., and Sim, M.S. (2010) Formation and stability of oxygen-rich bubbles that shape photosynthetic mats. Geobiology 8:45-55.

Bose, S. and Chafetz, H.S. (2012) Morphology and distribution of MISS: a comparison between modern siliciclastic and carbon at settings. In Microbial Mats in Siliciclastic 
Depositional System through Time, edited by N. Noffke and H. Chafetz, SEPM Special Publication Vol. 101, SEPM Society for Sedimentary Geology, Tulsa, OK, pp 3-15.

Boston, P.J. and Alexander, E.C., Jr. (2016) Preservation of microbial-mineral biosignatures in caves and paleo springs [abstract 2074]. In Biosignature Preservation and Detection in Mars Analog Environments I: Paleo-Hydrothermal Systems, Lunar and Planetary Institute, Houston.

Boston, P.J., Ivanov, M.V., and McKay, C.P. (1992) On the possibility of chemosynthetic ecosystems in subsurface habitats on Mars. Icarus 95:300-308.

Boston, P.J., Spilde, M.N., Northup, D.E., Melim, L.A., Soroka, D.S., Kleina, L.G., Lavoie, K.H., Hose, L.D., Mallory, L.M., Dahm, C.N., Crossey, L.J., and Schelble, R.T. (2001) Cave biosignature suites: microbes, minerals, and Mars. Astrobiology 1:25-55.

Braterman, P.S., Cairns-Smith, A.G., and Sloper, R.W. (1983) Photo-oxidation of hydrated $\mathrm{Fe}^{2+}$-significance for banded iron formations. Nature 303:163-164.

Brock, T.D (1978) Thermophilic Microorganisms and Life at High Temperatures, Springer, New York.

Buick, R. (1990) Microfossil recognition in Archean rocks: an appraisal of spheroids and filaments from a 3500 m.y. old chertbarite unit at North Pole, Western Australia. Palaios 5:441-459.

Burr, D.M., Grier J.A., McEwan, A.S., and Keszthelyi, L.P. (2002) Repeated aqueous flooding from the Cerberus Fossae: evidence for very recently extant, deep groundwater on Mars. Icarus 159:53-73.

Burr, D.M., Enga, M.-T., Williams, R.M.E., Zimbleman, J.R., Howard, A.D., and Brennand, T.A. (2009) Pervasive aqueous paleoflow features in the Aeolis/Zephyria Plana region, Mars. Icarus 200:52-76.

Cady, S.L. and Farmer, J.D. (1996) Fossilization processes in siliceous thermal springs: trends in preservation along thermal gradients. In Evolution of Hydrothermal Ecosystems on Earth (and Mars?), Ciba Foundation Symposium 202, edited by G. Bock and J. Goode, John Wiley, New York, pp 150-173.

Cady, S.L., Farmer, J.D., Grotzinger, J.P., Schopf, J.W., and Steele, A. (2003) Morphological biosignatures and the search for life on Mars. Astrobiology 3:351-368.

Cairns-Smith, A.G. (1978) Precambrian solution photochemistry, inverse segregation, and banded iron formations. Nature 276:807-808.

Callender, E. and Hammond, D.E. (1982) Nutrient exchange across the sediment-water interface in the Potomac River estuary. Estuar Coast Shelf Sci 15:395-413.

Campbell, K.A., Lynne, B.Y., Handley, K.M., Jordan, S., Farmer, J.D., Guido, D.M., Foucher, F., Turner, S., and Perry, R.S. (2015) Tracing biosignature preservation of geothermally silicified microbial textures into the geological record. Astrobiology 15:858-882.

Campbell, K.A., Guido, D.M., Farmer, J.D., Van Kranendonk, M.W., Ruff, S.W., and Westall, F. (2016) Tracing hot-spring facies and their geothermally silicified microbial textures into the terrestrial geologic record: relevance for Mars biosignature recognition [abstract 2023]. In Biosignature Preservation and Detection in Mars Analog Environments I: Paleo-Hydrothermal Systems, Lunar and Planetary Institute, Houston.

Carter, J., Loizeau, D., Mangold, N., Poulet, F., and Bibring, J.-P. (2015) Widespread surface weathering on early Mars: a case for a warmer and wetter climate. Icarus 248:373-382.

Castelltort, S. and Van Den Driessche, J. (2003) How plausible are high-frequency sediment supply-driven cycles in the stratigraphic record? Sedimentary Geology 157:3-13.
Castenholz, R.W. (1988) Culturing methods for cyanobacteria. Methods Enzymol 167:68-93.

Castenholz, R.W. and McDermott, T.R. (2010) The Cyanidiales: ecology, biodiversity, and biogeography. In Red Algae in the Genomic Age, edited by J. Seckbach and D.J. Chapman, Springer Science and Business Media, Dordrecht, The Netherlands, pp 357-371.

Castenholz, R.W. and Pierson, B.K. (1995) Ecology of thermophilic anoxygenic phototrophs. In Anoxygenic Photosynthetic Bacteria, edited by R.E. Blankenship, M.T. Madigan, and C.E. Bauer, Kluwer Academic Publishers, Dordrecht, The Netherlands, pp 87-103.

Cawood, P.A., Kröner, A., and Pisarevsky, S. (2006) Precambrian plate tectonics: criteria and evidence. GSA Today 16:4-11.

Chan, M.A, Beitler, B., Parry, W.T., Ormö, J., and Komatsu, G. (2004) A possible terrestrial analogue for haematite concretions on Mars. Nature 429:731-734.

Chan, M.A., Ormö, J., Park, A.J., Stich, M., Souza-Egipsy, V., and Komatsu, G. (2007) Models of iron oxide concretion formation: field, numerical, and laboratory comparisons. Geofluids 7:356-368.

Chan, C.S., Fakra, S.C., Emerson, D., Fleming, E.J., and Edwards, K.J. (2011) Lithotrophic iron-oxidizing bacteria produce organic stalks to control iron mineral growth: implications for biosignature formation. ISME J 5:717-727.

Christensen, P.R., Bandfield, J.L., Clark, R.N., Edgett, K.S., Hamilton, V.E., Hoefen, T., Kieffer, H.H., Kuzmin, R.O., Lane, M.D., Malin, M.C., Morris, R.V., Pearl, J.C., Pearson, R., Roush, T.L., Ruff, S.W., and Smith, M.D. (2000) Detection of crystalline hematite mineralization on Mars by the Thermal Emission Spectrometer: evidence for near-surface water. J Geophys Res 105:9623-9642.

Christensen, P.R., Morris, R.V., Lane, M.D., Bandfield, J.L., and Malin, M.C. (2001) Global mapping of martian hematite mineral deposits: remnants of water-driven processes on early Mars. J Geophys Res 106:23873-23885.

Christiansen, R.L. (2001) The Quaternary and Pliocene Yellowstone Plateau Volcanic Field of Wyoming, Idaho, and Montana, U.S. Geological Survey Professional Paper 729-G, U.S. Geological Survey, Reston, VA.

Clifford, S.M., Lasue, J., Heggy, E., Boisson, J., McGovern, P., and Max, M.D. (2010) Depth of the martian cryosphere: revised estimates and implications for the existence and detection of subpermafrost groundwater. J Geophys Res 115, doi:10.1029/2009JE003462.

Cockell, C.S. (1998) The biological effects of UV radiation on early Earth—a theoretical evaluation. J Theor Biol 193:719-731.

Cockell, C.S. and Knowland, J. (1999) Ultraviolet radiation screening compounds. Biol Rev Camb Philos Soc 74:311-345.

Cole, G.A. (1994) Textbook of Limnology, $4^{\text {th }}$ ed., Waveland Press, Prospect Heights, IL.

Colella, A. and Prior, D.B. (1990) Coarse-Grained Deltas, Special Publication 10, International Association of Sedimentologists, Blackwell Scientific Publications, Oxford.

Conner, A.J. and Benison, K.C. (2013) Acidophilic halophilc microorganisms in fluid inclusions in halite from Lake Magic, Western Australia. Astrobiology 13:850-860.

Cousins, C. (2011) Volcano-ice interaction: a haven for life on Mars? Astronomy \& Geophysics 52, doi:10.1111/j.14684004.2011.52136.x.

Currey, D.R. (1990) Quaternary palaeolakes in the evolution of semidesert basins, with special emphasis on Lake Bonneville and the Great Basin, U.S.A. Palaeogeogr Palaeoclimatol Palaeoecol 76:189-214. 
Daly, M.J. (2009) A new perspective on radiation resistance based on Deinococcus radiodurans. Nat Rev Microbiol 7:237-245.

Dartnell, L.R., Desorgher, L., Ward, J.M., and Coates, A.J. (2007) Modelling the surface and subsurface martian radiation environment: implications for astrobiology. Geophys Res Lett 34, doi:10.1029/2006GL027494.

Davila, A.F. and Schulze-Makuch, D. (2016) The last possible outposts for life on Mars. Astrobiology 16:159-168.

Davila, A.F., Fairén, A.G., Gago-Duport, L., Stoker, C., Amils, R., Bonaccorsi, R., Zavaleta, J., Lim, D., Schulze-Makuch, D., and McKay, C.P. (2008) Subsurface formation of oxidants on Mars and implications for the preservation of organic biosignatures. Earth Planet Sci Lett 272:456-463.

Davila, A.F., Hawes, I., Araya, J.G., Gelsinger, D.R., DiRuggiero, J., Ascaso, C., Osano, A., and Wierzchos J. (2015) In situ metabolism in halite endolithic microbial communities of the hyperarid Atacama Desert. Front Microbiol 6, doi:10.3389/fmicb.2015.01035.

De Wever, A., Muylaert, K., Van der Gucht, K., Pirlot, S., Cocquyt, C., Descy, J.-P., Plisnier, P.-D., and Vyverman, W. (2005) Bacterial community composition in Lake Tanganyika: vertical and horizontal heterogeneity. Appl Environ Microbiol 71:5029-5037.

Des Marais, D.J. (2000) When did photosynthesis emerge on Earth? Science 289:1703-1705.

Des Marais, D.J. (2013) Planetary climate and the search for life. In Comparative Climatology of Terrestrial Planets, edited by S.J. Mackwell, A.A. Simon-Miller, J.W. Harder, and M.A. Bullock, University of Arizona Press, Tucson, pp 583-601.

Des Marais, D.J., Jakosky, B.M., and Hynek, B.M. (2008a) Astrobiological implications of Mars surface composition and properties. In The Martian Surface: Composition, Mineralogy and Physical Properties, edited by J.A. Bell, Cambridge planetary science series 9, Cambridge University Press, New York, pp 599-623.

Des Marais, D.J., Nuth, J.A., III, Allamandola, L.J., Boss, A.P., Farmer, J.D., Hoehler, T.M., Jakosky, B.M., Meadows, V.S., Pohorille, A., Runnegar, B., and Spormann, A.M. (2008b) The NASA Astrobiology Roadmap. Astrobiology 8:715-730.

Di Achille, G. and Hynek, B. (2010) Ancient ocean on Mars supported by global distribution of deltas and valleys. Nat Geosci 3:459-463.

Dill, H.G. (2010) The "chessboard" classification scheme of mineral deposits: mineralogy and geology from aluminum to zirconium. Earth-Science Reviews 10:1-420.

Djokic, T. (2015) Constraining the palaeoecology and palaeoenvironment of Earth's earliest convincing evidence of life in a developing volcanic-hydrothermal system: the $c$. 3.5 Ga Dresser Formation, North Pole Dome, Pilbara Craton. Unpublished MPhil thesis, University of New South Wales, Sydney, Australia.

Djokic, T., Van Kranendonk, J.M., Campbell, K.A., Walter, M.R., and Ward, C.R. (2017) Earliest signs of life on land in c. $3.5 \mathrm{Ga}$ hot spring deposits. Nature Communications, doi: 10.1038/ncomms 15263 .

Edwards, K.J., Bach, W., McCollom, T.M., and Rogers, D.R. (2004) Neutrophilic iron-oxidizing bacteria in the ocean: their habitats, diversity, and roles in mineral deposition, rock alteration, and biomass production in the deep sea. Geomicrobiol J 21:393-404.

Edwards, K.J., Bach, W., and McCollom, T.M. (2005) Geomicrobiology in oceanography: mineral-microbe interactions at and below the seafloor. Trends Microbiol 13:449-456.
Edwards, K.J., Becker, K., and Colwell, F. (2012) The deep, dark energy biosphere: intraterrestrial life on Earth. Аnпи Rev Earth Planet Sci 40:551-568.

Ehlmann, B. (2016) Mars time and martian environments: changing habitability through time and prospects for ancient Mars [abstract 2080]. In Biosignature Preservation and Detection in Mars Analog Environments I: Paleo-Hydrothermal Systems, Lunar and Planetary Institute, Houston.

Ehlmann, B.L., Mustard, J.F., Swayze, G.A., Clark, R.N., Bishop, J.L., Poulet, F., Des Marais, D.J., Roach, L.H., Milliken, R.E., Wray, J.J., Barnouin-Jha, O., and Murchie, S.L. (2009) Identification of hydrated silicate minerals on Mars using MRO-CRISM: geologic context near Nili Fossae and implications for aqueous alteration. J Geophys Res 114, doi:10.1029/2009JE003339.

Ehlmann, B.L., Mustard, J.F., Murchie, S.L., Bibring, J.-P., Meunier, A., Fraeman, A.A., and Langevin, Y. (2011) Subsurface water and clay mineral formation during the early history of Mars. Nature 479:53-60.

Ehlmann, B.L., Berger, G., Mangold, N., Michalski, J.R., Catling, D.C., Ruff, S.W., Chassefière, E., Niles, P.B., Chevrier, V., and Poulet, F. (2013) Geochemical consequences of widespread clay mineral formation in Mars' ancient crust. Space Sci Rev 174:329-364.

Eigenbrode, J.L. and Freeman, K.H. (2006) Late Archean rise of aerobic microbial ecosystems. Proc Natl Acad Sci USA 103:15759-19764.

Eigenbrode, J.L., Steele, A., Summons, R.E., McAdam, A.C., Sutter, B., Franz, H.B., Freissinet, C., Millan, M., Glavin, D., Ming, D.W., Navarro-González, R., Pavlov, A., Hurowitz, J.A., Grotzinger, J., Conrad, P.G. and Mahaffy, P.R. (2016) In situ observations of refractory organic matter in lacustrine mudstones of Gale Crater and their implications for the search for organic biosignatures [abstract 2012]. In Biosignature Preservation and Detection in Mars Analog Environments I: PaleoHydrothermal Systems, Lunar and Planetary Institute, Houston.

Einsele, G. (2000) Sedimentary Basins: Evolution, Facies, and Sediment Budget, $2^{\text {nd }}$ ed., Springer-Verlag, Berlin.

El Maarry, M.R., Heggy, E., and Dohm, J.M. (2011) Assessment of a possible volcanic paleolake at Apollinaris Patera, Mars: constraints on the composition of the inner caldera and fan deposits using the shallow sounding radar (SHARAD) [abstract 2027]. In $42^{\text {nd }}$ Lunar and Planetary Science Conference, Lunar and Planetary Institute, Houston.

Emerson, D. and Moyer, C.L. (2002) Neutrophilic Fe-oxidizing bacteria are abundant at the Loihi Seamount hydrothermal vents and play a major role in Fe oxide deposition. Appl Environ Microbiol 68:3085-3093.

Emerson, D. and Revsbech, N.P. (1994) Investigation of an ironoxidizing microbial mat community located near Aarhus, Denmark: field studies. Appl Environ Microbiol 60:4022-4031.

Emry, J.R., Olcott Marshall, A., and Marshall, C.P. (2015) Life detection limitations due to fluorescence in Raman imaging [abstract 7505]. In Astrobiology Science Conference, Lunar and Planetary Institute, Houston.

Fallacaro, A. and Calvin, W.M. (2006) Spectral properties of Lake Superior banded iron formation: application to martian hematite deposits. Astrobiology 6:563-580.

Farley, K.A., Hurowitz, J.A., Asimow, P.D., Jacobson, N.S., and Cartwright, J.A. (2013) A double-spike method for K-Ar measurement: a technique for high precision in situ dating on Mars and other planetary surfaces. Geochim Cosmochim Acta 110:1-12.

Farley, K.A., Malespin, C., Mahaffy, P., Grotzinger, J.P., Vasconcelos, P.M., Milliken, R.E., Malin, M., Edgett, K.S., Pavlov, A.A., Hurowitz, J.A., Grant, J.A., Miller, H.B., Ar- 
vidson, R., Beegle, L., Calef, F., Conrad, P.G., Dietrich, W.E., Eigenbrode, J., Gellert, R., Gupta, S., Hamilton, V., Hassler, D.M., Lewis, K.W., McLennan, S.M., Ming, D., NavarroGonzález, R., Schwenzer, S.P., Steele, A., Stolper, E.M., Sumner, D.Y., Vaniman, D., Vasavada, A., Williford, K., Wimmer-Schweingruber, R.F., and the MSL Science Team. (2014) In situ radiometric and exposure age dating of the martian surface. Science 343, doi:10.1126/science.1247166.

Farmer, J.D. (1999) Taphonomic modes in microbial fossilization. In Size Limits of Very Small Microorganisms: Proceedings of a Workshop, Space Studies Board, National Research Council, National Academies Press, Washington, DC, pp 94-102.

Farmer, J.D. and Des Marais, D.J. (1999) Exploring for a record of ancient martian life. J Geophys Res 104:26977-26995.

Farrand, W.H., Glotch, T.D., Rice, J.W., Jr., Hurowitz, J.A., and Swayze, G.A. (2009) Discovery of jarosite within the Mawrth Vallis region of Mars: implications for the geologic history of the region. Icarus 52:478-488.

Farrand, W.H., Glotch, T.D., and Horgan, B. (2014) Detection of copiapite in the northern Mawrth Vallis region of Mars: evidence of acid sulfate alteration. Icarus 241:346-357.

Fassett, C.I., Dickson, J.L., Head, J.W., Levy, J.S., and Marchant, D.R. (2010) Supraglacial and proglacial valleys on Amazonian Mars. Icarus 208:86-100.

Fastook, J.L., Head, J.W., Marchant, D.R., Forget, F., and Madeleine, J.-B. (2012) Early Mars climate near the Noachian-Hesperian boundary: independent evidence for cold conditions from basal melting of the south polar ice sheet (Dorsa Argentea Formation) and implications for valley network formation. Icarus 219:25-40.

Fernández-Remolar, D.C. and Knoll, A.H. (2008) Fossilization potential of iron-bearing minerals in acidic environments of Río Tinto, Spain: implications for Mars exploration. Icarus 194:72-85.

Fernández-Remolar, D.C., Rodriguez, N., Gómez, F., and Amils, R. (2003) Geological record of an acidic environment driven by iron hydrochemistry: The Tinto River system. $J$ Geophys Res 108:1-15.

Ferris, F.G. and Magalhaes, E. (2008) Interfacial energetics of bacterial silicification. Geomicrobiol J 25:333-337.

Fisk, M.R. and Giovannoni, S.J. (1999) Sources of nutrients and energy for a deep biosphere on Mars. $J$ Geophys Res 104:11805-11815.

Fisk, M.R., Giovannoni, S.J., and Thorseth I.H. (1998) Alteration of oceanic volcanic glass: textural evidence of microbial activity. Science 281:978-980.

Fouke, B.W., Farmer, J.D., Des Marais, D.J., Pratt, L., Sturchio, N.C., Burns, P.C., and Discipulo, M.K. (2000) Depositional facies and aqueous-solid geochemistry of travertine-depositing hot springs (Angel Terrace, Mammoth Hot Springs, Yellowstone National Park, USA). Journal of Sedimentary Research 70:565-585.

Fraeman, A.A., Arvidson, R.E., Catelano, J.G., Grotzinger, J.P., Morris, R.V., Murchie, S.L., Stack, K.M., Humm, D.C., McGovern, J.A., Seelos, F.P., Seelos, K.D., and Viviano, C.E. (2013) A hematite-bearing layer in Gale Crater, Mars: mapping and implications for past aqueous conditions. Geology 41:1103-1106.

Frape, S.K. and Fritz, P. (1987) Geochemical trends for groundwater from the Canadian shield. In Saline Water and Gases in Crystalline Rocks, Special Paper 33, edited by P. Fritz and S.K. Frape, Geological Association of Canada, Memorial University, Newfoundland, pp 19-38.

French, J.E. and Blake, D.F. (2016) Discovery of naturally etched fission tracks and alpha-recoil tracks in submarine glasses: reevaluation of a putative biosignatures for Earth and Mars. International Journal of Geophysics 2016, doi:10.1155/ 2016/2410573.

Fryer, B.J. (1983) Rare earth elements in iron-formation. In Iron-Formation: Facts and Problems, edited by A.J. Trendall and A.J. Morris, Elsevier, Amsterdam, pp 345-358.

Furnes, H., Banerjee, N.R., Muehlenbachs, K., Staudigel, H., and de Wit, M. (2004) Early life recorded in Archean pillow lavas. Science 304:578-581.

Gay, A.L. and Grandstaff, D.E. (1980) Chemistry and mineralogy of Precambrian paleosols at Elliot Lake, Ontario, Canada. Precambrian Res 12:349-373.

Gibson, R.A., Talbot, H.M., Kaur, G., Pancost, R.D., and Mountain, B. (2008) Bacteriohopanepolyol signatures of cyanobacterial and methanotrophic bacterial populations recorded in a geothermal vent sinter. Org Geochem 39:1020-1023.

Glotch, T.D., Bandfield, J.L., Tornabene, L.L., Jensen, H.B., and Seelos, F.P. (2010) Distribution and formation of chlorides and phyllosilicates in Terra Sirenum, Mars. Geophys Res Lett 37:1-5. Gomez, F.G., Carles, A.G., Vazquez, L., and Amils, R. (2003) UV radiation effects over microorganisms and study of protective agents. In Proceedings of the III European Workshop on ExoAstrobiology, edited by R.A. Harris and L. Ouwehand, ESA Publications Division, Noordwijk, The Netherlands, pp 21-25.

Goodbred, S.L. and Kuehl, S.A. (2000) The significance of large sediment supply, active tectonism, and eustasy on margin sequence development: Late Quaternary stratigraphy and evolution of the Ganges-Brahmaputra Delta. Sediment Geol 133:227-248.

Gopal, B. and Chauhan, M. (2001) South Asian wetlands and their biodiversity: the role of monsoons. In B. Gopal, W.J. Junk, and T.A. Davis, Biodiversity in Wetlands: Assessment, Function and Conservation, Vol. 2, Backhuys Publishers, Leiden, The Netherlands.

Graham, H.V., Stern J.C., Baldridge A.M., and Thomsen B.J. (2016) Australian acid brine lake as a Mars analog: an analysis of preserved lipids in shore and lake sediments [abstract 2063] In Biosignature Preservation and Detection in Mars Analog Environments I: Paleo-Hydrothermal Systems, Lunar and Planetary Institute, Houston.

Grant, J.A., Irwin, R.P., III, and Wilson, S.A. (2010) Aqueous depositional settings in Holden Crater, Mars. In Lakes on Mars, edited by N.A. Cabrol and E.A. Grin, Elsevier, Amsterdam, pp 323-346.

Grotzinger, J.P., Gupta, S., Malin, M.C., Rubin, D.M., Schieber, J., Siebach, K., Sumner, D.Y., Stack, K.M., Vasavada, A.R., Arvidson, R.E., Calef, F., III, Edgar, L., Fischer, W.F., Grant, J.A., Griffes, J., Kah, L.C., Lamb, M.P., Lewis, K.W., Mangold, N., Minitti, M.E., Palucis, M., Rice, M., Williams, R.M.E., Yingst, R.A., Blake, D., Blaney, D., Conrad, P., Cirsp, J., Dietrich, W.E., Dromart, G., Edgett, K.S., Ewing, R.C., Gellert, R., Hurowitz, J.A., Kocurek, G., Mahaffy, P., McBride, M.J., McLennan, S.M., Mischna, M., Ming, D., Milliken, R., Newsom, H., Oehler, D., Parker, T.J., Vaniman, D., Wiens, R.C., and Wilson, S.A. (2015) Deposition, exhumation, and paleoclimate of an ancient lake deposit, Gale Crater, Mars. Science 350:177-188.

Gulick, V. (1998) Magmatic intrusions and a hydrothermal origin for fluvial valleys on Mars. J Geophys Res 103:19368-19387.

Gulick, V.C. (2001) Origin of the valley networks on Mars: a hydrological perspective. Geomorphology 37:241-268.

Gutzmer, J. and Beukes, N. (1998) Earliest laterites and possible evidence for terrestrial vegetation in the Early Proterozoic. Geology 26:263-266. 
Hanesch, M. (2009) Raman spectroscopy of iron oxides and (oxy)hydroxides at low laser power and possible applications in environmental magnetic studies. Geophys J Int 177:941-948.

Hassler, D.M., Zeitlin, C., Wimmer-Schweingruber, R.F., Ehresmann, B., Rafkin, S., Eigenbrode, J.L., Brinza, D.E., Weigle, G., Böttcher, S., Böhm, E., Burmeister, S., Guo, J., Köhler, J., Martin, C., Reitz, G., Cucinotta, F.A., Kim, M.-H., Grinspoon, D., Bullock, M.A., Posner, A., Gómez-Elvira, J., Vasavada, A., Grotzinger, J.P., and MSL Science Team. (2014) Mars surface radiation environment measured with the Mars Science Laboratory's Curiosity rover. Science 343, doi:10.1126/science.1244797.

Hausrath, E.M., Treiman, A.H., Vicenzi, E., Bish, D.L., Blake, D., Sarrazin, P., Hoehler, T., Midtkandl, I., Steele, A., and Brantley, S.L. (2008) Short- and long-term olivine weathering in Svalbard: Implications for Mars. Astrobiology 8:1079-1092.

Hausrath, E.M., Neaman, A., and Brantley, S.L. (2009) Elemental release rates from dissolving basalt and granite with and without organic ligands. Am J Sci 309:633-660.

Hausrath, E.M., Navarre-Sitchler, A.K., Sak, P.B., Williams, J.Z. and Brantley, S.L. (2011) Soil profiles as indicators of mineral weathering rates and organic interactions on a Pennsylvania diabase. Chem Geol 290:89-100.

Hays, L.E., editor-in-chief. (2015) NASA Astrobiology Strategy 2015. Available online at http://astrobiology.nasa.gov/uploads/ filer_public/01/28/01283266-e401-4dcb-8e05-3918b21edb79/ nasa_astrobiology_strategy_2015_151008.pdf

Hecht, M.H., Kounaves, S.P., Quinn, R.C., West, S.J., Young, S.M., Ming, D.W., Catling, D.C., Clark, B.C., Boynton, W.V., Hoffman, J., Deflores, L.P., Gospodinova, K., Kapit, J., and Smith, P.H. (2009) Detection of perchlorate and the soluble chemistry of martian soil at the Phoenix lander site. Science 325:64-67.

Hedges, J.I. and Keil, R.G. (1995) Sedimentary organic matter preservation: an assessment and speculative synthesis. Mar Chem 49:81-115.

Heezen, B., Tharp, M., and Ewing, M. (1959) The Floors of the Oceans. 1. The North Atlantic, GSA Special Papers 65, Geological Society of America, New York.

Heising, S. and Schink, B. (1998) Phototrophic oxidation of ferrous iron by a Rhodomicrobium vannielii strain. Microbiology 144:2263-2269.

Heising, S., Richter, L., Ludwig, W., and Schink, B. (1999) Chlorobium ferrooxidans sp. nov., a phototrophic green sulfur bacterium that oxidizes ferrous iron in coculture with a 'Geospirillum' sp. strain. Arch Microbiol 172:116-124.

Hickman-Lewis, K., Garwood, R.J., Brasier, M.D., Goral, T., Jiang, H., McLoughlin, N., and Wace, D. (2016) Carbonaceous microstructures of the $3.46 \mathrm{Ga}$ stratiform 'Apex Chert,' Pilbara, Western Australia: presenting a new suite of early Archean microbially induced sedimentary structures [abstract 2029]. In Biosignature Preservation and Detection in Mars Analog Environments I: Paleo-Hydrothermal Systems, Lunar and Planetary Institute, Houston.

Hinman, N.W., Kendall, T.A., MacKenzie, L.M., and Cady, S.L. (2016) Diagenetic changes in common hot spring microfacies [abstract 2047]. In Biosignature Preservation and Detection in Mars Analog Environments I: Paleo-Hydrothermal Systems, Lunar and Planetary Institute, Houston.

Hoehler, T.M. (2007) An energy balance concept of habitability. Astrobiology 7:824-838.

Hofmann, B.A., Farmer, J.D., von Blanckenburg, F., and Fallick, A.E. (2008) Subsurface filamentous fabrics: an evaluation of origins based on morphological and geochemical criteria, with implications for exopaleontology. Astrobiology 8:87-117.
Hoham, R. (2000) Snow algae: the effects of chemical and physical factors on their life cycles and populations. In Journey to Diverse Microbial Worlds: Adaptation to Exotic Environments, edited by J. Seckbach, Kluwer Academic Publishers, Dordrecht, The Netherlands, pp 131-145.

Holland, G., Sherwood Lollar, B., Li, L., Lacrampe-Couloume, G., Slater, G.F., and Ballentine, C.J. (2013) Deep fracture fluids isolated in the crust since the Precambrian era. Nature 497:357-360.

Horgan, B. (2016) Strategies for searching for biosignatures in ancient martian surface environments [abstract 2032]. In Biosignature Preservation and Detection in Mars Analog Environments I: Paleo-Hydrothermal Systems, Lunar and Planetary Institute, Houston.

Horgan, B.H., Rice, M.S., Farrand, W.H., Sheldon, N.D., and Bishop, J.L. (2015) Possible microbial energy pathways from iron and sulfur redox gradients at Mawrth Vallis and Gale Crater, Mars [abstract 7463]. In Astrobiology Science Conference, Lunar and Planetary Institute, Houston.

Horodyskyj, L.B., White, T.S., and Kump L.R. (2012) Substantial biologically mediated phosphorus depletion from the surface of a Middle Cambrian paleosol. Geology 40:503-506.

Hynek, B.M., Osterloo, M.K., and Kierin-Young, K.S. (2015) Late-stage formation of martian chloride salts through ponding and evaporation. Geology 43:787-790.

Ingledew, W.J. (1982) Thiobacillus ferrooxidans: the bioenergetics of an acidophilic chemolithotroph. Biochim Biophys Acta 683:89-117.

Inskeep, W.P. and McDermott, T.R. (2005) Geothermal Biology and Geochemistry in Yellowstone National Park, Montana State University Publications, Bozeman, MT.

Jahnke, L.L., Eder, W., Huber, R., Hope, J.M., Hinrichs, K.U., Hayes, J.M., Des Marais, D.J., Cady, S.L., and Summons, R.E. (2001) Signature lipids and stable carbon isotope analyses of Octopus Spring hyperthermophilic communities compared with those of Aquificales representatives. Appl Environ Microbiol 67:5179-5189.

Jahnke, L.L., Embaye, T., Hope, J., Turk, K.A., Van Zuilen, M., Des Marais, D.J., Farmer, J.D., and Summons, R.E. (2004) Lipid biomarker and carbon isotopic signatures for stromatoliteforming, microbial mat communities and Phormidium cultures from Yellowstone National Park. Geobiology 2:31-47.

Jahnke, L.L., Turk-Kubo, K.A., Parenteau, N., Green, S.J., Kubo, M.D., Vogel., M., Summons, R.E., and Des Marais, D.J. (2014) Molecular and lipid biomarker analysis of a gypsum-hosted endoevaporitic microbial community. Geobiology 12:62-82.

Jahnke, L.L., Parenteau, M.N., and Farmer, J.D. (2016) Organic biomarker preservation in silica-rich hydrothermal systems with implications to Mars [abstract 2083]. In Biosignature Preservation and Detection in Mars Analog Environments I: PaleoHydrothermal Systems, Lunar and Planetary Institute, Houston.

Johnson, J.R., Wiens, R.C., Maurice, S., Blaney, D., Gasnault, O., Cloutis, E., Le Mouélic, S., and Bender, S. (2015) ChemCam passive reflectance spectroscopy of ferric sulfates and ferric oxides near the base of Mt. Sharp [abstract 1433]. In $46^{\text {th }}$ Lunar and Planetary Science Conference, Lunar and Planetary Institute, Houston.

Johnson, S.S., Soni, M.L., Collins, D.J., Benison, K.C., Mormile, M.R., Chevrette, M.G., and Ehlmann, B. L. (2016) Biosignatures in Mars analog acid salt lakes [abstract 2072]. In Biosignature Preservation and Detection in Mars Analog Environments I: Paleo-Hydrothermal Systems, Lunar and Planetary Institute, Houston.

Kallmeyer, J., Pockalny, R., Adhikari, R.R., Smith, D.C., and D'Hondt, S. (2012) Global distribution of microbial abundance 
and biomass in subseafloor sediment. Proc Natl Acad Sci USA 109:16213-16216.

Kaufman, A.J., Hayes, J.M., and Klein, C. (1990) Primary and diagenetic controls of isotopic compositions of iron-formation carbonates. Geochim Cosmochim Acta 54:3461-3473.

Kaur, G., Mountain, B.W., and Pancost, R.D. (2008) Microbial membrane lipids in active and inactive sinters from Champagne Pool, New Zealand: elucidating past geothermal chemistry and microbiology. Org Geochem 39:1024-1028.

Kaur, G., Mountain, B.W., Hopmans, E.C., and Pancost, R.D. (2011) Preservation of microbial lipids in geothermal sinters. Astrobiology 11:259-274.

Keam, R. (1980) Waimangu. In Guide to the Geophysics of the Volcanic and Geothermal Area of the North Island of New Zealand, The Royal Society of New Zealand Miscellaneous Series, No 3, Royal Society of New Zealand, Wellington, New Zealand.

Klein, C. (2005) Some Precambrian banded iron-formations (BIFs) from around the world: their age, geologic setting, mineralogy, metamorphism, geochemistry, and origin. Am Mineral 90:1473-1499.

Klein, C. and Beukes, N.J. (1989) Geochemistry and sedimentology of a facies transition from limestone to iron-formation deposition in the early Proterozoic Transvaal Supergroup, South Africa. Econ Geol 84:1733-1774.

Konhauser, K.O., Schultze-Lam, S., Ferris, F.G., Fyfe, W.S., Longstaffe, F.J., and Beveridge, T.J. (1994) Mineral precipitation by epithlic biofilms in the Speed River, Ontario, Canada. Appl Envrion Microbiol 60:549-553.

Konhauser, K.O., Fisher, Q.J., Fyfe, W.S., Longstaffe, F.J., and Powell, M.A. (1998) Authigenic mineralization and detrital clay binding by freshwater biofilms: the Brahmani River, India. Geomicrobiol J 15:209-222.

Konhauser, K.O., Phoenix, V.R., Bottrell, S.H., Adams, D.G., and Head, I.M. (2001) Microbial-silica interactions in Icelandic hot spring sinter: possible analogues for some Precambrian siliceous stromatolites. Sedimentology 48:415-433.

Konhauser, K.O., Hamade, T., Raiswell, R., Morris, R.C., Ferris, F.G., Southam, G., and Canfield, D.E. (2002) Could bacteria have formed the Precambrian banded iron formations? Geology 30:1079-1082.

Lalonde, K., Mucci, A., Ouellet, A., and Gélinas, Y. (2012) Preservation of organic matter in sediments promoted by iron. Nature 483:198-200.

Lasue, J., Mangold, N., Hauber, E., Clifford, S., Feldman, W., Gasnault, O., Grima, C., Maurice, S., and Mousis, O. (2013) Quantitative assessments of the martian hydrosphere. Space Sci Rev 174:155-212.

Lerman, A. (1978) Chemical exchange across sediment-water interface. Annu Rev Earth Planet Sci 6:281-303.

Leshin, L.A., Mahaffy, P.R., Webster, C.R., Cabane, M., Coll., P., Conrad, P.G., Archer, P.D., Jr., Atreya, S.K., Brunner, A.E., Buch, A., Eigenbrode, J.L., Flesch, G.J., Franz, H.B., Freissinet, C., Glavin, D.P., McAdam, A.C., Miller, K.E., Ming, D.W., Morris, R.V., Navarro-González, R., Niles, P.B., Owen, T., Pepin, R.O., Squyres, S., Steele, A., Stern, J.C., Summons, R.E., Sumner, D.Y., Sutter, B., Szopa, C., Teinturier, S., Trainer, M.G., Wray, J.J., Grotzinger, J.P., and MSL Science Team. (2013) Volatile, isotope, and organic analysis of martian fines with the Mars Curiosity rover. Science 341, doi:10.1126/science.1238937

Leslie, K., van Geffen, P.W., MacFarlane, B., Oates, C.J., Kyser, T.K., and Fowle, D.A. (2013) Biogeochemical indicators of buried mineralization under cover, Talbot VMS CuZn prospect, Manitoba. Appl Geochem 37:190-202.
Leslie, K., Oates, C.J., Kyser, T.K., and Fowle, D.A. (2014) Biogeochemical controls on metal mobility: modeling a $\mathrm{Cu}-\mathrm{Zn}$ VMS deposit in column flow-through studies. Geochemistry: Exploration, Environment, Analysis 14:59-70.

Léveillé, R.J. and Datta, S. (2010) Lava tubes and basaltic caves as astrobiological targets on Earth and Mars: a review. Planet Space Sci 58:592-598.

Léveillé, R.J., Longstaffe, F.J., and Fyfe, W.S. (2007) An isotopic and geochemical study of carbonate-clay mineralization in basaltic caves: abiotic versus microbial processes. Geobiology 5:235-249.

Léveillé, R.J., Bridges, J., Wiens, R.C., Mangold, N., Cousin, A., Lanza, N., Forni, O., Ollila, A., Grotzinger, J., Clegg, S., Siebach, K., Berger, G., Clark, B., Fabre, C., Anderson, R., Gasnault, O., Blaney, D., Deflores, L., Leshin, L., Maurice, S., and Newsom, H. (2014) Chemistry of fracture-filling raised ridges in Yellowknife Bay, Gale Crater: window into past aqueous activity and habitability on Mars. J Geophys Res: Planets 119:2398-2415.

Lever, M.A., Rouxel, O., Alt, J.C., Shimizu, N., Ono, S., Coggon, R.M., Shanks, W.C., III, Lapham, L., Elvert, M., Prieto-Mollar, X., Hinrichs, K.-U., Inagake, F., and Teske, A. (2013) Evidence for microbial carbon and sulfur cycling in deeply buried ridge flank basalt. Science 339:1305-1308.

Liermann, L.J., Hausrath, E.M., Anbar, A.D., and Brantley, S.L. (2007) Assimilatory and dissimilatory processes of microorganisms affecting metals in the environment. $J$ Anal At Spectrom 22:867-877.

Lin, L.-H., Hall, J., Lippmann-Pipke, J., Ward, J.A., Sherwood Lollar, B., DeFlaun, M., Rothmel, R., Moser, D., Gihring, T.M., Mislowack, B., and Onstott, T.C. (2005) Radiolytic $\mathrm{H}_{2}$ in continental crust: nuclear power for deep subsurface microbial communities. Geochem Geophys Geosyst 6, doi: 10.1029/2004GC000907.

Lin, L.-H., Wang, P.-L., Rumble, D., Lippmann-Pipke, J., Boice, E., Pratt, L.M., Sherwood Lollar, B., Brodie, E.L., Hazen, T.C., Andersen, G.L., DeSantis, T.Z., Moser, D.P., Kershaw, D., and Onstott, T.C. (2006) Long-term sustainability of a high-energy, low-diversity crustal biome. Science 314:479-482.

Lindsay, M.R., Anderson, C., Fox, N., Scofield, G., Allen, J., Anderson, E., Bueter, L., Poudel, S., Sutherland, K., MunsonMcGee, J.H., Van Nostrand, J.D., Zhou, J., Spear, J.R., Baxter, B.K., Lageson, D.R., and Boyd, E.S. (2017) Microbialite response to an anthropogenic salinity gradient in Great Salt Lake, Utah. Geobiology 15:131-145.

Lipp, J.S., Morono, Y., Inagaki, F., and Hinrichs, K.-U. (2008) Significant contribution of archaea to extant biomass in marine subsurface sediments. Nature 454:991-994.

Lomstein, B.A., Langerhuus, A.T., D’Hondt, S., Jørgensen, B.B., and Spivack, A. (2012) Endospore abundance, microbial growth and necromass turnover in deep subseafloor sediment. Nature 484:101-104.

Lovely, D.R. (1993) Dissimilatory metal reduction. Annu Rev Microbiol 47:263-269.

Lowe, D.R. (1980) Archean sedimentation. Annu Rev Earth Planet Sci 8:145-167.

Lynch, K.L., Horgan, B.H., Munakata-Marr, J., Hanley, J., Schneider, R.J., Rey, K.A., Spear, J.R., Jackson, W.A., and Ritter S.M. (2015) Near-infrared spectroscopy of lacustrine sediments in the Great Salt Lake Desert: an analog study for martian paleolake basins. J Geophys Res: Planets 120:599-623.

Lynch, K.L., Biddle, J.F., Schneider, R.J., Rey, K.A., Wray, J.J., and Rosenzweig, R.F. (2016) The Pilot Valley Basin, Utah: a modern habitability and preservation model for groundwater-fed martian paleolake basins [abstract 2075]. In Biosignature Preservation 
and Detection in Mars Analog Environments I: PaleoHydrothermal Systems, Lunar and Planetary Institute, Houston. Madigan, M.T., Jung, D.O., Karr, E.A., Sattley, W.M., Achenbach, L.A., and van der Meer, J. (2005) Diversity of anoxygenic phototrophs in contrasting extreme environments. In Geothermal Biology and Geochemistry in Yellowstone National Park, edited by W.P. Inskeep and T.R. McDermott, Thermal Biology Institute, Montana State University, Bozeman, pp 203-219.

Mahaney, W.C., Dohm, J.M., Schwartz, S., Findling, N., Hart, K.M., Conway, S.J., Allen, C.C.R., Miyamoto, H., and. Fairén A.G. (2014) Mineralogy, chemistry and biological contingents of an early-middle Miocene Antarctic paleosol and its relevance as a martian analogue. Planet Space Sci 104:253-269.

Mangold, N., and Ansan, V. (2004) Long term stability of liquid water on early Mars from the identification of lakes and deltas [abstract 2006]. Geophysical Research Abstracts 6:01605.

Margulis, L., Walker, J.C.G, and Rambler, M. (1976) Reassessment of roles of oxygen and ultraviolet light in Precambrian evolution. Nature 264:620-624.

Martín-Torres, F.J., Zorzano, M.-P., Valentín-Serrano, P., Harri, A.-M., Genzer, M., Kemppinen, O., Rivera-Valentin, E.G., Jun, I., Wray, J., Madsen, M.B., Goetz, W., McEwen, A.S., Hardgrove, C., Renno, N., Chevrier, V.F., Mischna, M., NavarroGonzález, R., Martinez-Frías, J., Conrad, P., McConnochi, T., Cockell, C., Berger, G., Vasavada, A.R., Sumner, D., and Vaniman, D. (2015) Transient liquid water and water activity at Gale Crater on Mars. Nat Geosci 8:357-361.

Mata, S.A., Harwood, C.L., Corsetti, F.A., Stork, N.J., Eilers, K., Berelson, W.M., and Spear, J.R. (2012) Influence of gas production and filament orientation on stromatolite microfabric. Palaios 27:206-219.

Mayer, L.M. (1994) Surface area control of organic carbon accumulation in continental shelf sediments. Geochim Cosmochim Acta 58:1271-1284.

McCollom, T.M. and Seewald, J.S. (2013) Serpentinites, hydrogen, and life. Elements 9:129-134.

McCollom, T.M. and Shock, E.L. (1997) Geochemical constraints on chemolithoautotrophic metabolism by microorganisms in seafloor hydrothermal systems. Geochim Cosmochim Acta 61:4375-4391.

McCollom, T.M., Hynek, B.M., and Rogers, K.L. (2016) Potential for preservation of biosignatures from endolithic microbial communities in a Mars analog fumarole environment [abstract 2006]. In Biosignature Preservation and Detection in Mars Analog Environments I: Paleo-Hydrothermal Systems, Lunar and Planetary Institute, Houston.

McMahon, S. and Parnell, J. (2013) Weighing the deep continental biosphere. FEMS Microbiol Ecol 87:113-120.

Michalski, J.R., Cuadros, J., Niles, P.B., Parnell, J., Rogers, A.D., and Wright, S.P. (2013) Groundwater activity on Mars and implications for a deep biosphere. Nat Geosci 6:133-138.

Milliken, R.E. and Bish, D.L. (2010) Sources and sinks of clay minerals on Mars. Philosophical Magazine Letters 90:2293-2308.

Milliken, R.E., Swayze, G., Arvidson, R., Bishop, J., Clark, R., Ehlmann, B., Green, R., Grotzinger, J., Morris, R., Murchie, S., Mustard, J., and Weitz, C. (2008) Opaline silica in young deposits on Mars. Geology 36:847-850.

Milliken, R.E., Grotzinger, J.P., and Thomson, B.J. (2010) Paleoclimate of Mars as captured by the stratigraphic record in Gale Crater. Geophys Res Lett 37:1-6.

Milliman, J.D. (1991) Flux and fate of fluvial sediment and water in coastal seas. In Ocean Margin Processes in Global Change, edited by R.F.C. Mantoura, J-M. Martin, and R. Wollast., Wiley \& Sons, Chichester, UK, pp 69-89.
Mitsch, W.J. and Gosselink, J.G. (2000) Wetlands, John Wiley \& Sons, New York.

Moore, J.M., Howard, A.D., Dietrich, W.E., and Schenk P.M. (2003) Martian layered fluvial deposits: implications for Noachian climate scenarios. Geophys Res Lett 30, doi:10.1029/ 2003GL019002.

Morris, R.C. (1993) Genetic modeling for banded ironformations of the Hamersley Group, Pilbara Craton, Western Australia. Precambrian Res 60:243-286.

Mountain, B.W., Benning, L.G., and Boerema, J.A. (2003) Experimental studies on New Zealand hot spring sinters: rates of growth and textural development. Can J Earth Sci 40: 1643-1667.

Müller, P.J. and Suess, E. (1979) Productivity, sedimentation rate, and sedimentary organic matter in the oceans-I. Organic matter preservation. Deep Sea Res A 26:1347-1362.

Munoz-Saez, C., Salthiel, S., Manga, M., Nguyen, C., and Gonnermann, H. (2016) Physical and hydraulic properties of modern sinter deposits: El Tatio, Atacama. Journal of Volcanology and Geothermal Research 325:156-168.

Mustard, J.F., Adler, M., Allwood, A., Bass, D.S., Beaty, D.W., Bell, J.F., III, Brinckerhoff, W.B., Carr, M., Des Marais, D.J., Drake, B., Edgett, K.S., Eigenbrode, J., Elkins-Tanton, L.T., Grant, J.A., Milkovich, S.M., Ming, D., Moore, C., Murchie, S., Onstott, T.C., Ruff, S.W., Sephton, M.A., Steele, A., and Treiman, A. (2013) Report of the Mars 2020 Science Definition Team, posted July 1, 2013, by the Mars Exploration Program Analysis Group (MEPAG) at http://mepag.jpl.nasa.gov/reports/ MEP/Mars_2020_SDT_Report_Final.pdf

Naeem, S., Hahn, D.R., and Schuurman, G. (2000) Producerdecomposer co-dependency influences biodiversity effects. Nature 403:762-764.

Neaman, A., Chorover, J., and Brantley, S.L. (2005) Element mobility patterns record organic ligands in soils on early Earth. Geology 33:117-120.

Neukum, G., Basilevsky, A.T., Kneissl, T., Chapman, M.G., van Gasselt, S., Michael, G., Jaumann, R., Hoffmann, H., and Lanz, J.K. (2010) The geologic evolution of Mars: episodicity of resurfacing events and ages from cratering analysis of image data and correlation with radiometric ages of martian meteorites. Earth Planet Sci Lett 294:204-222.

Noe Dobrea, E.Z., Bishop, J.L., McKeown, N.K., Fu, R., Rossi, C.M., Michalski, J.R., Heinlein, C., Hanus, V., Poulet, F., Mustard R.J.F., Murchie, S., McEwen, A.S., Swayze, G., Bibring, J.-P., Malaret, E., and Hash, C. (2010) Mineralogy and stratigraphy of phyllosilicate-bearing and dark mantling units in the greater Mawrth Vallis/west Arabia Terra area: constraints on geological origin. J Geophys Res: Planets 115 doi:10.1029/2009JE003351.

Noe Dobrea, E.Z., Michalski, J.R., and Swayze, G.A. (2011) Aqueous mineralogy and stratigraphy at and around the proposed Mawrth Vallis MSL landing site: new insights into the aqueous history of the region. International Journal of Mars Science and Exploration 1:1-13.

Noe Dobrea, E.Z., McAdam, A.C., Freissinet, C., Franz, H., Belmahdi, I., Hammersley, M.R., Stoker, C.R., Parker, B., Ja Kim, K., Glavin, D.P., Calef, F., and Aubrey, A.D. (2016) Characterizing the mechanisms for the preservation of organics at the Painted Desert: Lessons for MSL, ExoMars, and Mars 2020 [abstract 2796]. In $47^{\text {th }}$ Lunar and Planetary Science Conference, Lunar and Planetary Institute, Houston.

Noffke, N., Gerdes, G., Klenke, T., and Krumbein, W.E. (2001) Microbially induced sedimentary structures-a new category 
within the classification of primary sedimentary structures. Journal of Sedimentary Research 7:649-656.

Noffke, N., Christian, D., Wacey, D., and Hazen R.M. (2013) Microbially induced sedimentary structures recording an ancient ecosystem in the $c a$. 3.48 billion-year-old Dresser Formation, Pilbara, Western Australia. Astrobiology 12:1103-1124.

Northup, D.E., Melim, L.A., Spilde, M.N., Hathaway, J.J.M., Garcia, M.G., Moya, M., Stone, F.D., Boston, P.J., Dapkevicius, M.L.N.E., and Riquelme, C. (2011) Lava cave microbial communities within mats and secondary mineral deposits: implications for life detection on other planets. Astrobiology 11:601-618.

Ojha, L., Wilhelm, M.B., Murchie, S.L., McEwen, A.S., Wray, J.J., Hanley, J., Massé, M., and Chojnacki, M. (2015) Spectral evidence for hydrated salts in recurring slope lineae on Mars. Nat Geosci 8:829-832.

Olariu, C. and Bhattacharya, J.P. (2006) Terminal distributary channels and delta front architecture of river-dominated delta systems. Journal of Sedimentary Research 76:212-233.

Olson, J.M. and Pierson, B.K. (1986) Photosynthesis 3.5 thousand million years ago. Photosynth Res 9:251-259.

Onstott, T.C., Harris, R.L., Sherwood Lollar, B., Pedersen, K.A., Colwell, F.S., Pfiffner, S.M., Phelps, T.J., Kieft, T.L., and Bakermans, C. (2016) Biomarker Preservation Potential of Subsurface Ecosystems [abstract 2041]. In Biosignature Preservation and Detection in Mars Analog Environments I: Paleo-Hydrothermal Systems, Lunar and Planetary Institute, Houston.

Oren, A., Padan, E., and Avron, M. (1977) Quantum yields for oxygenic and anoxygenic photosynthesis in the cyanobacterium Oscillatoria limnetica. Proc Natl Acad Sci USA 74:2152-2156.

Osburn, M.R., LaRowe, D.E., Momper, L.M., and Amend, J.P. (2014) Chemolithotrophy in the continental deep subsurface: Sanford Underground Research Facility (SURF), USA. Front Microbiol 5, doi:10.3389/fmicb.2014.00610.

Osinski, G.R., Tornabene, L.L., Banerjee, N.R., Cockell, C.S., Flemming, R., Izawa M.R.M., McCutcheon, J., Parnell, J., Preston, L., Pickersgill, A.E., Pontefract, A., Sapers, H.M., and Southam, G. (2012) Impact-generated hydrothermal systems on Earth and Mars. Icarus 224:347-363.

Osterloo, M.M., Anderson, F.S., Hamilton, V.E., and Hynek, B.M. (2010) Geologic context of proposed chloride-bearing materials on Mars. J Geophys Res 115, doi:10.1029/2010 JE003613.

Pancost, R.D., Pressley, S., Coleman, J.M., Benning, L., and Mountain, B.W. (2005) Lipid biomolecules in silica sinters: indicators of microbial biodiversity. Environ Microbiol 7:66-77.

Pancost, R.D., Pressley, S., Coleman, J.M., Talbot, H.M., Kelly, S.P., Farrimond, P., Schouten, S., Benning, L., and Mountain, B.W. (2006) Composition and implications of diverse lipids in New Zealand geothermal sinters. Geobiology 4:71-92.

Papineau, D., Walker, J.J., Mojzsis, S.J., and Pace, N.R. (2005) Composition and structure of microbial communities from stromatolites of Hamelin Pool in Shark Bay, Western Australia. Appl Environ Microbiol 71:4822-4832.

Parenteau, M.N. and Cady, S.L. (2010) Microbial biosignatures in iron-mineralized phototrophic mats at Chocolate Pots Hot Springs, Yellowstone National Park, United States. Palaios 25:97-111.

Parenteau, M.N., Jahnke, L.L., Farmer, J.D. and Cady, S.L. (2014) Production and early preservation of lipid biomarkers in iron hot springs. Astrobiology 14:502-521.

Parenteau, M.N., Jahnke, L.L., Bristow, T.F., Som, S.M., Des Marais, D.J., and Farmer, J.D. (2016) Preservation of organic compounds in circumneutral iron deposits [abstract 2076]. In
Biosignature Preservation and Detection in Mars Analog Environments I: Paleo-Hydrothermal Systems, Lunar and Planetary Institute, Houston.

Parnell, J. and McMahon, S. (2016) Physical and chemical controls on habitats for life in the deep subsurface beneath continents and ice. Philos Trans A Math Phys Eng Sci 374, doi:10.1098/rsta.2014.0293.

Pavlov, A.A., Vasilyev, G., Ostryakov, V.M., Pavlov, A.K., and Mahaffy, P. (2012) Degradation of the organic molecules in the shallow subsurface of Mars due to irradiation by cosmic rays. Geophys Res Lett 39, doi:10.1029/2012GL052166.

Peary, J. and Castenholz, R.W. (1964) Temperature strains of a thermophilic blue-green alga. Nature 202:720-721.

Pedersen, K., Hallbeck, L., Arlinger, J., Erlandson, A.-C., and Jahromi, N. (1997) Investigation of the potential for microbial contamination of deep granitic aquifers during drilling using 16S-rRNA gene sequencing and culturing methods. $J$ Microbiol Methods 30:179-192.

Pfennig, N. (1974) Rhodopseudomonas globiformis, sp. n., a new species of the Rhodospirillaceae. Arch Microbiol 100:197-206.

Phoenix, V.R., Adams, D.G., and Konhauser, K.O. (2000) Cyanobacterial viability during hydrothermal biomineralization. Chem Geol 169:329-338.

Pierson, B.K., Mitchell, H.K., and Ruff-Roberts, A.L. (1993) Chloroflexus aurantiacus and ultraviolet radiation: implications for archean shallow-water stromatolites. Orig Life Evol Biosph 23:243-260.

Pierson, B.K., Parenteau, M.N., and Griffin, B.M. (1999) Phototrophs in high-iron-concentration microbial mats: physiological ecology of phototrophs in an iron-depositing hot spring. Appl Environ Microbiol 65:5474-5483.

Plescia, J.B. and Johnson, J.R. (2016) Visible near-infrared reflectance spectra of hydrothermal silica sinter deposits and extremophiles [abstract 2045]. In Biosignature Preservation and Detection in Mars Analog Environments I: Paleo-Hydrothermal Systems, Lunar and Planetary Institute, Houston.

Pondrelli, M., Rossi, A.P., Marinangeli, L., Hauber, E., Gwinner, K., Baliva, A., and Di Lorenzo, S. (2008) Evolution and depositional environments of the Eberswalde fan delta, Mars. Icarus 197:429-451.

Popa, R., Smith, A.R., Popa, R., Boone, J., and Fisk, M. (2012) Olivine-respiring bacteria isolated from the rock-ice interface in a lava-tube cave, a Mars analog environment. Astrobiology 12:9-18.

Posamentier, H.W. and Kolla, V. (2003) Seismic geomorphology and stratigraphy of depositional elements in deep-water settings. Journal of Sedimentary Research 73:367-388.

Postma, G. (2001) Physical climate signatures in shallow- and deep-water deltas. Glob Planet Change 28:93-106.

Potter-McIntyre, S.L., Chan, M.A., and McPherson, B.J. (2014) Textural and mineralogical characteristics of microbial fossils associated with modern and ancient iron (oxyhydr)oxides. Astrobiology 14:1-14.

Potter-McIntyre, S.L., Williams, J., Phillips-Landers, C., and O'Connell, L. (2016) Progressive diagenetic alteration of macroand micro-scopic biosignatures in ancient springs and spring-fed lacustrine envrionments [abstract 2005]. In Biosignature Preservation and Detection in Mars Analog Environments I: PaleoHydrothermal Systems, Lunar and Planetary Institute, Houston. Raven, M.R., Sessions, A.L., Adkins, J.F., and Thunell, R.C. (2015) Rapid organic matter sulfurization in sinking particles from the Cariaco Basin water column. Geochim Cosmochim Acta 190:175-190. 
Retallack, G.J. (2014) Paleosols and paleoenvironments of early Mars. Geology 42:755-758.

Retallack, G.J., Bestland, E.A., and Fremd, T.J. (1999) Eocene and Oligocene Paleosols of Central Oregon, GSA Special Papers 344, Geological Society of America, Boulder, CO.

Retallack, G.J., Bestland, E.A., and Fremd, T.J. (2000) Eocene and Oligocene paleosols of central Oregon. GSA Special Papers 344:1-192.

Reysenbach, A.-L., Longenecker, F., and Kirshtein, J. (2000) Novel bacterial and archaeal lineages from an in situ growth chamber deployed at a Mid-Atlantic Ridge hydrothermal vent. Appl Environ Microbiol 66:3798-3806.

Reysenbach, A.-L., Banta, A., Civello, S., Daly, J., Mitchel, K., Lalonde, S., Konhauser, K., Rodman, A., Rustenholtz, K., and Takacs-Vesbach, C. (2005) The Aquificales of Yellowstone National Park. In Geothermal Biology and Geochemistry in Yellowstone National Park: Workshop Proceedings from the Thermal Biology Institute's Yellowstone National Park Conference, October 2003, edited by W.P. Inskeep and T.R. McDermott, Montana State University, Bozeman, pp 129-142.

Rice, M.S., Bell, J.F., III, Gupta, S., Warner, N.H., Goddard, K., and Anderson, R.B. (2013) A detailed geologic characterization of Eberswalde Crater, Mars. International Journal of Mars Science and Exploration 8:15-57.

Richardson, C.D., Hinman, N.W., McHenry, L.J., Kotler, J.M., Knipe, D.L., and Scott, J.R. (2012) Secondary sulfate mineralization and basaltic chemistry of Craters of the Moon National Monument, Idaho: potential Mars analog. Planet Space Sci 65:93-103.

Rosen, M.R. (1994) The Importance of Groundwater in Playas: A Review of Playa Classification and the Sedimentology and Hydrology of Playas, GSA Special Papers 289, Geological Society of America, Boulder, CO.

Ruff, S.W. and Farmer, J.D. (2016) Silica deposits on Mars with features resembling hot spring biosignatures at El Tatio in Chile. Nat Commun 7, doi:10.1038/ncomms13554.

Ruff, S.W., Farmer, J.D., Calvin, W.M., Herkenhoff, K.E., Johnson, J.R., Morris, R.V., Rice, M.S., Arvidson, R.E., Bell, J.F., III, Christensen, P.R., and Squyres, S.W. (2011) Characteristics, distribution, origin, and significance of opaline silica observed by the Spirit rover in Gusev Crater, Mars. J Geophys Res 116, doi:10.1029/2010JE003767.

Ruff, S.W., Niles, P.B., Alfano, F., and Clarke, A.B. (2014) Evidence for a Noachian-aged ephemeral lake in Gusev Crater, Mars. Geology 42:359-362.

Rummel, J.D., Beaty, D.W., Jones, M.A., Bakermans, C., Barlow, N.G., Boston, P.J., Chevrier, V.F., Clark, B.C., de Vera, J.P., Gough, R.V., Hallsworth, J.E., Head, J.W., Hipkin, V.J., Kieft, T.L., McEwen, A.S., Mellon, M.T., Mikucki, J.A., Nicholson, W.L., Omelon, C.R., Peterson, R., Roden, E.E., Sherwood Lollar, B., Tanaka, K.L., Viola, D., and Wray, J.J. (2014) A new analysis of Mars "Special Regions": findings of the Second MEPAG Special Regions Science Analysis Group (SR-SAG2). Astrobiology 14:887-968.

Russell, J.A., Brady, A.L., Cardman, Z., Slater, G.F., Lim, D.S., and Biddle, J.F. (2014) Prokaryote populations of extant microbialites along a depth gradient in Pavilion Lake, British Columbia, Canada. Geobiology 12:250-264.

Rye, R. and Holland, H.D. (2000) Life associated with a $2.76 \mathrm{Ga}$ ephemeral pond?: evidence from Mount Roe \#2 paleosol. Geology 28:483-486.

Sagan, C. (1973) Ultraviolet radiation selection pressure on the earliest organisms. J Theor Biol 39:195-200.
Santschi, P., Hohener, P., Benoit, G., and Buchholtzenbrink, M. (1990) Chemical processes at the sediment water interface. Mar Chem 30:269-315.

Sapers, H.M., Cannon, K., Mustard, J., Amend, J., Beaty, D., Cockell, C., Des Marais, D., Hoehler, T., McCollom, T., Michalski, J., Nealson, K., Osinski, G.R., Onstott, T., Orphan, V., Sherwood-Lollar, B., Templeton, A., and Wanger, G. (2016) Biosignatures from a deep biosphere: the largest and longest-lived habitable environments on Mars [abstract 2086]. In Biosignature Preservation and Detection in Mars Analog Environments I: Paleo-Hydrothermal Systems, Lunar and Planetary Institute, Houston.

Schelble, R.T., Westall, F., and Allen, C.C. (2004) 1.8 Ga iron-mineralized microbiota from the Gunflint Iron Formation, Ontario, Canada: implications for Mars. Adv Space Res $33: 1268-1273$.

Schon, S.C., Head, J.W., and Fassett, C.I. (2012) An overfilled lacustrine system and progradational delta in Jezero Crater, Mars: implications for Noachian climate. Planet Space Sci 67:28-45.

Schopf, J.W. (1999) Cradle of Life, Princeton University Press, Princeton, NJ.

Schopf, J.W. and Walter, M.R. (1983) Archean microfossils: new evidence of ancient microbes. In Earth's Earliest Biosphere: Its Origin and Evolution, edited by J.W. Schopf, Princeton University Press, Princeton, NJ, pp 214-239.

Schrenk, M.O., Brazelton, W.J., and Lang, S.Q. (2013) Serpentinization, carbon, and deep life. In Carbon in Earth, edited by R.M. Hazen, A.P. Jones, and J. Baross, Reviews in Mineralogy and Geochemistry Vol. 75, Mineralogical Society of America, Chantilly, VA, pp 575-606.

Schwenzer, S.P. and Kring, D.A. (2009) Impact-generated hydrothermal systems capable of forming phyllosilicates on Noachian Mars. Geology 37:1091-1094.

Schwenzer, S.P., Abramov, O., Allen, C.C., Bridges, J.C., Clifford, S.M., Filiberto, J., Kring, D.A., Lasue, J., McGovern, P.J., Newsom, H.E., Treiman, A.H., Vaniman, D.T., Wiens, R.C., and Wittmann, A. (2012a) Gale Crater: formation and postimpact hydrous environments. Planet Space Sci 70:84-95.

Schwenzer, S.P., Abramov, O., Allen, C.C., Clifford, S.M., Cockell, C.S., Filiberto, J., Kring, D.A., Lasue, J., McGovern, P.J., Newsom, H.E., Treiman, A.H., Vaniman, D.T., and Wiens, R.C. (2012b) Puncturing Mars: how impact craters interact with the martian cryosphere. Earth Planet Sci Lett 335:9-17.

Seki, O., Nakatsuka, T., Shibata, H., and Kawamura, K. (2010) A compound-specific $n$-alkane $\delta^{13} \mathrm{C}$ and $\delta \mathrm{D}$ approach for assessing source and delivery processes of terrestrial organic matter within a forested watershed in northern Japan. Geochim Cosmochim Acta 74:599-613.

Sheldon, N. and Tabor, N. (2009) Quantitative paleoenvironmental and paleoclimatic reconstruction using paleosols. Earth-Science Reviews 95:1-52.

Sherwood Lollar, B., Voglesonger, K., Lin, L.H., LacrampeCouloume, G., Telling, J., Abrajano, T.A., Onstott, T.C., and Pratt, L.M. (2007) Hydrogeologic controls on episodic $\mathrm{H}_{2}$ release from Precambrian fractured rocks-energy for deep subsurface life on Earth and Mars. Astrobiology 7:971-986.

Shock, E.L., Holland, M., Meyer-Dombard, D., Amend, J.P., Osburn, G.R., and Fischer, T.P. (2010) Quantifying inorganic sources of geochemical energy in hydrothermal ecosystems, Yellowstone National Park, USA. Geochim Cosmochim Acta 74:4005-4043.

Simkus, D.N., Slater, G.F, Sherwood Lollar, B., Wilkie, K., Kieft, T.L., Magnabosco, C., Lau, M.C.Y., Pullin, M.J., 
Hendrickson, S.B., Wommack, K.E., Sakowski, E.G., van Heerden, E., Kuloyo, O., Linage, B., Borgonie, G., and Onstott, T.C. (2016) Variations in microbial carbon sources and cycling in the deep continental subsurface. Geochim Cosmochim Acta 173:264-283.

Sklute, E.C., Kashyap, S., Holden, J.F., and Dyar, M.D. (2016) Spectral evolution of bioreduced ferrihydrite by hyperthermophiles [abstract 2048]. In Biosignature Preservation and Detection in Mars Analog Environments I: Paleo-Hydrothermal Systems, Lunar and Planetary Institute, Houston.

Skok, J.R., Mustard, J.F., Ehlmann, B.L., Milliken, R.E., and Murchie, S.L. (2010) Silica deposits in the Nili Patera caldera on the Syrtis Major volcanic complex on Mars. Nat Geosci 3:838-841.

Skok, J.R., Farmer, J.D., Jerman, G., Gaskin, J., Lindsey, N., Munoz-Saez, C., Kaasalainen, H., Tobler, D., Parente, M., and Craft, K.L. (2016) Seeking signs of life in ancient martian hot springs with Icelandic analogs [abstract 2021]. In Biosignature Preservation and Detection in Mars Analog Environments I: Paleo-Hydrothermal Systems, Lunar and Planetary Institute, Houston.

Sobek, S., Durisch-Kaiser, E., Zurbrugg, R., Wongfun, N., Wessels, M., Pasche, N., and Wehrli, B. (2009) Organic carbon burial efficiency in lake sediments controlled by oxygen exposure time and sediment source. Limnol Oceanogr 54:2243-2254.

Spear, J.R., Walker, J.J., McCollom, T.M., and Pace, N.R. (2005) Hydrogen and bioenergetics in the Yellowstone geothermal ecosystem. Proc Natl Acad Sci USA 102:2555-2560.

Squyres, S.W., Wilhelms, D.E., and Moosman, A.C. (1987) Large-scale volcano-ground ice interactions on Mars. Icarus 70:385-408.

Staudigel, H., Furnes, H., McLoughlin, N., Banerjeee, N.R., Connell, L.B., and Templeton, A. (2008) 3.5 billion years of glass bioalteration: volcanic rocks as a basis for microbial life? Earth-Science Reviews 89:156-176.

Stevens, A.H., Amador, E.S., Cable, M.L., Cantrell, T., Chaudry, T., Chaudry, N., Cullen, T., Duca, Z., Gentry, D.M., Jacobsen, M.B., McCaig, H., Murukesan, G., Rennie, V., Schwieterman, E.W., Tan, G., Yin, C., Stockton, A., Cullen, D.C., and Geppert, W. (2016) Spatial variability and correlation of multiple biomarkers in Icelandic Mars analogue environments and the implications for life detection missions. [abstract 2010]. In Biosignature Preservation and Detection in Mars Analog Environments I: Paleo-Hydrothermal Systems, Lunar and Planetary Institute, Houston.

Stevens, T.O. and McKinley, J.P. (2000) Abiotic controls on $\mathrm{H}_{2}$ production from basalt-water reactions and implications for aquifer biogeochemistry. Environ Sci Technol 34:826-831.

Stillman, D.E., Michaels, T.I., Grimm, R.E., and Hanley, J. (2016) Observations and modeling of northern mid-latitude recurring slope lineae (RSL) suggest recharge by a presentday martian briny aquifer. Icarus 265:125-138.

Straub, K.L., Benz, M., Schink, B., and Widdel, F. (1996) Anaerobic, nitrate-dependent microbial oxidation of ferrous iron. Appl Environ Microbiol 62:1458-1460.

Summons, R.E., Amend, J.P, Bish, D., Buick, R., Cody, G.D., Des Marais, D.J., Dromart, G., Eigenbrode, J.L., Knoll, A.H., and Sumner, D.Y. (2011) Preservation of martian organic and environmental records: final report of the Mars Biosignature Working Group. Astrobiology 11:157-181.

Sumner, D.Y. (2004) Poor preservation potential of organics in Meridiani Planum hematite-bearing sedimentary rocks. $J$ Geophys Res: Planets 109:1-8.
Szynkiewicz, A. and Mikucki, J. (2016) Sulfur biosignatures in continental hot spring, stream, and crater lake sediments affected by hydrothermal $\mathrm{H}_{2} \mathrm{~S}$ gas emission. [abstract 2034]. In Biosignature Preservation and Detection in Mars Analog Environments I: Paleo-Hydrothermal Systems, Lunar and Planetary Institute, Houston.

Takai, K., Nakamura, K., Toki, T., Tsunogai, U., Miyazaki, M., Miyazaki, J., Hirayama, H., Nakagawa, S., Nunoura, T., and Horikoshi, K. (2008) Cell proliferation at $122^{\circ} \mathrm{C}$ and isotopically heavy $\mathrm{CH}_{4}$ production by a hyperthermophilic methanogen under high-pressure cultivation. Proc Natl Acad Sci USA 105:10949-10954.

Takano, O. and Waseda, A. (2003) Sequence stratigraphic architecture of a differentially subsiding bay to fluvial basin: the Eocene Ishikari Group, Ishikari Coal Field, Hokkaido, Japan. Sediment Geol 160:131-158.

Talbot, H.M., Farrimond, P., Schaeffer, P., and Pancost, R.D. (2005) Bacteriohopanepolyols in hydrothermal vent biogenic silicates. Org Geochem 36:663-672.

Tiercelin, J.-J., Pflumio, C., Castrec, M., Boulégue, J., Gente, P., Rolet, J., Coussement, C., Stetter, K.O., Huber, R., Buku, S., and Mifundu, W. (1993) Hydrothermal vents in Lake Tanganyika, East African Rift system. Geology 21:499-502. Tyson, G.W., Chapman, J., Hugenholtz, P., Allen, E.E., Ram, R.J., Richardson, P.M., Solovyev, V.V., Rubin, E.M., Rokhsar, D.S., and Banfield, J.F. (2004) Community structure and metabolism through reconstruction of microbial genomes from the environment. Nature 428:37-43.

Van Kranendonk, M.J. (2006) Volcanic degassing, hydrothermal circulation and the flourishing of early life on Earth: new evidence from the Warrawoona Group, Pilbara Craton, Western Australia. Earth-Science Reviews 74:197-240.

Van Kranendonk, M.J., Webb, G.E., and Kamber B.S. (2003) Geological and trace element evidence for a marine sedimentary environment of deposition and biogenicity of $3.45 \mathrm{Ga}$ stromatolitic carbonates in the Pilbara Craton, and support for a reducing Archaean ocean. Geobiology 1:91-108.

Van Kranendonk, M.J., Djokic, T., Campbell, K.A., Walter, M.R., Oto, T., and Nakamura, E. (2016) Earliest life on Earth preserved in hotspring deposits: evidence from the $3.5 \mathrm{Ga}$ Dresser Formation, Pilbara Craton, Australia, and implications for the search for life on Mars [abstract 2011]. In Biosignature Preservation and Detection in Mars Analog Environments I: Paleo-Hydrothermal Systems, Lunar and Planetary Institute, Houston.

Villanueva, G.L., Mumma, M.J., Novak, R.E., Kaufl, H.U., Hartogh, P., Encrenaz, T., Tokunaga, A., Khayat, A., and Smith, M.D. (2015) Strong water isotopic anomalies in the martian atmosphere: probing current and ancient reservoirs. Science 348:218-221.

Voorhies, A.A., Biddanda, B.A., Kendall, S.T., Jain, S., Marcus, D.N., Nold, S.C., Sheldon, N.D., and Dick, G.J. (2012) Cyanobacterial life at low $\mathrm{O}_{2}$ : community genomics and function reveal metabolic versatility and extremely low diversity in a Great Lakes sinkhole mat. Geobiology 10:250-267.

Vreeland, R.H., Rosenzweig, W.D., and Powers, D.W. (2000) Isolation of a 250 million-year old halotolerant bacterium from a primary salt crystal. Nature 407:897-900.

Wacey, D., Kilburn, M.R., Saunder, M., Cliff, J., and Brasier, M.D. (2011) Microfossils of sulphur-metabolizing cells in 3.4-billion-year-old rocks of Western Australia. Nat Geosci 4:698-702.

Wade, M.L., Agresti, D.G., Wdowiak, T.J., Armendarez, L.P., and Farmer, J.D. (1999) A Mössbauer investigation of iron-rich 
terrestrial hydrothermal vent systems: lessons for Mars exploration. J Geophys Res 104:8489-8507.

Waldbauer, J.R., Sherman, L.S., Sumner, D.Y., and Summons, R.E. (2009) Late Archean molecular fossils from the Transvaal Supergroup record the antiquity of microbial diversity and aerobiosis. Precambrian Res 169:28-47.

Walter, M.R. and Des Marais, D.J. (1993) Preservation of biological information in thermal spring deposits: developing a strategy for the search for fossil life on Mars. Icarus 101:129-143.

Walter, M.R., Des Marais, D.J., Farmer, J.D., and Hinman, N.W. (1996) Lithofacies and biofacies of Mid-Paleozoic thermal spring deposits in the Drummond Basin, Queensland, Australia. Palaios 11:497-518.

Walter, M.R., McLoughlin, S., Drinnan, A.N., and Farmer, J.D. (1998) Palaeontology of Devonian thermal spring deposits, Drummond Basin, Australia. Alcheringa 22:285-314.

Wanger, G., Southam, G., and Onstott, T.C. (2006) Structural and chemical characterization of a natural fracture surface from 2.8 kilometers below land surface: biofilms in the deep subsurface. Geomicrobiol J 23:443-452.

Warner, N.H., Gupta, S., Calef, F., Grindrod, P., Boll, N., and Goddard, K. (2015) Minimum effective area for high resolution crater counting of martian terrains. Icarus 245: 198-240.

Watanabe, Y., Martini, J., and Ohmoto, H. (2000) Geochemical evidence for terrestrial ecosystems 2.6 billion years ago. Nature 408:574-578.

Watanabe, Y., Stewart, B.W., and Ohmoto, H. (2004) Organicand carbonate-rich soil formation $\sim 2.6$ billion years ago at Schagen, East Transvaal district, South Africa, Geochim Cosmochim Acta 68:2129-2151.

Westall, F., Loizeau, D., Foucher, F., Bost, N., Betrand, M., Vago, J.L., and Kminek, G. (2013) Habitability on Mars from a microbial point of view. Astrobiology 13:887-897.

Westall, F., Foucher, F., Bost, N., Bertrand, M., Loizeau, D., Vago, J.L., Kminek, G., Gaboyer, F., Campbell, K.A., Bréhéret, J.-G., Gautret, P., and Cockell, C.S. (2015a) Biosignatures on Mars: what, where, and how? Implications for the search for martian life. Astrobiology 15:998-1029.

Westall, F., Campbell, K.A., Bréhéret, J.-G., Foucher, F., Gautret, P., Hubert, A., Sorieul, S., Grassineau, N., and Guido, D.M. (2015b) Archean (3.33 Ga) microbe-sediment systems were diverse and flourished in a hydrothermal context. Geology 43:615-618.

Westall, F., Campbell, K.A., Gautret, P., Bréhéret, J.-G., Foucher, F., Gaboyer, F., Vago, J.L., Kminek, G., Hubert, A., Hickman-Lewis, K., and Cockell, C.S. (2016) Hydrothermal chemotrophic biosignatures on Mars [abstract 2028]. In Biosignature Preservation and Detection in Mars Analog Environments I: Paleo-Hydrothermal Systems, Lunar and Planetary Institute, Houston.

Wetzel, R.G. (2001) Limnology: Lake and River Ecosystems, $3^{\text {rd }}$ ed., Academic Press, San Diego, CA.

Whitman, W.B, Coleman, D.C., and Wiebe, W.J. (1998) Prokaryotes: the unseen majority. Proc Natl Acad Sci USA 95:6578-6583.

Widdel, F., Schnell, S., Heising, S., Ehrenreich, A., Assmus, B., and Schink, B. (1993) Ferrous iron oxidation by anoxygenic phototrophic bacteria. Nature 362:834-836.
Williams, A.J., Sumner, D.Y., Alpers, C.N., Karunatillake, S., and Hofmann, B.A. (2015) Preserved filamentous microbial biosignatures in the Brick Flat Gossan, Iron Mountain, California. Astrobiology 15:637-668.

Williams, A.J., Sumner, D.Y., Eigenbrode, J.L., Wilhelm, M.B., Cook, C.L., and Mahaffy, P.R. (2016) Physical and molecular biosignature preservation in hydrous ferric oxides: implications for detection with MSL and future missions [abstract 2015]. Biosignature Preservation and Detection in Mars Analog Environments I: Paleo-Hydrothermal Systems, Lunar and Planetary Institute, Houston.

Williams, K.E., McKay, C.P., Toon, O.B., and Head, J.W. (2010) Do ice caves exist on Mars? Icarus 209:358-368

Wilson, J.T., Eke, V.R., Massey, R.J., Elphic, R.C., Feldman, W.C., Maurice, S., and Teodoro, L.F.A. (2016) Recurring slope lineae on Mars are not fed by subsurface water [abstract 2813]. In $47^{\text {th }}$ Lunar and Planetary Science Conference, Lunar and Planetary Institute, Houston.

Winogradsky, S.E. (1888) Zur Morphologie und Physiologie der Schwefelbacterien, Felix, Leipzig.

Wood, L.J. (2006) Quantitative seismic geomorphology of the Mars Eberswalde Delta. Geol Soc Am Bull 118:557-566.

Wray, J.W., Murchie, S.L., Ehlmann, B.L., Milliken, R.E., Seelos, K.D., Noe Dobrea, E.Z., Mustard, J.F., and Squyres, S.W. (2011) Evidence for regional deeply buried carbonate-bearing rocks on Mars [abstract 2635]. In $42^{\text {nd }}$ Lunar and Planetary Science Conference, Lunar and Planetary Institute, Houston.

Yen, A.S., Gellert, R., Schroder, C., Morris, R.V., Bell, J.F., III, Knudson, A.T., Clark, B.C., Ming, D.W., Crisp, J.A., Arvidson, R.E., Blaney, D., Brückner, J., Christensen, P.R., Des Marais, D.J., de Souza, P.A., Jr., Thanasis, E.E., Ghosh, A., Hahn, B.C., Herkenhoff, K.E., Haskin, L.A., Hurowitz, J.A., Joliff, B.L., Johnson, J.R., Klingelhöfer, G., Madsen, M.B., McLennan, S.M., McSween, H.Y., Richter, L., Rieder, R., Rodionov, D., Soderblom, L., Squyres, S.W., Tosca, N.J., Wang, A., Wyatt, M., and Zipfel, J. (2005) An integrated view of the chemistry and mineralogy of martian soils. Nature 436:49-54.

Address correspondence to: Lindsay E. Hays

Jet Propulsion Laboratory California Institute of Technology 4800 Oak Grove Dr. M/S 321-690

Pasadena, CA 91109

E-mail: lindsay.e.hays@jpl.nasa.gov

Submitted 17 November 2016 Accepted 24 January 2017

\begin{tabular}{|c|} 
Abbreviations Used \\
CRISM $=$ Compact Reconnaissance Imaging \\
Spectrometer for Mars \\
IFs $=$ iron formations \\
TOC $=$ total organic carbon \\
VNIR $=$ visible/near-infrared
\end{tabular}

